Perkin: Magnet. Circular-Polarisat. d. Verbind. ete. 523

Bemerkung zu den Tabellen S. 518-521. In den vorstehenden Tabellen finden sich die vor einigen Jahren ausgeführten Untersuchungen des Lichtbrechungsvermögens gewisser Substanzen. Das linke Terpenhydrat, linke Terpen aus russischem Terpentinöl und das Isoterpen aus Citronenöl habe ich von Prof. F. Flawitrky erhalten, welchem auch die Bestimmungen der Dichte dieser Substanzen zu verdanken sind. Die Haloïdderivate des Aethans habe ich von dem verstorbenen Prof. G. Glynsky erhalten, der ebenfalls die Bestimmungen der Dichte ausgeführt hat. Alle untersuchten Verbindungen sind analysirt worden. Die spectrometrischen Untersuchungen wurden im physikalischen Institut des Prof. R. Colley an der Universität Kasan ausgeführt, da in jener Zeit das cheñische Laboratorium noch kein Spectrometer besass.

Ueber die magnetische Cireular-Polarisation der Verbindungen im Verhältniss zu deren chemischen Constitation, mit Bemerkungen inber die Darstellnng and specifischen Gewichte der untersuchten Körper;

\author{
von
}

W. H. Perkin.

(Fortsetzung und Schluss.) ${ }^{1}$ )

Aldehyde.

Acetaldehyd. - Aethyl-Aldehyd.

Dieser Körper (von Hopkin und Williams bezogen) wurde einige Minuten mit Chlorcalcium geschüttelt, davon abfiltrirt und mit Hülfe eines 1 Meter langen Fractionsrohres fractionirt. Das zur Untersuchung verwendete Präparat siedete bei $21-22^{\circ}$. Bestimmungen der Dichte, welche gleich nach der Destillation gemacht wurden, ergaben:

$$
d \frac{10^{0}}{10^{0}}=0,79509, d \frac{13^{0}}{13^{0}}=0,79138, d \frac{16^{0}}{16^{0}}=0,78761 \text {. }
$$

Mit frisch destillirtem Aldehyd wurden die folgenden Zahlen für die magnetische Rotation erhalten:

1) Vergl. dies Journ. [2] 31, $481 \mathrm{ff}$. 
524 Perkin: Ueber magnetische Cirenlar-Polarisation

\begin{tabular}{|c|c|c|c|}
\hline & $t$ & Sp. Rotation. & Mol. Rotation. \\
\hline & $15,0^{\prime \prime}$ & 0,7680 & 2,380 \\
\hline & 15,0 & 0,7679 & 2,380 \\
\hline & 15,0 & 0,7648 & 2,369 \\
\hline & 17,5 & 0,7712 & 2,400 \\
\hline & $17, \overline{0}$ & 0,7679 & 2,390 \\
\hline & 18,0 & 0,7677 & 2,392 \\
\hline Mittel & 16,3 & 0,7678 & 2,385 \\
\hline
\end{tabular}

Diese Substanz wurde kurze Zeit mit Chlorcalcium getrocknet und dann fractionirt, siedete bei $47^{\circ}-49^{\circ}$ corr. und ergab folgendes specifisches Gewicht:

$$
d \frac{15^{\prime \prime}}{15^{0}}=0,80648, d \frac{25^{0}}{25^{0}}=0,79664
$$

Rossi's ${ }^{1}$ ) Zahlen ergeben: $a \frac{15^{0}}{15^{0}}=0,806$, dievon Pierre und Puchot $d_{25^{\prime \prime}}^{25^{\prime \prime}}=0,7972$ und die von Brühl $a_{15^{\prime \prime}}=$ 0,8129 .

Der frisch destillirte Aldehyd lieferte folgende Zahlen für die magnetische Rotation:

\begin{tabular}{|c|c|c|}
\hline$t$ & Sp. Rotation. & Mol. Rotation. \\
\hline $14,4^{\circ}$ & 0,8424 & 3.363 \\
\hline 14,4 & 0,8279 & $\because, 305$ \\
\hline 14,4 & 0,8375 & 3,338 \\
\hline 14,1 & 0,8329 & 3,324 \\
\hline 14,1 & 0,8421 & 3,361 \\
\hline 12,25 & 0,8357 & 3,327 \\
\hline 12,75 & 0,8317 & 3,315 \\
\hline 12,75 & 0,8302 & 3,304 \\
\hline 13,3 & 0,8394 & 3,346 \\
\hline 13,6 & 0,8355 & 3,332 \\
\hline
\end{tabular}

Isobutyraldehyd.

Dieser Körper, durch Oxydation des Isobutylalkohols erhalten, wurde schnell mittelst Chlorcalcium getrocknet und fractionirt; er siedete bei $63^{\circ}-64^{0}$ corr. und die Bestimmungen seiner Dichte ergaben:

1) Ann. Chem. Pharm. 159, 79. 
4. Verbind. im Verhältn. zu deren chem. Constitut. etc. 525

$$
d \frac{15^{0}}{15^{0}}=0,79722, d \frac{25^{0}}{25^{0}}=0,78787 .
$$

Aus Brübl's Zahlen folgt $d \frac{15^{0}}{15^{0}}=0,7999$.

Magnetische Rotation des Isobutyraldehyds:

\begin{tabular}{cccc} 
& $t$ & Sp. Rotation. & Mol. Rotation. \\
& $22,0^{\circ}$ & 0,8526 & 4,314 \\
24,0 & 0,8509 & 4,315 \\
24,0 & 0,8507 & 4,314 \\
& 14,5 & 0,8626 & 4,326 \\
& 15,5 & 0,8607 & 4,321 \\
& 16,0 & 0,8628 & 4,334 \\
\hline Mittel & 19,3 & 0,8567 & 4,321
\end{tabular}

Isovaleraldehyd.

Dieser Aldehyd wurde kurze Zeit mit Chlorcalcium getrocknet und fractionirt; er siedete bei $92^{\circ}-94^{\circ}$ corr. und besass für Natrinmlicht eine bleibende Rotation von $+2^{\circ} 39^{\prime}$ fuir eine $200 \mathrm{Mm}$. lange Schicht. Bestimmungen seiner Dichte ergalen:

$$
d \frac{15^{0}}{15^{0}}=0,80405, \quad d \frac{25^{0}}{25^{\prime \prime}}=0,79607 .
$$

Magnetische Rotation des Isovaleraldehyds:

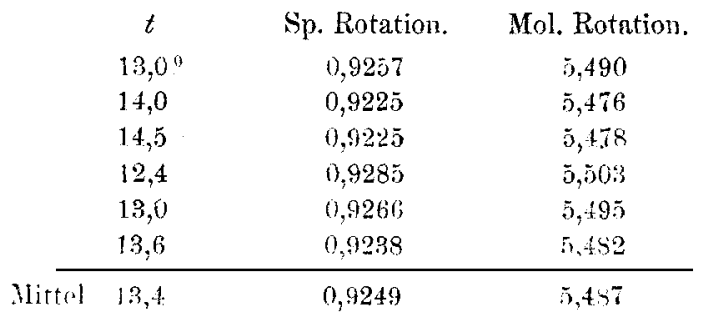

\section{Oenanthaldehyd.}

Durch Fractionirung gereinigt, siedete derselbe bri $1.52 .2^{\circ}-153,2^{\circ}$ and ergab:

$$
d \frac{15^{0}}{15^{\prime \prime}}=0,82264, \quad d \frac{25^{\prime \prime}}{25^{\circ}}=0,81578 .
$$

Magnetische Rotation des Oenanthaldehyds: 
526 Perkin: Ueber magnetische Circular-Polarisation

\begin{tabular}{cccc} 
& Sp. Kotation. & Mōl. Kotatiòn. \\
$14,0^{0}$ & 0,9655 & 7,427 \\
14,8 & 0,9674 & 7,447 \\
14,8 & 0,9681 & 7,452 \\
15,7 & 0,9617 & 7,410 \\
15,8 & 0,9639 & 7,426 \\
15,8 & 0,9609 & 7,400 \\
16,7 & 0,9617 & 7,415 \\
17,5 & 0,9623 & 7,426 \\
& 17,8 & 0,9597 & $\mathbf{7 , 4 0 8}$ \\
19,0 & 0,9596 & $\mathbf{7 , 4 0 5}$ \\
\hline Mittel & 16,2 & $\mathbf{0 , 9 6 3 1}$ & $\mathbf{7 , 4 2 2}$
\end{tabular}

Ketone.

Aceton.

Dasselbe wurde mittelst sauren schwefligsauren Natriums gereinigt, zuerst über Chlorcalcium, dann drei Monate lang über wasserfreiem schwefelsaurem Kupfer stehen gelassen; es siedete bei $55,6^{\circ}-55,9^{\circ}$.

Spec. Gewicht: $d \frac{15^{\circ}}{15^{0}}=0,79652, d \frac{25^{\circ}}{25^{0}}=0,78669$.

Diese Werthe liegen tiefer als die meisten angegebenen, stimmen aber ziemlich genau mit der von Linnemann gefundenen Zahl: $d \frac{15^{0}}{15^{0}}=0,7975$. Thorpe's Beobachtungen, für diese Temperatur umgerechnet, ergeben: $d \frac{15^{0}}{15^{0}}=0,80244$.

Folgende Zahlen wurden für die magnetische Rotation ermittelt:

\begin{tabular}{cccc}
$t$ & Sp. Rotation. & Mol. Rotation. \\
$15,2^{\circ}$ & 0,8716 & 3,526 \\
15,2 & 0,8642 & 3,496 \\
15,2 & 0,8699 & 3,519 \\
15,2 & 0,8691 & $3, \overline{5} 16$ \\
15,2 & $0,871^{i}$ & 3,526 \\
15,2 & 0,8642 & 3,496 \\
& 15,2 & 0,8699 & 3,519 \\
& 15,2 & 0,8691 & 3,516 \\
\hline Mittel & $\mathbf{1 5 , 2}$ & 0,8687 & 3,514
\end{tabular}


d. Verbind, im Verhältn. zu deren chem. Constitut. ete. 527

Methylpropylketon.

Dieser Körper, von Kahlbaum bezogen und durch Fractioniren gereinigt, wurde zur völligen Reindarstellung in die Verbindung mit saurem schwefligsaurem Natrium übergeführt, welche, gut abgesaugt, abgepresst und getrocknet, wieder in ihre Componenten zersetzt wurde. Das von Wasser befreite and destillirte Keton siedete bei $102^{\circ}$ corr. Zwei Reihen von Dichte-Bestimmungen wurden ausgeführt; das Produkt II hatte circa drei Monate lang über wasserfreiem schwefelsaurem Kupfer gestanden.

$$
\begin{array}{rlrl}
d \frac{15^{0}}{15^{0}}=0,81238 & \text { I. } & \text { II. } \\
d \frac{25^{0}}{25^{0}}=0,81233 \\
\end{array}
$$

Frankland und Duppa's Zahlen geben $d \frac{15^{0}}{15^{0}}=0,8117$.

Magnetische Rotation des Methylpropylketons:

\begin{tabular}{ccc}
\multicolumn{1}{c}{$t$} & Sp. Rotation. & Mol. Rotation. \\
$17,0^{\circ}$ & 0,9306 & 5,484 \\
17,0 & 0,9335 & 5,501 \\
18,0 & 0,9323 & 5,500 \\
19,0 & 0,9250 & 5,462 \\
14,2 & 0,9410 & 5,530 \\
14,2 & 0,9404 & 5,527 \\
14,8 & 0,9342 & 5,494 \\
14,8 & 0,9348 & 5,497 \\
Mittel 16,1 & 0,9340 & 5,499
\end{tabular}

\section{Paraldehyd.}

Derselbe wurde langsam abgekühlt, bis ungefähr die Hälfte krystallisirt war; die von dem flüssigen Antheil getrennten Krystalle wurden geschmolzen, und demselben Processe wie oben nochmals unterworfen:

Spec. Gewicht: $d \frac{15^{0}}{15^{0}}=0,99925, d \frac{25^{0}}{25^{0}}=0,99003$.

Brühl fand Zahlen, die $d \frac{15^{0}}{15^{0}}=1,001$ ergaben.

Obiges Präparat siedete bei $103,5^{0}-103,7^{0}$. 
528 Perkin: Ueber magnetisehe Circular-Polarisation Ilagnetische Rotation des Paraldehyds:

$\begin{array}{ccc}t & \text { Sp. Rotation. } & \text { Mol. Rotation. } \\ 16,3^{\circ} & 0,1079 & 6,671 \\ 16,3 & 0,9091 & 6,681 \\ 15,0 & 0,9025 & 6,642 \\ 18,0 & 0,9049 & 6,659 \\ 18,0 & 0,9046 & 6,657 \\ \text { Nittel } 17,3 & 10,9058 & 6,662\end{array}$

Säuren.

Ameisensäure.

Diese Säure (von Kahlbaum bezogen) schmolz bei $8^{\prime \prime}$ iml argab:

$$
a \frac{15^{\circ}}{15^{\circ}}=1,2283
$$

Un sie noch weiter zu trocknen, wurde sie mit $10^{\circ}$ Phosphorsäureanhydrid behandelt. Letzteres zersetzte einen Theil der Sünre und löste sich dann darin auf. Die ans lem Gemisch destillirte Säure siedete bei $101^{\circ}$ corr. und besass eine der obigen sehr nahe liegende Dichte, nämlich:

$$
d^{15^{\prime \prime}}=1,22734, d \frac{25^{0}}{25^{\circ}}=1,21741 \text {. }
$$

Die folgenden Zahlen wurden für die magnetische Rotation erlualten:

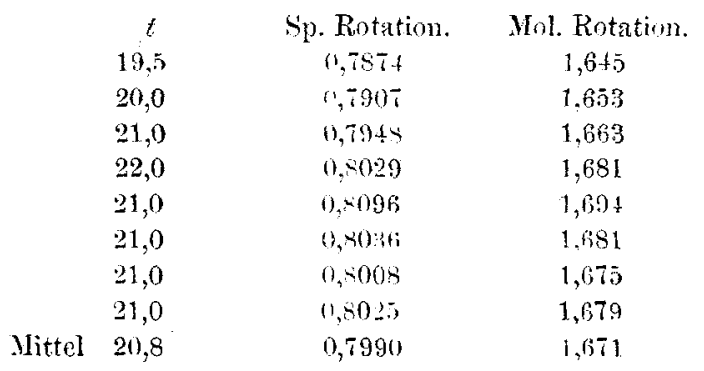

Essigsäure.

Gewöhnlicher Fisessig wnrde anf zweierlei Weise gotwoknet; ein Theil wurde mit Phosphorsäureanhydrid behandelt und dann destillirt: er siedete bei $18^{\prime \prime}-118,5^{\prime \prime}$ corr. und ergab $d \frac{150 "}{150}=1,0 ; 56$. 
d Verbind im Verhältn. zu deren chem Constitut. etc. 529

Der zweite Antheil wurde mit circa 10\% Phosphortrichlorür behandelt. Das davon abdestillirte Product durch Fractioniren von dem entstandenen Acetylchlorid getrennt und schliesslich durch Destillation über wasserfreiem essigsaurem Natron von Spuren Salzsäure befreit; diese Säure siedete bei $118^{\circ}-118,8^{\circ}$ corr. und ergab:

$$
d \frac{15^{0}}{15^{0}}=1,05704, d \frac{25^{0}}{25^{0}}=1,04792 .
$$

Diese Dichte ist der obigen beinahe gleich: die geringe Erhöhung rührt wahrscheinlich von einer Spur Essigsäureanhydrids her, welches durch die Wirkung des essigsauren Natrons auf eine geringe Menge Acethylchlorid gebildet war.

Magnetische Rotation der Essigsäure:

\begin{tabular}{ccc}
$t$ & Sp. Rotation. & Mol. Rotation. \\
$20,5^{\circ}$ & 0,8039 & 2,547 \\
22,0 & 0,7859 & 2,493 \\
24,5 & 0,7918 & 2,491 \\
22,5 & 0,8016 & 2,544 \\
22,5 & 0,7974 & 2,531 \\
25,5 & 0,7970 & 2,530 \\
18,3 & 0,8000 & 2,530 \\
18,3 & 0,8022 & 2,537 \\
Mittel 21,04 & 0,7983 & 2,520 \\
\hline
\end{tabular}

\section{Propionsäure.}

Diese Säure wurde auch nach den beiden oben beschriebenen Methoden getrocknet. Das mittelst Phosphortrichlorür getrocknete Product siedete bei $141^{\circ}-142^{\circ}$ corr. und zeigte die Dichte:

$$
d \frac{15^{0}}{15^{0}}=0,99890, d \frac{25^{0}}{25^{0}}=0,99021 .
$$

Das mit Phosphorsäureanhydrid getrocknete und fractionirte Präparat siedete bei $141,3^{\circ}$ corr. und ergab:

$$
d \frac{15^{0}}{15^{0}}=0,99816, d \frac{25^{0}}{25^{0}}=0,98957 .
$$

Dasselbe wurde nochmals mit Phosphorsäureanhydrid behandelt und wieder fractionirt; es siedete bei derselben Temperatur und ergab: 
530 Perkin: Ueber magnetische Circular-Polarisation

$$
d \frac{15^{0}}{15^{0}}=0,99833, d \frac{25^{0}}{25^{0}}=0,98963 .
$$

Linnemann ${ }^{1}$ ) fand den Siedepunkt $140,67^{\circ}$ und das specif. Gewicht $d \frac{19^{0}}{19^{0}}=0,9961$, welches auf $15^{0}$ umgerechnet ${ }^{d} \frac{15^{0}}{15^{\circ}}=0,9996$ ergiebt.

Die folgenden Zahlen wurden für die magnetische Rotation ermittelt:

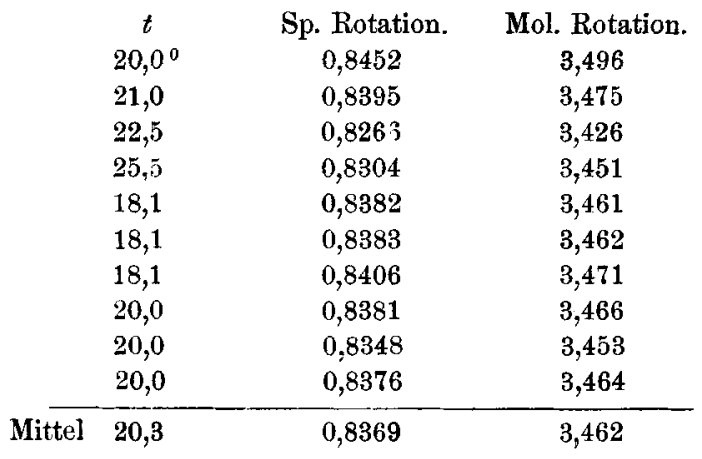

Buttersäure.

Diese mittelst Phosphortrichlorür getrocknete Säure siedete bei $161^{\circ}-163^{\circ}$ corr. und ergab:

$$
d \frac{15^{0}}{15^{0}}=0,96704, d \frac{25^{0}}{25^{0}}=0,95882 .
$$

Linnemann ${ }^{2}$ ) giebt den Siedepunkt 162,3 und die Dichte $d \frac{14^{0}}{14^{0}}=0,9580$ an, welche auf $15^{\circ}$ umgerechnet $d \frac{15^{0}}{15^{\circ}}$ $=0,9572$ ergiebt. $B r u ̈ h 1^{3}$ ) fand den Siedepunkt 161,50$162,5^{\circ}$ bei $753,2 \mathrm{Mm}$. und die Dichte $d \frac{20^{0}}{4^{0}}=0,9587$, oder $d \frac{15^{\circ}}{15^{0}}=0,9655$, also niedriger, als die von mir ermittelte.

Magnetische Rotation der Buttersäure:

1) Ann. Chem. Pharm. 160, 218.

2) Das. 160, 228.

3) Das. 203, 19. 
d. Verbind. im Verhältn. zu deren chem. Constitut. ete. 531

\begin{tabular}{cccc}
$c$ & Sp. Rotation. & Mol. Rotation. \\
$18,0^{0}$ & 0,8823 & 4,472 \\
18,0 & 0,8811 & 4,466 \\
18,0 & 0,8844 & 4,482 \\
19,9 & 0,8806 & 4,471 \\
19,9 & 0,8800 & 4,468 \\
\hline Mittel & 18,8 & 0,8817 & 4,472
\end{tabular}

\section{Valeriansäure (normale).}

Diese Säure wurde aus Propylmalonsäure, welche sich bekanntlich beim Erhitzen in Valeriansäure und Kohlensäure spaltet, dargestellt. Die Operation wurde in emem, mit einem langen Hals versehenen Kölbchen ausgeführt. Das Erhitzen wurde gemässigt, bis die Reaction beendigt zu sein schien, dann wurde die Säure überdestillirt. Das Produkt wurde in Kalilauge gelöst und die Lösung gekocht, um etwa vorhandenen Valeriansäureäther zu zersetzen. ${ }^{1}$ ) Die wässrige Lösung des valeriansauren Kaliums wurde mit Salzsäure zersetzt, und die Valeriansäure mit Aether ausgeschüttelt. Die ätherische Schicht wurde dann über Chlorcalcium getrocknet und destillirt. Die Säure ging als farbloses Oel über; nochmals fractionirt siedete sie bei $185,2^{\circ}-187,2^{\circ}$ corr. Phosphorsäureanhydrid konnte nicht zum Trocknen dieser Säure benutzt werden, da es ein wenig darauf einwirkt.

Spec. Gewicht: $d \frac{15^{0}}{15^{0}}=0,94462, d \frac{25^{0}}{25^{0}}=0,93749$.

Diese Werthe sind ein wenig niedriger als der von Lieben und Rossi ${ }^{2}$ ) erhaltene: 0,9415 bei $20^{\circ}$.

Die folgenden Zahlen wurden für die magnetische Rotation erhalten:

1) Die Bildung dieses Aethers bängt mit dem Vorhandensein einer geringen Quantität sauren propylmalonsauren Aethyls in der angewandten Säure zusammen.

2) Ann. Chem. Pharm. 159, 48. 
532 Perkin: Ueber magnetische Circular-Polarisation

\begin{tabular}{ccc}
$t$ & Sp. Rotation. & Mol. Rotation. \\
$16,0^{0}$ & 0,9241 & 5,548 \\
12,2 & 0,9265 & 5,547 \\
12,6 & 0,9266 & 5,549 \\
13,4 & 0,9140 & 5,476 \\
13,4 & 0,9160 & 5,489 \\
13,6 & 0,9183 & 5,503 \\
13,8 & 0,9144 & 5,481 \\
\hline Mittel & 0,9200 & 5,513 \\
\multicolumn{3}{c}{ Oenanthsäure. - Heptylsäure. }
\end{tabular}

Diese Säure wurde nach den Angaben Schorlemmer's ${ }^{1}$ ) durch Oxydation des Oenanthols mittelst Chromsäure dargestellt; mit Phosphorsäureanhydrid getrocknet, siedete dieselbe bei $222,5^{\circ}-223,5^{\circ}$ corr.

Spec. Gewicht: $d \frac{15^{0}}{15^{0}}=0,92298, d \frac{25^{0}}{25^{0}}=0,91672$.

Da Anfangs die magnetische Rotation dieser Säure nicht normal zu sein schien, so wurde sie in ihr Barytsalz übergeführt, dieses umkrystallisirt und mit Salzsäure zersetzt. Wieder mit Phosphorsäure getrocknet, destillirte sie bei $222^{\circ}-222,5^{\circ}$ corr. und ergab:

$$
d \frac{15^{0}}{15^{0}}=0,92245, d \frac{25^{0}}{25^{0}}=0,91602 .
$$

Die Bestimmungen der magnetischen Rotation dieser Substanz waren sehr schwer auszuführen, wegen ihrer Neigung, Wärmeströmungen zu geben.

Magnetische Rotation der Heptylsäure:

\begin{tabular}{lcc}
\multicolumn{1}{c}{$t$} & Sp. Rotation. & Mol. Rotation. \\
$10,0^{\circ}$ & 0,9659 & 7,537 \\
12,25 & 0,9653 & 7,544 \\
11,0 & 0,9682 & 7,560 \\
12,0 & 0,9626 & 7,522 \\
16,0 & 0,9618 & 7,537 \\
21,0 & 0,9603 & 7,552 \\
21,25 & 0,9626 & 7,570 \\
15,4 & 0,9679 & 7,563 \\
15,4 & 0,9680 & 7,564
\end{tabular}

1) Ann. Chem. Pharm. 170, 141. 
d. Verbind. im Verhältn. zu deren chem. Constitut. etc. 533

\begin{tabular}{cccc}
$t$ & Sp. Rotation. & Mol. Rotation. \\
15,4 & 0,9669 & 7,556 \\
10,4 & 0,9661 & 7,540 \\
15,9 & 0,9658 & 7,565 \\
10,4 & 0,9672 & 7,550 \\
14,1 & 0,9656 & 7,555 \\
Mittel & 17,0 & 0,9639 & 7,558 \\
\hline \multicolumn{3}{c}{0,9652} & 7,552 \\
& 14,5 &
\end{tabular}

Diese (von Kahlbaum iezogene) Săure wurde mehrmals fractionirt, der zwischen $236^{\circ}$ und $239^{\circ}$ siedende Antheil in das Bariumsalz übergeführt, und aus diesem die Säure mittelst Salzsäure frei gemacht und mit Aether ausgeschüttelt. Der Rückstand der über Chlorcalcium getrockneten ätherischen Lösung wurde unter vermindertem Drucke destillirt. Bei $338 \mathrm{Mm}$. siedete die Säure fast constant bei $211^{\circ}$ corr. und ging als tarbloses Oel über. Beim Abkühlen erstarrte sie zu einer bei $15^{\circ}$ schmelzenden krystallinischen Masse. Zincke giebt den Schmelzpunkt der, durch Oxydation des normalen Octylalkohols erhaltenen Säure bei $16,5^{\circ}$ an. Bestimmungen der Dichte ergaben:

$$
d \frac{15^{0}}{15^{0}}=0,91275, d \frac{25^{0}}{25^{0}}=0,90826 .
$$

Zincke fand etwas höhere Zahlen $\left(d \frac{15^{0}}{15^{0}}=0,9165\right)$. Magnetische Rotation der Caprylsäure:

$\begin{array}{ccc}t & \text { Sp. Rotation. } & \text { Mol. Rotation. } \\ 17,0^{\circ} & 0,9749 & 8,543 \\ 18,0 & 0,9752 & 8,550 \\ 18,0 & 0,9748 & 8,547 \\ 19,3 & 0,9785 & 8,586 \\ 19,6 & 0,9748 & 8,556 \\ 19,6 & 0,9760 & 8,566 \\ 17,0 & 0,9822 & 8,606 \\ 17,5 & 0,9774 & 8,567 \\ 20,5 & 0,9757 & 8,567 \\ \text { Mittel } 18,5 & 0,9766 & 8,565 \\ & & \end{array}$

Diese (von K a hlb a um bezogene) Substanz musste wiederholt fractionirt werden; da sie sich beim Destilliren partiell 
534 Perkin: Ueber magnetische Circular-Polarisation zu zersetzen scheint, wurde sie nicht absolut rein erhalten. Die zu den Messungen benutzte Fraction siedete bei $247^{\circ}-$ $250^{\circ}$ uncorr. Abgekühlt erstarrte sie zu einer bei $10,5^{\circ}$ schmelzenden, krystallinischen Masse. Die von Zincke und Franchimont aus Octylcyanid dargestellte Säure schmolz bei $12,5^{\circ}$.

Spec. Gewicht: $d \frac{15^{0}}{15^{0}}=0,91028, d \frac{25^{0}}{25^{0}}=0,90484$.

Zincke und Franchimont's bei $17,5^{\circ}$ genommene, auf Wasser von $4^{0}$ bezogene Dichte giebt $d \frac{15^{0}}{15^{0}}=0,9090$, also einen etwas niedrigeren Werth. Wahrscheinlich liegt die richtige Dichte zwischen dem Werth von Zincke und Franchimont und dem meinigen.

Magnetische Rotation der Nonylsäure:

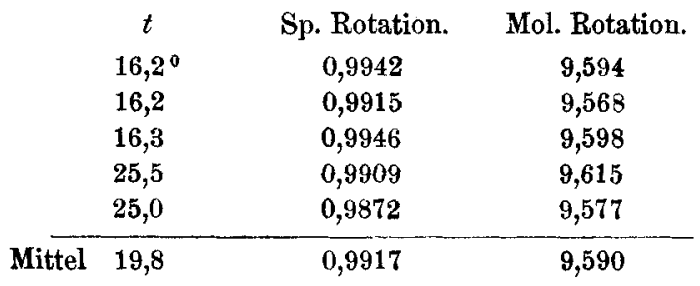

Isobuttersäure.

Das zuerst untersuchte Präparat war durch Oxydation des Isobutylalkohols erhalten; mit Phosphortrichlorür getrocknet (siehe Essigsäure), siedete es bei $153^{\circ}-154^{\circ}$ corr. und ergab:

$$
d \frac{15^{0}}{15^{0}}=0,95490, d \frac{25^{0}}{25^{0}}=0,94995 .
$$

Da diese Substanz ganz unerwartete magnetische Rotation gab, so lag der Verdacht nahe, dies könne von einer Verunreinigung der Säure herstammen. Daher wurde die Säure aus Dimethylmalonsäure dargestellt, welche, völlig rein und trocken, in einem mit Rückflusskühler versehenen Kölbchen langsam erhitzt wurde, bis keine Kohlensäure mehr entwich. Die resultirende Isobuttersäure siedete bei $153^{\circ}-$ $153,5^{0}$ corr. und ergab: 
d. Verbind. im Verhältn. zu deren chem. Constitut. etc. 535

$$
d \frac{15^{0}}{15^{0}}=0,95386, d \frac{25^{0}}{25^{0}}=0,94567 .
$$

Diese Säure ergab für die magnetische Rotation Werthe, welche mit denen der gewöhnlichen Säure vollkommen stimmte.

\begin{tabular}{ccc}
$t$ & Sp. Rotation. & Mol. Rotation. \\
$\mathbf{1 5 , 0 ^ { \circ }}$ & 0,8686 & 4,452 \\
15,0 & 0,8706 & 4,462 \\
17,5 & 0,8727 & 4,483 \\
17,5 & 0,8717 & 4,478 \\
17,5 & 0,8719 & 4,479 \\
17,5 & 0,8691 & 4,464 \\
18,3 & 0,8757 & 4,501 \\
18,3 & 0,8759 & 4,502 \\
18,3 & 0,8770 & 4,508 \\
19,5 & 0,8721 & 4,487 \\
19,5 & 0,8662 & 4,457 \\
19,5 & 0,8701 & $\mathbf{4 , 4 7 7}$ \\
\hline Mittel $\mathbf{1 7 , 8}$ & $\mathbf{0 , 8 7 1 8}$ & $\mathbf{4 , 4 7 9}$
\end{tabular}

\section{Isovaleriansäure.}

Dies war die gewöhnliche, aus Amylalkohol dargestellte Säure. Sie wurde mit Phosphorsäureanhydrid getrocknet und fractionirt. Das untersuchte Präparat siedete bei $175,5^{\circ}$ $-176,5^{\circ}$.

Spec. Gewicht: $d \frac{15^{0}}{15^{0}}=0,93355, d \frac{25^{0}}{25^{0}}=0,92610$.

Die bleibende Rotation für das Natrium-Licht betrug $4,07^{\circ}$ für eine $200 \mathrm{Mm}$. lang Schicht. Die Rotation der von Pedler aus seinem actirsten Alkohol dargestellte Säure betrug $17,2^{\circ}$. Mein Präparat enthält daher circa $23,6 \%$ der activen Säure. Wie andere Forscher schon bemerkt haben, wird die magnetische Rotation von Körpern, die eine bleibende Rotation besitzen, auf der einen Seite von dieser letzten vergrössert, auf der andern verkleinert.

Diese Säure ergab folgende Zahlen für die magnetische Rotation: 
Perkin: Ueber magnetische Circular-Polarisation

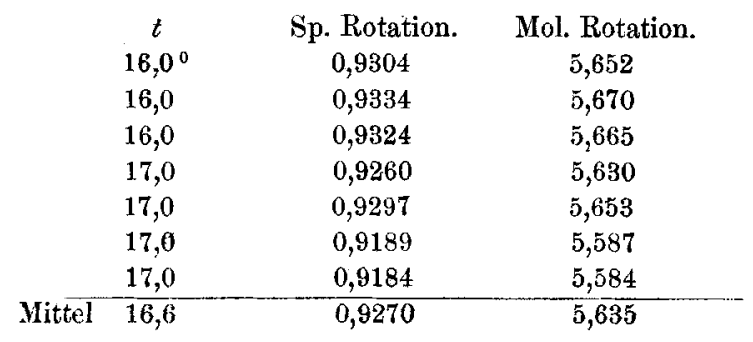

Aether der Fettsàuren.

Ameisensaures Aethyl.

Dieser Aether wurde durch Sättigung eines gut abgekühlten Gemisches von Ameisensäure und Aethylalkohol mit Salzsäuregas dargestellt. Das Produkt wurde, nach 24 stündigem Stehen und nach Verdünnen mit dem gleichen Volumen Wasser aus dem Wasserbade abdestillirt. Der Kühler war mit Eiswasser gefüllt, auch die Vorlage mit Eis abgekühlt. Der Aether destillirte schnell und beinahe frei von Alkohol und Salzsüure über: sobald die Destillation sich verlangsamte, wurde aufgehört. Das Destillat wurde nach mehrtägigem Stehen über wasserfreiem kohlensaurem Kali sorgfältigst fractionirt. Es siedete fast constant bei $54^{\circ}$ corr. Eine Dichte-Bestimmung ergab $d \frac{15^{0}}{15^{0}}=0,92263$.

Da diese mit den Angaben anderer Forscher nicht stimmte, so wurde der Aether nochmals sehr langsam fractionirt. Der Siedepunkt variirte aber nur um einen kleinen Bruchtheil eines Grades von dem vorigen, und die Dichte blieb dieselbe. Phosphorsäureanhydrid wurde dann langsam eingetragen. Zuerst verursachte jeder Zusatz ein Zischen, bald aber hörte dieses auf, dann wurde destillirt. Das specif. Gewicht stieg auf 0,92542 bei $15^{\circ}$. Der Aether wurde nochmals in gleicher Weise behandelt und destillirt, was wieder eine Erhöhung der Dichte hervorbrachte. Jetzt wurde er wiederholt über Phosphorsäureanhydrid destillirt, bis dieses nicht mehr auf ihn einwirkte. Das Produkt ergab:

$$
d \frac{15^{0}}{15^{0}}=0,92973, d \frac{25^{0}}{25^{0}}=0,91863 \text {. }
$$


d.Verbind. im Verhältn. zu deren chem. Constitut. etc. 537

Als später dieses Präparat nochmals über Phosphorsäureanhydrid destillirt, und die Dichte mittelst des modificirten Sprengel'schen Rohres bestimmt wurde, ergab es:

$$
d \frac{15^{0}}{15^{0}}=0,92987, d \frac{25^{0}}{25^{0}}=0,91881 .
$$

Diese letzten Bestimmungen wurden bei der Berechnung der magnetischen Rotation angewandt. Der Siedepunkt blieb während obiger Proceduren fast constant 54,2 ${ }^{\circ}$ corr.

Diese specifischen Gewichte sind höher als die bisher beobachteten. Die von Elsässer ${ }^{1}$ ) angegebenen Werthe ergeben $d \frac{15^{0}}{15^{0}}=0,91974$. Kopp fand die Dichte bei $0^{0}$ $=0,9447$, was umgerechnet $d \frac{15^{0}}{15^{0}}=0,9282$ giebt. Dieser Werth kommt dem obigen am nächsten.

Magnetische Rotation des ameisensauren Aethyls:

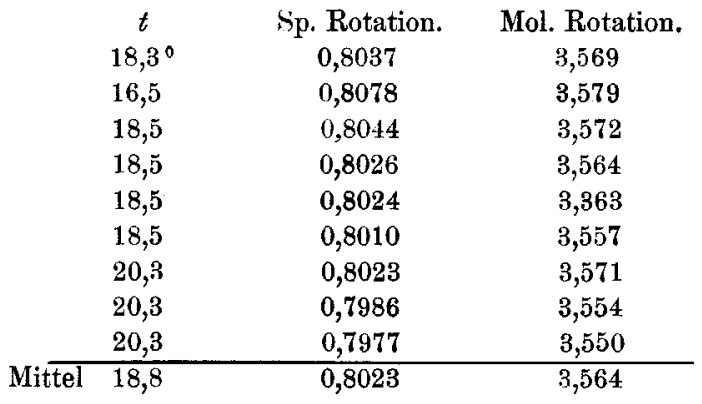

Ameisensaures Methyl.

Dieser Aether wurde aus Ameisensäure und Methylalkohol in genau derselben Weise wie die Aethylverbindung dargestellt; er verhielt sich auch wie diese gegen Phosphorsäureanhydrid. Mit letzterem behandelt, bis die Dichte constant geworden, lieferte er folgende Werthe:

$$
d \frac{15^{0}}{15^{0}}=0,98239, d \frac{25^{0}}{25^{0}}=0,96948 .
$$

1) Ann. Chem. Phar. 218, 311. 
538 Perkin: Ueber magnetische Circular-Polarisation

Diese Dichte ist höher, als die bis jetzt angegebenen. Am nächsten kommt ihr die von Grodzki und Krämer, welche bei $15^{\circ}$ gleich 0,9797 ist. Elsässer fand für den von ihm untersuchten Körper $d \frac{15^{0}}{15^{0}}=0,9776$. Den Siedepunkt dieses Aethers fand ich bei $32^{\circ}-32,5^{\circ}$ corr.

Magnetische Rotation des ameisensauren Methyls:

\begin{tabular}{|c|c|c|}
\hline$t$ & Sp. Rotation. & Mol. Rotation. \\
\hline $16,5^{0}$ & 0,7311 & 2,486 \\
\hline 16,5 & 0,7382 & 2,510 \\
\hline 16,5 & 0,7823 & 2,490 \\
\hline 16,5 & 0,7335 & 2,495 \\
\hline
\end{tabular}

\section{Ameisensaures Propyl.}

Diese Substanz, durch Sättigen eines Gemisches von Ameisensäure und Propylalkohol mit Salzsäure bereitet, und mit Phosphorsäureanhydrid getrocknet, siedete bei $80,5^{\circ}-$ $81,5^{0}$ corr.

Spec. Gewicht: $d \frac{15^{0}}{15^{0}}=0,90989, d \frac{25^{0}}{25^{0}}=0,90016$.

Folgende Zahlen wurden für die magnetische Rotation ermittelt:

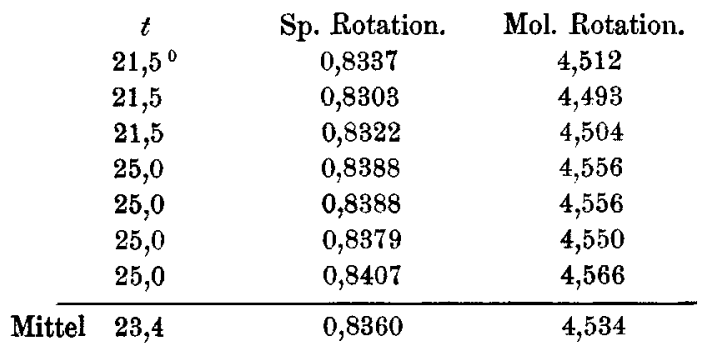

Fssigsaures Aethyl.

Versuche, diesen Aether durch Fractioniren des käuflichen Produktes rein zu erhalten, fielen unbefriedigend aus.

Eine Darstellungsmethode wurde daher gesucht, welche ihn gleich trocken und frei von Alkohol, Aether und anderen 
d. Verbind. im Verhältn. zu deren chem. Constitut. etc. 539 in der Nähe siedenden Körpern liefern sollte. Dies wurde durch Anwendung von Alkohol und überschüssigem Essigsäureanhydrid erreicht, da hier die Produkte nur Essigsäure und Essigäther sein konnten.

Zur Darstellung des letzteren wurde Essigsäureanhydrid nach und nach in siedenden Alkohol, welcher sich in einem mit einem circa $1 \mathrm{M}$. langen Rohre versehenen Destillirkölbchen befand, zufliessen gelassen. Sobald die Reaction vollendet, wurde das Gemisch eine Zeit lang digerirt, dann stärker erwärmt, und die Destillation fortgesetzt bis das im oberen Theile des Halses befindliche Thermometer auf $100^{\circ}$ gestiegen war.

Das Destillat wurde im gleichen Apparate fractionirt, wobei man ein zwischen $72^{\circ}$ und $78^{\circ}$ siedendes Produkt erhielt. Durch weiteres Fractioniren lieferte dieses eine bei 77,50 corr. fast constant siedende Flüssigkeit. Diese erwies sich durch die Analyse als Essigäther.

Spec. Gewicht: $d \frac{15^{0}}{15^{0}}=0,90727, d \frac{25^{0}}{25^{0}}=0,89685$.

Der Aether wurde mit Phosphorsäureanhydrid behandelt, davon abgegossen, wieder fractionirt und gab nun folgende Werthe:

$$
d \frac{15^{0}}{15^{0}}=0,90724, d \frac{25^{0}}{25^{0}}=0,89711 .
$$

Linnemannn $n^{1}$ ) stellte diesen Körper aus essigsaurem Silber und Jodäthyl dar und beobachtete den Siedepunkt: $77^{\circ}$ und $d \frac{15^{0}}{15^{0}}=0,9068$.

Die kleine, etwas niedriger (zwischen $72^{\circ}$ und $77^{\circ}$ ) siedende Fraction wird scheinbar durch Absorption einer kleinen Menge Feuchtigkeit aus der Luft verursacht, da deren Siedepunkt nach dem Behandeln mit Phosphorsäureanhydrid erhöht wird.

1) Ann. Chem. Phar. 160, 201. 
540 Perkin: Ueber magnetische Circular-Polarisation

Elsässer hat auch neuerdings die Dichte und Ausdehnung des Essigäthers bestimmt; seine Zahlen ergeben $d \frac{15^{0}}{15^{0}}=0,90710:$ der Siedepunkt seines Präparats lag bei $77,1^{0}$.

Essigäther erträgt das Destilliren mit Phosphorsäureanhydrid weniger gut als Ameisensäureäther; doch scheint das Destillat vollkommen rein zu sein, obwohl das Anhydrid sich färbt und ein Verlust an Substanz eintritt.

Folgende Zahlen wurden für die magnetische Rotation des nach der oben beschriebenen Methode dargestellten Aethers erhalten:

\begin{tabular}{ccc}
\multicolumn{1}{c}{$t$} & Sp. Rotation. & Mol. Rotation. \\
$16,5^{0}$ & 0,8290 & 4,475 \\
10,0 & 0,8317 & 4,460 \\
10,5 & 0,8318 & 4,460 \\
10,5 & 0,8311 & 4,456 \\
17,75 & 0,8255 & 4,440 \\
17,75 & 0,8309 & 4,480 \\
17,75 & 6,8268 & 4,459 \\
\hline Mittel 14,5 & 0,8295 & 4,462
\end{tabular}

\section{Acetessigäther.}

Derselbe wurde durch Fractioniren, zuerst unter gewöhnlichem, nachher unter vermindertem Drucke gereinigt. Bei $760 \mathrm{Mm}$. siedete er zwischen $180^{\circ}-182^{\circ}$; unter $330 \mathrm{Mm}$. bei $152,5^{\circ}-153^{\circ}$ (Faden im Dampf). Bestimmungen der Dichte ergaben:

$$
d \frac{15^{0}}{15^{0}}=1,03174, d \frac{25^{0}}{25^{0}}=1,02353 .
$$

Die folgenden Zahlen wurden für die magnetische Rotation ermittelt:

\begin{tabular}{cccc} 
& $t$ & Sp. Rotation. & Mol. Rotation. \\
& $13,5^{\circ}$ & 0,9333 & 6,525 \\
& 13,5 & 0,9339 & 6,530 \\
13,5 & 0,9318 & 6,515 \\
& 19,0 & 0,9230 & 6,481 \\
& 19,0 & 0,9220 & 6,475 \\
& 19,0 & 0,9230 & 6,481 \\
\hline Mittel & 16,25 & 0,9278 & 6,501
\end{tabular}


d. Verbind. im Verhältn. zu deren chem. Constitut. etc. 541

\section{Essigsaures Methyl.}

Dieser Körper wurde aus Essigsäureanhydrid und Methylalkohol, genau wie die Aethylverbindung dargestellt. Die Dichte zweier Präparate wurde bestimmt. Das erstere, bei $56^{\circ}-56,5^{\circ}$ corr. siedende ergab:

$$
d \frac{15^{0}}{15^{0}}=0,93912, d \frac{25^{0}}{25^{0}}=0,92788 .
$$

Das zweite, mit Phosphorsäureanhydrid behandelt und dann destillirt, siedete bei $57,5^{\circ}$ corr. und ergab:

$$
d \frac{15^{0}}{15^{0}}=0,93975, d \frac{25^{0}}{25^{0}}=0,92858 \text {. }
$$

Elsässer's Bestimmungen, nach diesen Temperaturen umgerechnet, ergeben:

$$
d \frac{15^{0}}{15^{0}}=0,93928, d \frac{25^{0}}{25^{0}}=0,92825 .
$$

Der Berechnung der Resultate wurden die Werthe II) zu Grunde gelegt.

Magnetische Rotation des essigsauren Methyls:

\begin{tabular}{cccc} 
& $t$ & Sp. Rotation. & Mol. Rotation. \\
& $2^{0}$ & 0,7835 & 3,381 \\
& 22 & 0,7770 & 3,353 \\
& 22 & $\mathbf{0 , 7 7 7 2}$ & 3,353 \\
\hline Mittel & $\mathbf{2 2}$ & 0,7792 & 3,362
\end{tabular}

\section{Essigsaures Propyl.}

Dasselbe, aus Essigsäureanhydrid und Propylalkohol genau wie der vorige Aether dargestellt, wurde mit Phosphorsäureanhydrid behandelt und siedete dann bei $102^{\circ}$ $103^{0}$ corr.

Spec. Gewicht: $d \frac{15^{0}}{15^{0}}=0,89331, d \frac{25^{0}}{25^{0}}=0,88398$.

Elsässer fand für sein Produkt eine Dichte, welche umgerechnet, $d \frac{15^{0}}{15^{0}}=0,89373$ ergibt.

Folgende Zahlen wurden für die magnetische Rotation erhalten: 
542 Perkin: Ueber magnetische Circular-Polarisation

$\begin{array}{ccc} & \text { Sp. Rotation. } & \text { Mol. Rotation. } \\ 15,0^{\circ} & 0,8660 & 5,494 \\ 17,0 & 0,8627 & 5,485 \\ 17,6 & 0,8643 & 5,498 \\ 18,0 & 0,8592 & 5,468 \\ 18,5 & 0,8575 & 5,460 \\ 13,0 & 0,8702 & 5,509 \\ 13,4 & 0,8649 & 5,478 \\ 13,8 & 0,8672 & 5,495 \\ 13,2 & 0,8683 & 5,498 \\ 13,5 & 0,8626 & 5,464 \\ 13,8 & 0,8689 & 5,506 \\ \text { Mittel } 15,2 & 0,8647 & 5,487\end{array}$

\section{Esșigsaures Isobutyl.}

Aus Essigsäureanhydrid und Isobutylalkohol dargestellt, siedete dieser Aether bei $117^{\circ}$ corr.; sein specif. Gewicht ist:

$$
d \frac{15^{0}}{15^{0}}=0,87743, d \frac{25^{0}}{25^{0}}=0,86885 .
$$

Elsässer's Bestimmungen ergeben $d \frac{15^{0}}{15^{0}}=0,87769$.

Folgende Zahlen wurden für die magnetische Rotation ermittelt :

\begin{tabular}{|c|c|c|}
\hline$t$ & Sp. Rotation. & Mol. Rotation. \\
\hline $10,5^{0}$ & 0,9072 & 6,628 \\
\hline 10,5 & 0,9076 & 6,631 \\
\hline 9,8 & 0,9063 & 6,620 \\
\hline 9,0 & 0,9041 & 6,602 \\
\hline 10,0 & 0,9070 & 6,629 \\
\hline 10,0 & 0,9068 & 6,628 \\
\hline Mittel $\quad 10,0$ & 0,9065 & 6,623 \\
\hline
\end{tabular}

\section{Essigsaures Octyl.}

Dieser Aether wurde aus reinem Octylalkohol und überschüssigem Essigsäureanhydrid durch Erhitzen dargestellt. Das Fractioniren des Produktes wurde bei vermindertem Luftdrucke (250 Mm.) ausgeführt. Unter diesem Drucke siedet der Aether bei $211,25^{\circ}-212^{\circ}$ (Faden im Dampf). Bestimmungen seiner Dichte ergaben:

$$
d \frac{15^{0}}{15^{0}}=0,87443, d \frac{25^{0}}{25^{0}}=0,86776 \text {. }
$$


d. Verbind. im Verhältn. zu deren chem. Constitut. etc. 543

Magnetische Rotation des essigsauren Octyls:

\begin{tabular}{cccc} 
& $t$ & Sp. Rotation. & Mol. Rotation. \\
& $15,4^{0}$ & 0,9722 & 10,628 \\
& $\mathbf{1 6 , 0}$ & $\mathbf{0 , 9 7 0 4}$ & $\mathbf{1 0 , 6 1 2}$ \\
& $\mathbf{1 6 , 8}$ & $\mathbf{0 , 9 6 3 2}$ & $\mathbf{1 0 , 5 6 4}$ \\
\hline Mittel & $\mathbf{1 6 , 1}$ & $\mathbf{0 , 9 6 8 6}$ & $\mathbf{1 0 , 6 0 1}$
\end{tabular}

Propionsaures Aethyl.

Diese mit Phosphorsäure getrocknete, dann fractionirte Verbindung siedete bei $99,5^{\circ}-99,8^{\circ}$ corr. und ergab:

$$
d \frac{15^{0}}{15^{0}}=0,89579, d \frac{25^{0}}{25^{0}}=0,88628 .
$$

Linnemann ${ }^{1}$ ) beobachtete $d \frac{15^{0}}{15^{0}}=0,8973$. Elsässer erhielt den Werth: $d \frac{15^{0}}{15^{0}}=0,89669$. Die niedrigeren Zahlen liegen wahrscheinlich der Wahrheit am nächsten.

Dieser Aether gab folgende Zahlen für die magnetische Rotation:

$\begin{array}{cccc}t & \text { Sp. Rotation. } & \text { Mol. Rotation. } \\ 16,5^{0} & 0,8586 & 5,440 \\ 17,5 & 0,8588 & 5,447 \\ 15,0 & 0,8640 & 5,466 \\ 15,0 & 0,8634 & 5,461 \\ & 15,0 & 0,8599 & 5,440 \\ 15,0 & 0,8625 & 5,456 \\ \text { Mittel } & 15,7 & 0,8612 & 5,452\end{array}$

Essigsaures Cetyl.

Dieser Körper wurde durch dreitägiges Kochen eines Gemisches von Cetylalkohol und überschüssigem Essigsäureanhydrid dargestellt; nach Abdestilliren des grössten Theiles der gebildeten Essigsäu re sowie des überschüssigen Anhydrids wurde der oberhalb $200^{\circ}$ gebliebene Rückstand unter vermindertem Luftdrucke fractionirt. Der unter $190 \mathrm{Mm}$. bei $277^{\circ}-278^{\circ}$ siedende Antheil wurde zur Untersuchung verwendet. Noch bei diesem Drucke scheint eine geringe Zersetzung stattzufinden. Dieser Aether schmilzt bei $18,5^{\circ}$. Bestimmungen seiner Dichte ergaben:

1) Ann. Chem. Pharm. 160, 220. 
544 Perkin: Ueber magnetische Circular-Polarisation

$$
d \frac{21^{0}}{21^{0}}=0,86404, d \frac{25^{0}}{25^{0}}=0,86120 .
$$

Magnetische Rotation des essigsauren Cetyls:

\begin{tabular}{|c|c|c|}
\hline$t$ & Sp. Rotation. & Mol. Rotation. \\
\hline $22,0^{\circ}$ & 1,0262 & 18,755 \\
\hline 21,0 & 1,0271 & 18,755 \\
\hline 20,0 & 1,0280 & 18,757 \\
\hline 19,0 & 1,0306 & 18,789 \\
\hline 20,0 & 1,0290 & 18,774 \\
\hline 20,5 & 1,0298 & 18,797 \\
\hline 21,0 & 1,0292 & 18,793 \\
\hline 22,0 & 1,0264 & 18,758 \\
\hline 20,7 & 1,0283 & 18,772 \\
\hline
\end{tabular}

Propionsaures Propyl.

Dieser mehrmals mit Phosphorsäureanhydrid behandelte und fractionirte Aether siedete bei $122^{\circ}-123^{\circ}$ und ergab:

$$
\begin{array}{cccc}
d \frac{15^{0}}{15^{0}} & 0,88696 & \text { I } & \text { Mittel } \\
d \frac{25^{0}}{25^{0}} & 0,87812 & 0,87800 & 0,88684 \\
& & 0,87806
\end{array}
$$

Linnemann's ${ }^{1}$ ) Dichtebestimmung, für diese Temperatur umgerechnet, ergibt $d \frac{15^{0}}{15^{\circ}}=0,8868$; der von Elsässser ${ }^{2}$ ) bestimmte Werth für die gleiche Temperatur ist 0,88844 .

Folgende Zahlen wurden für die magnetische Rotation erhalten:

\begin{tabular}{lccc} 
& \multicolumn{1}{c}{ Sp. Rotation. } & Mol. Rotation. \\
$17,0^{\circ}$ & 0,8824 & 6,425 \\
18,0 & 0,8806 & 6,418 \\
18,0 & 0,8815 & 6,425 \\
18,0 & 0,8800 & 6,414 \\
21,5 & 0,8774 & 6,417 \\
21,5 & 0,8779 & 6,421 \\
& 24,0 & 0,8790 & 6,446 \\
& 25,0 & 0,8763 & 6,432 \\
& 25,0 & 0,8796 & 6,456 \\
& 25,0 & 0,8769 & 6,436 \\
\hline Mittel & 21,3 & 0,8792 & 6,429
\end{tabular}

1) Ann. Chem. Pharm. 161, 31.

2) Das. 218, 321 . 
d. Verbind. im Verhältn. zu deren chem. Constitut. ete. 545

\section{Propionsaures Isopropyl.}

Diese Verbindung, durch Sättigen eines Gemisches von Dimethylcarbinol (Isopropylalkohol) und Propionsäure mit Salzsäure dargestellt, nach dem Waschen mit Phosphorsäureanhydrid getrocknet, und fractionirt, siedete bei $109,5^{\circ}-$ $110,5^{\circ}$ corr. und ergab:

$$
d \frac{15^{0}}{15_{0}}=0,87172, d \frac{25^{0}}{25^{0}}=0,86262 .
$$

Folgende Zahlen wurden für die magnetische Rotation ermittelt:

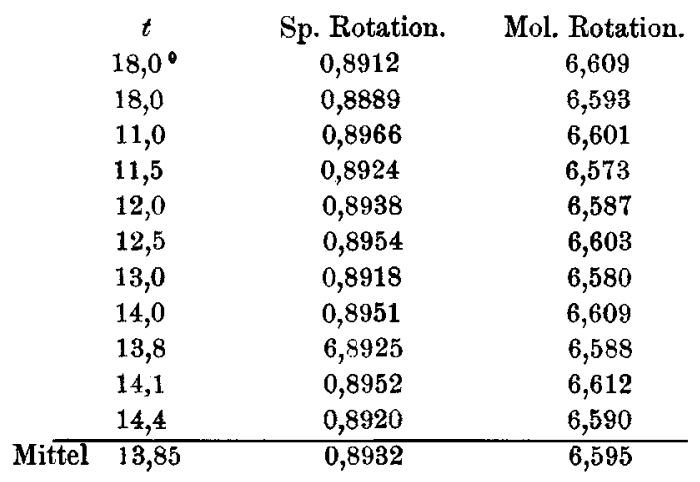

\section{Buttersaures Aethyl.}

Dieser A ether, durch Sättigen eines Gemisches von Buttersäure und Alkohol mit Salzsäure erhalten, wurde mehrmals fractionirt, und der bei $121^{\circ}-121,5^{\circ}$ corr. siedende Antheil zur Untersuchung verwendet.

Elsässer giebt den Siedepunkt bei $119^{\circ}$ an und Linne$\left.\operatorname{man} n^{1}\right)$ bei $121,1^{0}$.

Bestimmungen der Dichte ergaben:

$$
d \frac{15^{0}}{15^{0}}=0,88493, d \frac{25^{0}}{25^{0}}=0,87615 .
$$

Elsässer's umgerechnete Bestimmungen liefern:

$$
d \frac{15^{0}}{15^{0}}=0,88481 \text {. }
$$

1) Ann. Chem. Pharm. 116, 33.

Journal f. prakt. Chemie [2] Bd. 32. 
546 Perkin: Ueber magnetische Circular-Polarisation

Die folgenden Zahlen wurden für die magnetische Rotation erhalten:

\begin{tabular}{|c|c|c|}
\hline$t$ & Sp. Rotation. & Mol. Rotation. \\
\hline $17,0^{0}$ & 0,8849 & 6,457 \\
\hline 18,0 & $0,885 \overline{5}$ & 6,468 \\
\hline 18,0 & 0,8840 & 6,457 \\
\hline 13,0 & 0,8878 & 6,453 \\
\hline 13,0 & 0,8877 & 6,452 \\
\hline 13,0 & 0,8915 & 6,479 \\
\hline 13,0 & 0,8925 & 6,486 \\
\hline 18,8 & 0,8911 & 6,514 \\
\hline 18,8 & 0,8917 & 6,518 \\
\hline 18,8 & 0,8874 & 6,487 \\
\hline 16,1 & 0,8884 & 6,477 \\
\hline
\end{tabular}

\section{Buttersaures Methyl.}

Dieser Körper wurde ähnlich dem vorigen dargestellt. Mit Phosphorsäureanhydrid getrocknet und fractionirt, siedete er bei $102^{\circ}-103^{\circ}$ corr. Krämer und Grodzkil) geben den Siedepunkt bei $102,5^{\circ}-103,5^{0}$ an. Elsässer ${ }^{2}$ ) bei $102,3^{\circ}$.

Bestimmungen der Dichte ergaben:

$$
d \frac{15^{0}}{15^{0}}=0,90365, d \frac{25^{0}}{25^{0}}=0,89452 .
$$

Elsässer's Bestimmungen ergaben $d \frac{15^{0}}{15^{0}}=0,90427$.

Die folgenden Zahlen wurden für die magnetische Rotation erhalten:

\begin{tabular}{cccc} 
& $t$ & Sp. Rotation. & Mol. Rotation. \\
& $16,4^{0}$ & 0,8577 & 5,386 \\
& 16,4 & 0,8588 & 5,393 \\
& 16,4 & 0,8569 & 5,381 \\
\hline Mittel & 16,4 & 0,8578 & 5,387
\end{tabular}

\section{Isobuttersaures Aethyl.}

Dieser durch Sättigen eines Gemisches von Isobuttersäure (durch Oxydation des Isobutylalkohols erhalten) und Aethylalkohol mit Salzsäure gewonnene Körper, wurde

1) Ber. Berl. chem. Ges. 11, 1358.

2) Ann. Chem. Pharm. 218, 313. 
d. Verbind. in Verbältn. zu deren chem. Constitut. etc. 547 nach dem Waschen mit wasserfreiem kohlensaurem Kali gut getrocknet, und oftmals fractionirt. Das untersuchte Präparat siedete bei $110^{\circ}-110,6^{\circ}$ corr. und ergab:

$$
d \frac{15^{0}}{15^{0}}=0,87580, d \frac{25^{0}}{25^{0}}=0,86695 .
$$

Elsässer giebt den Siedepunkt bei $110,1^{\circ}$ an; seine Dichte-Bestimmung umgerechnet, ergiebt $d \frac{15^{0}}{15^{0}}=0,87568$.

Die für die magnetische Rotation erhaltenen Zahlen sind:

\begin{tabular}{rcc}
$t$ & Sp. Rotation. & Mol. Rotation. \\
$24,0^{0}$ & 0,8732 & 6,484 \\
24,8 & 0,8726 & 6,485 \\
25,5 & 0,8671 & 6,449 \\
18,8 & 0,8799 & 6,500 \\
18,8 & 0,8773 & 6,480 \\
18,8 & 0,8770 & 6,478 \\
\hline Mittel 21,8 & 0,8745 & 6,479
\end{tabular}

Isovaleriansaures Aethyl.

Diese Verbindung, durch Sättigen eines Gemisches von Aethylalkohol und Isovaleriansäure (aus gewöhnlichem Amylalkohol) mit Salzsäure erhalten, siedete nach mehrmaligem Fractioniren bei $135^{\circ}-135,25^{\circ}$ corr. Zwei Reihen DichteBestimmungen, beide mit demselben Präparat, wurden ausgeführt, aber das letztere war vor der zweiten Reihe nochmals mit Phosphorsäureanhydrid behandelt und fractionirt:

$$
\begin{array}{cccc}
\text { I } & \text { II } & \text { Mittel } \\
d \frac{1^{0}}{15^{0}}=0,87139 & 0,87133 & 0,87136 \\
d \frac{25^{0}}{25^{0}}=0,86321 & 0,86312 & 0,86316
\end{array}
$$

Elsässer's Präparat siedete bei $134,3^{\circ}$ und ergab: $d \frac{15^{0}}{15^{0}}=0,87262$. Pierre und Puchot geben den Siedepunkt bei $135,5^{\circ}$ an.

Die bleibende Rotation meines Präparates betrug für die D-Linie $+6,2^{\circ}$ für eine $200^{\circ}$ lange Schicht $\left(t=15^{\circ}\right)$. Die höchste beobachtete Rotation des Aethyläthers der activen 
548 Perkin: Ueber magnetische Circular-Polarisation Säure ist die von Pierre und $\mathrm{Puchot}{ }^{1}$ ) angegebene, die $[\alpha]_{D}=1,50^{\circ}$ beträgt.

Folgende Zahlen wurden für die magnetische Rotation erhalten:

\begin{tabular}{cccc} 
& $t$ & Sp. Rotation. & Mol. Rotation. \\
& $18,0^{\circ}$ & 0,9171 & 7,623 \\
18,0 & 0,9167 & 7,619 \\
15,0 & 0,9205 & 7,630 \\
& 19,5 & 0,9130 & 7,600 \\
& 19,5 & 0,9143 & 7,605 \\
\hline Mittel & $\mathbf{1 8 , 0}$ & 0,9163 & $\mathbf{7 , 6 1 5}$
\end{tabular}

Capronsaures Aethyl.

Die zur Darstellung dieses Aethers angewandte Säure (von Kahlbaum bezogen, und durch Gährung dargestellt), wurde durch Sättigen ihrer alkoholischen Lösung mit Salzsäure ätherificirt. Die ätherische Lösung wurde mittelst Chlorcalcium getrocknet, der Aether abdestillirt und der Rückstand mehrmals fractionirt. Die untersuchte Substanz siedete bei $166,5^{\circ}-168,5^{\circ}$ (Faden im Dampf). Bestimmungen der Dichte ergaben:

$$
d \frac{15^{0}}{15^{0}}=0,87716, d \frac{25^{0}}{25^{0}}=0,86961 .
$$

Magnetische Rotation:

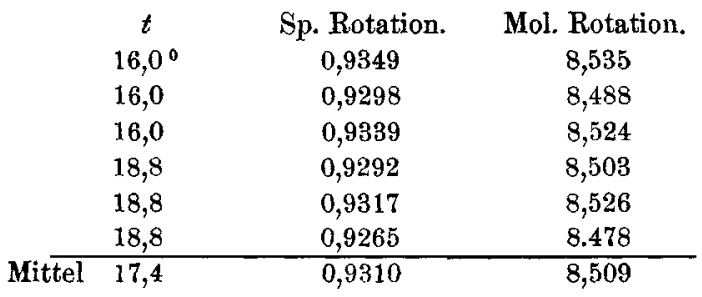

\section{Heptyl- oder Oenanthylsaures Aethyl.}

Von dieser ähnlich der vorigen dargestellten Substanz wurden zwei Präparate untersucht. I siedete bei $187^{\circ}-188^{\circ}$ corr., II bei $187,5^{\circ}-189,5^{\circ}$ corr. Ihr specifisches Gewicht betrug :

1) Compt. rend. 76, 1332. 
d. Verbind. im Verhältn. zu deren chem. Constitut. etc. 549

$$
\begin{array}{cc}
d \frac{15^{0}}{15^{0}}=0,87163 & \text { II } \\
d \frac{25^{0}}{25^{0}}=0,86477 & 0,864199
\end{array}
$$

Eine grosse Anzahl Messungen der magnetischen Rotation dieser Substanz wurden ausgeführt, da die Resultate durch Wärmeströmungen in Folge kleiner Temperatur-

\begin{tabular}{|c|c|c|}
\hline$t$ & Sp. Rotation. & Mol. Rotation \\
\hline $13,7^{\circ}$ & 0,9524 & 9,578 \\
\hline 12,5 & 0,9476 & 9,520 \\
\hline 12,5 & 0,9474 & 9,517 \\
\hline 12,5 & 0,9488 & 9,531 \\
\hline 13,0 & 0,9496 & 9,541 \\
\hline 13,0 & 0,9520 & 9,568 \\
\hline 13,5 & 0,9446 & 9,498 \\
\hline 13,5 & 0,9459 & 9,511 \\
\hline 16,0 & 0,9468 & 9,542 \\
\hline 16,5 & 0,9472 & 9,546 \\
\hline 17,8 & 0,9491 & 9,576 \\
\hline 17,8 & 0,9447 & 9,532 \\
\hline 17,8 & 0,9470 & 9,554 \\
\hline 17,8 & 0,9489 & 9,574 \\
\hline 14,9 & 0,9480 & 9,541 \\
\hline
\end{tabular}
schwankungen beeinflusst werden.

Magnetische Rotation:

Nonyl- oder Pelargonsanres Aethyl.

Dieser aus der untersuchten und schon beschriebenen Säure (s. 533) dargestellt, siedete bei $226^{\circ}-228^{\circ}$ (Faden im Dampf).

Spec. Gewicht desselben: $d \frac{15^{0}}{15^{0}}=0,87033, d \frac{25^{0}}{25^{0}}=0,86407$.

Zincke und Franchimont fanden eine Dichte, welche, wenn sie auf Wasser von $4^{0}$ bezogen war, $d \frac{15^{0}}{15^{0}}=0,8682$ ergeben würde. Der wahre Werth liegt wahrscheinlich zwischen diesem und dem meinigen.

Folgende Zahlen wurden für die magnetische Rotation erbalten: 
550 Perkin: Ueber magnetische Circular-Polarisation

\begin{tabular}{rcc}
$t$ & Sp. Rotation. & Mol. Rotation. \\
$17,9^{\circ}$ & 0,9655 & 11,554 \\
17,9 & 0,9657 & 11,555 \\
16,9 & 0,9745 & 11,586 \\
18,9 & 0,9737 & 11,602 \\
18,9 & 0,9721 & 11,582 \\
18,9 & 0,9695 & 11,551 \\
\hline Mittel 18,2 & 0,9701 & 11,571
\end{tabular}

\section{Oenanthyl- oder Heptylsaures Heptyl.}

$\mathrm{Da}$ die Methode von Cross'), welcher diesen Aether durch Einwirkung von Jodäthyl auf oenanthylsaures Silber darstellte, sehr umständlich ist, so wurde eine andere versucht: Ein Gemisch ron Heptylalkohol mit etwas mehr als der berechneten Menge Heptylsäure wurde, mit Salzsäure gesättigt, in einem zugeschmolzenen Rohr auf $100^{\circ}$ erhitzt. Dem Produkt wurde mit Aether nach Zusatz von Wasser und von kohlensaurem Natron das heptylsaure Heptyl entzogen, der über wasserfreiem kohlensaurem Kali getrocknete Aether abdestillirt, und der Rückstand fractionirt. Ein grosser Theil des Produkts ging bei $276^{\circ}-278^{\circ}$ (Faden im Dampf) über. Bestimmungen der Dichte ergaben:

$$
d \frac{15^{0}}{15^{0}}=0,86522, d \frac{25^{0}}{25^{0}}=0,85933 .
$$

Cross giebt den Siedepunkt bei $270^{\circ}-272^{\circ}$ an, sagt aber nicht, ob der Faden ganz im Dampf gewesen ist, auch giebt er ein böheres spec. Gewicht: 0,870 bei $16^{\circ}$ an.

Die magnetische Rotation dieses Körpers war wegen der Wärmeströmungen, die bei geringer Temperaturänderung leicht zu Stande kamen, sehr schwierig zu bestimmen:

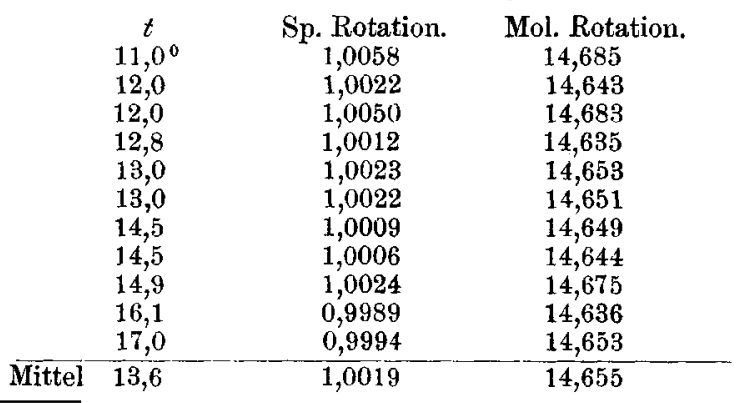

1) Journ. Chem. Soc. 32, 127. 
d. Verbind. im Verhältn. zu deren chem. Constitut. ete. 551

Mehrwerthige Alkohole und ihre Derivate.

$$
\text { Aethylenhydrat - Glycol. }
$$

Dieser Körper wurde aus seinem Monoacetat durch Bebandeln mit Baryt dargestellt; wiederholt fractionirt siedete er bei $196^{\circ}-199^{\circ}$ corr. und ergab:

$$
d \frac{15^{0}}{15^{0}}=1,11678, d \frac{25^{0}}{25^{0}}=1,11208 .
$$

Folgende Zahlen wurden für die magnetische Rotation erhalten:

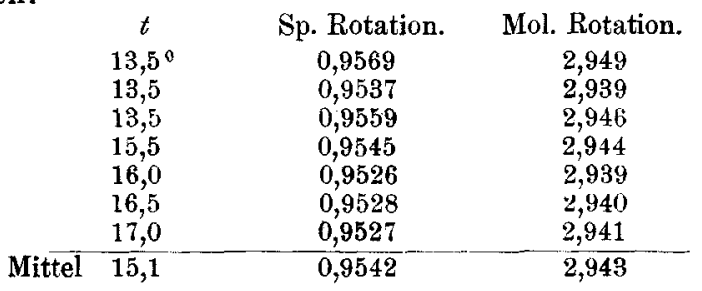

Essigsaures Glycol - Aethylenacetat.

Zunächst wurde das Monoacetat des Glycols nach Atkinson's $\left.{ }^{1}\right)$ Methode durch Erhitzen eines Gemisches von Aethylenbromid, essigsaurem Kali und Alkohol bei $100^{\circ}$ (im Rohr) dargestellt. Nach Destilliren des Produktes, mehrstündigem Kochen mit überschüssigem Essigsäureanhydrid und mehrmaligem Fractioniren, siedete das Diacetat bei $190^{\circ}-190,5^{\circ}$ corr. Bestimmungen der Dichte ergaben:

$$
d \frac{15^{0}}{15^{0}}=0,11076, d \frac{25^{0}}{25^{0}}=1,10183 .
$$

Fólgende Zahlen wurden für die magnetische Rotation erhalten:

\begin{tabular}{ccc}
$t$ & Sp. Rotation. & Mol. Rotation. \\
$13,0^{0}$ & 0,9918 & 6,501 \\
13,0 & 0,8888 & 6,476 \\
13,0 & 0,8864 & 6,463 \\
14,8 & 0,8807 & 6,430 \\
15,2 & 0,8810 & 6,434 \\
15,6 & 0,8834 & 6,453 \\
25,0 & 0,8756 & 6,445 \\
26,0 & 0,8756 & 6,450 \\
26,0 & 0,8722 & 6,432 \\
\hline Mittel 18,0 & 0,8717 & 6,454
\end{tabular}

1) Phil. Mag. [4] 16, 433. 
552 Perkin: Ueber magnetische Circular-Polarisation

Propionsaures Glyeol - Aethylenpropionat.

Dieser durch mehrtägiges Kochen von Glycol und Propionsäureanhydrid und Fractioniren des Productes erhaltene Aether siedete bei $210,5^{\circ}-212^{\circ}$ corr. und ergab:

$$
d \frac{15^{0}}{15^{0}}=1,05440, d \frac{25^{0}}{25^{0}}=1,04566 \text {. }
$$

Folgende Zahlen wurden für die magnetische Rotation ermittelt:

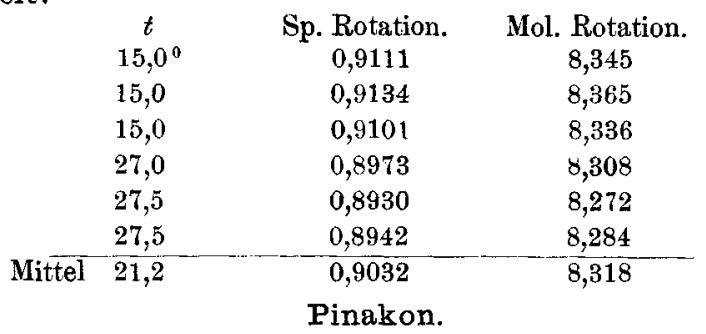

Diese Substanz wurde durch sorgfältige Destillation des von Kahlbaum bezogenen Hydrates dargestellt. Man darf die Destillation desselben nicht $\mathrm{zu}$ schnell ausführen, da sonst leicht etwas des condensirten Wassers in die siedende Flüssigkeit zurückfliesst. Das wasserfreie Pinakon siedete constant bei $170^{\circ}$ corr. Da es sich lange Zeit im Zustande der Ueberschmelzung hält, so kann seine Dichte bei Temperaturen unter seinem Schmelzpunkt bestimmt werden. Folgende Resultate wurden erhalten:

$$
d \frac{15^{0}}{15^{0}}=0,96718, d \frac{25^{0}}{25^{0}}=0,96087 .
$$

\begin{tabular}{|c|c|c|}
\hline$t$ & Sp. Rotation. & Mol. Rotation. \\
\hline $22,0^{\circ}$ & 1,0721 & 7,311 \\
\hline 22,0 & 1,0618 & 7,230 \\
\hline 22,0 & 1,0712 & 7,294 \\
\hline 22,0 & 1,0608 & 7,224 \\
\hline 22,0 & 1,0660 & 7,259 \\
\hline 22,0 & 1,0639 & 7,245 \\
\hline 21,0 & 1,0633 & 7,236 \\
\hline 21,0 & 1,0617 & 7,225 \\
\hline 26,5 & 1,0564 & 7,215 \\
\hline 26,5 & 1,0601 & 7,240 \\
\hline 26,5 & 1,0567 & 7,217 \\
\hline 23,0 & 1,0631 & 7,245 \\
\hline
\end{tabular}

Magnetische Rotation des Pinakons: 
d. Verbind. im Verhältn. zu deren chem. Constitut. ete. 553

\section{Dimethylacetal - Aethylidendimethyläther.}

Dieser von Kahlbaum bezogene, mit wasserfreiem kohlensaurem Kali getrocknete und dann fractionirte Körper siedete bei $64^{\circ}$ corr. und ergab:

$$
d \frac{15^{0}}{15^{0}}=0,85739, \quad{ }^{2} \frac{25^{0}}{25^{0}}=0,84764 \text {. }
$$

Folgende Zahlen wurden für seine magnetische Rotation erhalten:

\begin{tabular}{cccc} 
& $t$ & Sp. Rotation. & Mol. Rotation. \\
& $22,0^{\circ}$ & 0,7858 & 4,620 \\
& 13,0 & 0,8036 & 4,675 \\
& 13,4 & 0,7963 & 4,635 \\
& 13,8 & 0,8001 & 4,659 \\
\hline Mittel & 15,5 & 0,7965 & 4,647
\end{tabular}

\section{Acetal - Aethylidendiäthyläther.}

Mit wasserfreiem kohlensaurem Kali getrocknet, siedete dieser Körper bei $104^{0}-104,1^{\circ}$ corr. und ergab:

$$
d \frac{15^{0}}{15^{0}}=0,83187, \quad l \frac{25^{0}}{25^{0}}=0,82334 .
$$

Folgende Zahlen wurden für die magnetische Rotation erhalten:

\begin{tabular}{cccc} 
& $t$ & Sp. Rotation. & Mol. Rotation. \\
& $21,8^{\circ}$ & 0,8767 & 6,957 \\
13,7 & 0,8836 & 6,973 \\
& 14,2 & 0,8836 & 6,977 \\
Mittel & 14,8 & 0,8816 & 6,964 \\
\hline & 16,1 & 0,8814 & 6,968 \\
& & & \\
& & \\
& &
\end{tabular}

Diese durch Destillation wasserfrei erhaltene Substanz siedete bei $290^{\circ}-290,5^{\circ}$ corr. fast ohne Zersetzung. Bestimmungen der Dichte ergaben:

$$
d \frac{15^{0}}{15^{0}}=1,26241, d \frac{25^{0}}{25^{0}}=1,25881 .
$$

Folgende Zahlen wurden für die magnetische Rotation erhalten : 
554 Perkin: Ueber magnetische Circular-Polarisation

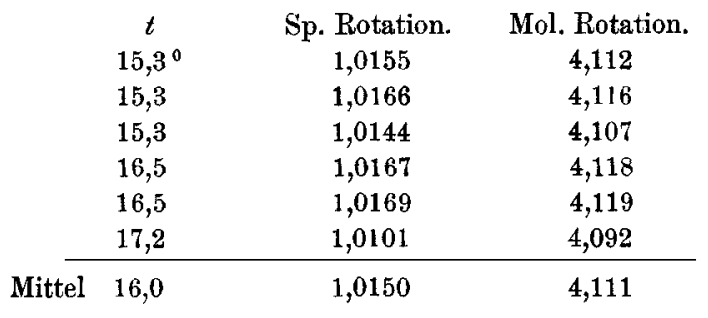

Aether der zweibasischen Säuren.

Oxalsaures Aethyl.

Das angewandte Präparat siedete bei $185^{\circ}$ corr. und ergab:

$$
d \frac{15^{0}}{15^{0}}=1,08563, d \frac{25^{0}}{25^{0}}=1,07609 .
$$

Kopp fand für die Dichte $d \frac{15^{0}}{15^{0}}=1,0856$, und Brühl $d \frac{15^{0}}{15^{0}}=1,0858$.

Folgende Zahlen wurden für die magnetische Rotation erhalten:

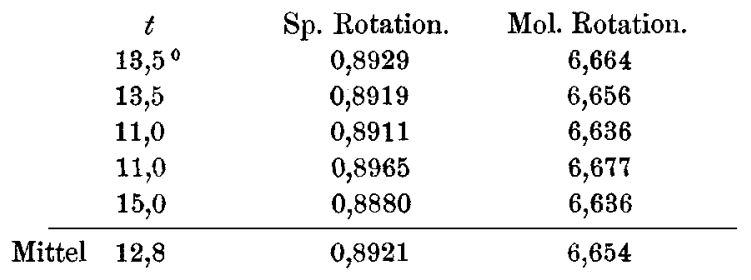

\section{Malonsaures Aethyl.}

Dieser, von Kahlbaum bezogene und sorgfältig fractionirte Körper siedete bei $197,7^{\circ}-198,2^{\circ}$ corr. und er gab

$$
d \frac{15^{0}}{15^{0}}=1,06104, d \frac{25^{0}}{25^{0}}=1,05248 .
$$

Folgende Zahlen wurden für die magnetische Rotation ermittelt: 
d. Verbind. im Verhältn. zu deren chem. Constitut. ete. 555

\begin{tabular}{ccc}
$t$ & Sp. Rotation. & Mol. Rotation. \\
$8,0^{0}$ & 0,8883 & 7,400 \\
8,0 & 0,8907 & 7,420 \\
8,0 & 0,8951 & 7,456 \\
9.0 & 0,8907 & 7,425 \\
14,0 & 0,8837 & 7,404 \\
16,5 & 0,8845 & 7,418 \\
17,0 & 0,8810 & 7,392 \\
17,0 & 0,8826 & 7,406 \\
17,0 & 0,8827 & 7,407 \\
17,0 & 0,8831 & 7,409 \\
19,0 & 0,8759 & 7,378 \\
19,0 & 0,8791 & 7,405 \\
\hline Mittel 14,1 & 0,8848 & 7,410
\end{tabular}

Malonsaures Mothyl.

Derselbe wurde durch Sättigen eines Gemisches von Malonsäure und Methylalkohol mit Salzsäure bereitet.

Nach etwa 24 Stunden wurde Wasser zugesetzt, und die ölige Schicht mit Aether aufgenommen. Letztere durch Waschen mit einer Sodalösung von Säure befreit und über wasserfreiem kohlensaurem Kali getrocknet, lieferte den gesuchten Aether. Fast alle der folgenden Aetherarten wurde auf ähnliche Weise dargestellt.

Das malonsaure Methyl siedete bei $181,5^{0}$ corr. und ergab :

$$
d_{15^{0}}^{15^{0}}=1,16028, d_{25^{0}}^{25^{0}}=1,15110 \text {. }
$$

Folgende Zahlen wurden für die magnetische Rotation erhalten:

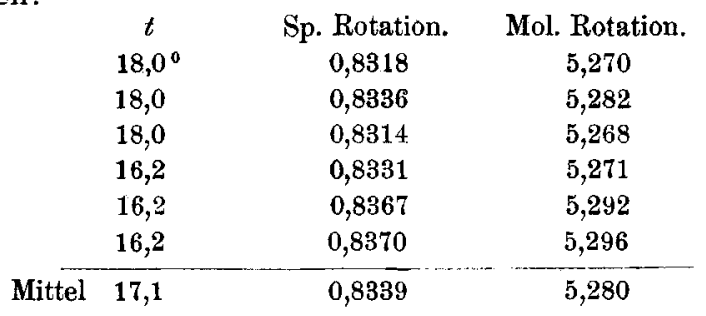


556 Perkin: Ueber magnetische Circular-Polarisation

Substitutions-Produkte des Aethylmalonats.

Anfangs wurden diese Verbindungen nach der von Con$\operatorname{rad}^{1)}$ beschriebenen Methode dargestellt, und einfach durch Fractioniren gereinigt. Jedoch erwies sich diese Reinigung als nicht genügend, da sich Nebenprodukte in Folge einer partieilen Verseifung eines Theils des Malonsäureäthers durch Natriumäthylat bilden. Die so erzeugte salzartige Verbindung wirkt auf die vorhandenen Jodide ein, so dass entsprechende Aether entstehen. Gewöhnlich ist auch eine kleine Menge eines, durch Fractioniren nicht zu entfernenden jodhaltigen Körpers vorhanden. Meist wurden daher die nach Conrad's Methode dargestellten Körper verseift, die Säure gereinigt und wieder ätherificirt. Langes Sieden dieser Verbindungen ist schädlich, man fractionirt sie daher am besten unter vermindertem Drucke.

\section{Methylmalonsaures Aethyl: $\mathrm{CH}\left(\mathrm{CH}_{3}\right)\left\{\begin{array}{l}\mathrm{COOC}_{2} \mathrm{H}_{5} \\ \mathrm{COOC}_{2} \mathrm{H}_{5}\end{array}\right.$.}

Um diese Verbindung zu erhalten, wurde Malonsäureäther wie gewöhnlich mit Natriumäthylat und Jodmethyl behandelt. Das Produkt wurde fractionirt und ergab: $d \frac{15^{0}}{15^{0}}=1,02865$.

Die durch Verseifung daraus gewonnene Säure wurde aus Wasser umkrystallisirt, zwischen Tuch gut gepresst und dann ätherificirt.

So gereinigt siedete der Aether bei $198,5^{\circ}-199,5^{\circ}$ corr. und batte ein merklich geringeres specifisches Gewicht als das zuerst untersuchte Produkt:

$$
d \frac{15^{0}}{15^{0}}=1,02132, d \frac{25^{0}}{25^{0}}=1,01295 .
$$

Folgende Zahlen wurden für die magnetische Rotation erhalten:

1) Ann. Chem. Pharm. 204, 129. 
d. Verbind. im Verhältn. zu deren chem. Constitut. etc. 557

$\begin{array}{rcc}t & \text { Sp. Rotation. } & \text { Mol. Rotation. } \\ 19,2^{\circ} & 0,8761 & 8,321 \\ 19,2 & 0,8750 & 8,311 \\ 19,2 & 0,8781 & 8,339 \\ 16,3 & 0,8802 & 8,340 \\ 16,3 & 0,8786 & 8,325 \\ 16,3 & 0,8780 & \mathbf{8 , 3 2 0} \\ \text { Mittel } 17,7 & 0,8777 & \mathbf{8 , 3 2 6}\end{array}$

\section{Dimethylmalonsaures Aethyl: $\mathrm{C}_{\left(\mathrm{CH}_{3}\right)_{2}} \underset{\mathrm{COOC}_{2} \mathrm{H}_{5}}{\mathrm{COOC}_{5} \mathrm{H}_{5}}$.}

Diese Verbindung wurde nach der Conrad'schen Methode dargestellt, dann destillirt, verseift, und die Dimethylmalonsäure abgeschieden und gereinigt. Die Säure wurde wiederholt aus Wasser umkrystallisirt, bis der Schmelzpunkt constant blieb, und dann ätherificirt. Der so gereinigte Aether siedete bei $196,2-196,7^{\circ}$ corr. Bestimmungen der Dichte ergaben:

$$
d \frac{15^{0}}{15^{0}}=1,00153, d \frac{25^{0}}{25^{0}}=0,99356 .
$$

Folgende Zahlen wurden für die magnetische Rotation ermittelt:

\begin{tabular}{ccc}
$t$ & Sp. Rotation. & Mol. Rotation. \\
$10,5^{0}$ & 0,8925 & 9,274 \\
12,3 & 0,8912 & 9,275 \\
12,3 & 0,8910 & 9,273 \\
12,7 & 0,8929 & 9,295 \\
12,7 & 0,8882 & 9,246 \\
13,5 & 0,8906 & 9,276 \\
14,2 & 0,8925 & 9,301 \\
14,5 & 0,8890 & 9,267 \\
18,5 & 0,8847 & 9,251 \\
18,5 & 0,8850 & 9,255 \\
18,5 & 0,8836 & 9,238 \\
\hline Mittel 14,4 & 0,8892 & $\mathbf{9 , 2 6 8}$
\end{tabular}

Aethylmalonsaures Aethyl: $\mathbf{C H}\left(\mathrm{C}_{2} \mathrm{H}_{5}\right) \underset{\mathrm{COOC}_{2} \mathrm{H}_{5}}{\mathrm{COOC}_{5} \mathrm{H}_{5}}$.

Nach den Angaben von Conrad ${ }^{1}$ ) dargestellt, siedete dieser Aether bei 209,5 $5^{0}-211,5^{0}$ und ergab: $d \frac{15^{0}}{15^{0}}=1,01395$.

1) Ann. Chem. Pharm. 204, 134. 
558 Perkin: Ueber magnetische Circular-Polarisation

Die daraus durch Verseifen erhaltene Säure wurde in das Calciumsalz übergeführt, welches, trocken in Alkohol suspendirt, mittelst Salzsäure ätherificirt wurde. Das so erhaltene Produkt siedete bei $209,5^{0}-210,5^{0}$ corr. und die DichteBestimmungen ergaben:

$$
d \frac{15^{0}}{15^{0}}=1,01235, d \frac{25^{0}}{25^{0}}=1,00441 .
$$

Magnetische Rotation des Aethylmalonsäureäthers:

\begin{tabular}{|c|c|c|}
\hline $\begin{array}{c}t \\
13,2^{0}\end{array}$ & $\begin{array}{c}\text { Sp. Rotation. } \\
0,9057\end{array}$ & $\begin{array}{c}\text { Mol Rotation } \\
9,330\end{array}$ \\
\hline 13,5 & 0,9019 & 9,291 \\
\hline 13,8 & 0,9010 & 9,287 \\
\hline 14,1 & 0,8996 & 9,274 \\
\hline 14.1 & 0,8990 & 9,269 \\
\hline 14,1 & 0,9020 & 9,299 \\
\hline 14,1 & 0,9035 & 9,315 \\
\hline 16,5 & 0,8959 & 9,254 \\
\hline 16,5 & 0,8931 & 9,225 \\
\hline 16,5 & 0,8956 & 9,251 \\
\hline 17,0 & 0,8975 & 9,260 \\
\hline 17,4 & 0,8963 & 9,249 \\
\hline 17,6 & 8,8964 & 9,252 \\
\hline 18,0 & 0,8955 & 9,246 \\
\hline 15,5 & 0,8988 & 9,272 \\
\hline
\end{tabular}

\section{Diäthylmalonsaures Aethyl.}

Dieser nach der Angabe Conrad's ${ }^{1}$ ) dargestellte Aether wurde unter vermindertem Drucke fractionirt. Der unter $330 \mathrm{Mm}$.bei $195^{\circ}-198^{\circ}$ übergehende Theil wurde nochmals unter gewöhnlichem Luftdrucke fractionirt, und die bei $230^{\circ}-$ $230,5^{\circ}$ siedende Fraction zur Untersuchung verwendet. Bestimmungen der Dichte ergaben:

$$
d \frac{15^{0}}{15^{0}}=0,99167, d \frac{25^{0}}{25^{0}}=0,98441 .
$$

Folgende Zahlen wurden für die magnetische Rotation erhalten:

1) Ann. Chem. Pharm. 204, 138. 
d. Verbind. im Verhältn. zu deren chem. Constitut. etc. 559

\begin{tabular}{ccc}
$t$ & Sp. Rotation. & Mol. Rotation. \\
$17,6^{\circ}$ & 0,9280 & 11,251 \\
17,6 & 0,9178 & 11,127 \\
17,6 & 0,9232 & 11,193 \\
17,6 & 0,9235 & 11,196 \\
20,5 & 0,9226 & 11,210 \\
20,5 & 0,9232 & 11,216 \\
20,5 & 0,9205 & 11,184 \\
\hline Mittel 18,8 & 0,9227 & 11,197
\end{tabular}

\section{Propylmalonsaures Aethyl.}

Nach der Con rad'schen Methode dargestellt, siedete dieser Aether bei $221^{0}-224^{\circ}$ (uncorr.) und ergab: $d \frac{15^{0}}{15^{0}}=0,9955$. Er wurde durch Verseifen, Ueberführen der Säure in das Calciumsalz und Aetherificirung der daraus abgeschiedenen Säure gereinigt. Unter $330 \mathrm{Mm}$. Druck siedete der Haupttheil bei 193,5-194,50 (Faden im Dampf). Bestimmungen der Dichte ergaben:

$$
d \frac{15^{0}}{15^{0}}=0,99309, d \frac{25^{0}}{25^{0}}=0,98541 \text {. }
$$

Folgende Zahlen wurden furr die magnetische Rotation erhalten:

\begin{tabular}{ccc}
$t$ & Sp. Rotation. & Mol. Rotation. \\
$12,8^{\circ}$ & 0,9226 & 10,408 \\
12,8 & 0,9195 & 10,374 \\
12,8 & 0,9185 & 10,362 \\
13,5 & 0,9199 & 10,383 \\
13,5 & 0,9185 & 10,367 \\
13,5 & 0,9206 & 10,391 \\
13,5 & 0,9225 & 10,413 \\
18,0 & 0,9145 & 10,358 \\
18,0 & 0,9142 & 10,355 \\
18,0 & 0,9148 & 10,361 \\
19,4 & 0,9114 & 10,335 \\
24,5 & 0,9117 & 10,379 \\
25,0 & 0,9056 & 10,313 \\
25,0 & 0,9122 & 10,389 \\
25,5 & 0,9091 & 70,357 \\
\hline Mittel 18,1 & 0,9152 & 10,367
\end{tabular}


560 Perkin: Ueber magnetische Circular-Polarisation

Isopropylmalonsaures Aethyl.

Diese aus Malonsäureäther, Natriumäthylat und Isopropyljodid dargestellte Substanz siedete bei $216,5^{0}-217,5^{0}$ corr. und ergab $d \frac{15^{0}}{15^{0}}=0,99908$. Wie der vorige Körper gereinigt, destillirte dieser Aether unter einem Drucke von $330 \mathrm{Mm}$. bei $188^{\circ}-188,5^{\circ}$ (Faden im Dampf). Bestimmungen des specifischen Gewichts ergaben:

$$
d \frac{15^{0}}{15^{0}}=0,99271, d \frac{25^{0}}{25^{0}}=0,98521 \text {. }
$$

Folgende Zahlen wurden für die magnetische Rotation ermittelt:

\begin{tabular}{ccc}
\multicolumn{1}{c}{$t$} & Sp. Rotation. & Mol. Rotation. \\
$16,3^{\circ}$ & 0,9265 & 10,485 \\
17,0 & 0,9245 & 10,467 \\
17,5 & 0,9236 & 10,461 \\
18,5 & 0,9252 & 10,486 \\
22,75 & 0,9193 & 10,454 \\
14,2 & 0,9292 & 10,498 \\
14,2 & 0,9285 & 10,490 \\
15,0 & 0,9340 & 10,517 \\
16,8 & 0,9257 & 10,479 \\
Mittel 16,9 & 0,9267 & 10,482 \\
& \multicolumn{3}{c}{ Bernsteinsaures Aothyl. }
\end{tabular}

Durch Sättigen eines Gemisches von Bernsteinsäure und Alkohol mit Salzsäure erhalten, siedete dieser Aether bei $216,5^{\circ}$ corr. und ergab:

$$
d \frac{15^{0}}{15^{5}}=1,04645, d \frac{25^{0}}{25^{0}}=1,03832 \text {. }
$$

\begin{tabular}{|c|c|c|}
\hline$t$ & Sp. Rotation. & Mol. Rotation. \\
\hline $18,5^{0}$ & 0,9043 & 8,376 \\
\hline 18,5 & 0,9041 & 8,373 \\
\hline 19,5 & 0,9022 & 8,363 \\
\hline 19,5 & 0,9026 & 8,366 \\
\hline 19,5 & 0,9075 & 8,412 \\
\hline 19,5 & 0,9013 & 8,355 \\
\hline 19,4 & 0,9062 & 8,400 \\
\hline 14,5 & 0,9084 & 8,388 \\
\hline 14,5 & 0,9081 & 8,385 \\
\hline 14,5 & 0,9080 & 8,384 \\
\hline 17,8 & 0.9053 & 8,380 \\
\hline
\end{tabular}

Magnetische Rotation des Bernsteinsäureäthers: 
d. Verbind. im Verhältn. zu deren chem. Constitut. ete. 561

\section{Bernsteinsaures Methyl.}

Analog dem Aethyläther dargestellt, siedete dieser Körper bei $195,25^{\circ}$ corr. Der Schmelzpunkt liegt nach den Iehrbüchern bei $20^{\circ}$, ich fand ihn bei $18,5^{\circ}$; der Aether bleibt aber bei weit niederigerer Temperatur noch lange Zeit flüssig. Einmal blieb er 14 Tage unterhalb seines Schmelzpunktes flüssig, bei $15^{\circ}$. Die Einführung des Thermometers verursachte sehr bald Erstarren zu einer schönen Krystallmasse. Bestimmungen der Dichte ergaben:

$$
d \frac{15^{0}}{15^{0}}=1,12611, d \frac{25^{0}}{25^{0}}=1,11718 \text {. }
$$

Folgende Zahlen wurden für die magnetische Rotation erhalten:

\begin{tabular}{ccc}
\multicolumn{1}{c}{$t$} & Sp. Rotation. & Mol. Rotation. \\
$18,0^{0}$ & 0,8590 & 6,202 \\
18,0 & 0,8666 & 6,257 \\
18,0 & 0,8609 & 6,216 \\
18,5 & 0,8641 & 6,242 \\
18,5 & 0,8643 & 6,243 \\
\hline Mittel 18,3 & 0,8640 & 6,232
\end{tabular}

\section{Brenzweinsaures Aethyl.}

Dieser, dem vorigen ähnlich dargestellte Aether siedete bei $217,5^{\circ}-218,5^{\circ}$ corr. und hatte das specifische Gewicht:

$$
d \frac{15^{0}}{15^{0}}=1,01885, d \frac{25^{0}}{25^{0}}=1,01126 .
$$

Magnetische Rotation des Brenzweinsäureäthers:

\begin{tabular}{ccc}
$t$ & Sp. Rotation. & Mol. Rotation. \\
$18,5^{\circ}$ & 0,9084 & 9,336 \\
18,5 & 0,9079 & 9,332 \\
18,5 & 0,9076 & 9,328 \\
17,9 & 0,9130 & 9,380 \\
17,0 & 0,9087 & 9,329 \\
17,5 & 0,9069 & 9,316 \\
14,0 & 0,9175 & 9,398 \\
17,5 & 0,9118 & 9,364 \\
17,8 & 0,9083 & 9,330 \\
16,0 & 0,9115 & 9,350 \\
17,5 & 0,9118 & 9,364 \\
18,0 & 0,9085 & 9,334 \\
\hline Mittel 17,4 & 0,9102 & 9,347
\end{tabular}


562 Perkin: Ueber magnetische Circular-Polarisation

\section{Acetylbernsteinsaures Aethyl.}

Das zur Untersuchung dienende Präparat wurde mir von Dr. Thorne überlassen; es war durch Wechselwirkung von Monochloressigäther und Natracetessigäther dargestellt und siedete bei $239^{\circ}-240^{\circ}$ (Faden im Dampf) unter $300 \mathrm{Mm}$. Druck. Bestimmungen seiner Dichte ergaben:

$$
d \frac{15^{0}}{15^{0}}=1,08809, d \frac{25^{0}}{25^{0}}=1,08049 .
$$

Folgende Zahlen wurden für die magnetische Rotation erhalten:

\begin{tabular}{cccc} 
& $t$ & Sp. Rotation. & Mol. Rotation. \\
& $\mathbf{2 1 , 5}$ & 0,9389 & 10,402 \\
& $\mathbf{2 1 , 5}$ & 0,9297 & 10,300 \\
& $\mathbf{2 3 , 5}$ & 0,9324 & 10,337 \\
& $\mathbf{2 3 , 5}$ & 0,9327 & 10,341 \\
& $\mathbf{2 3 , 5}$ & 0,9324 & 10,337 \\
\hline Mittel & $\mathbf{2 2 , 7}$ & 0,9332 & 10,343
\end{tabular}

\section{Korksaures Aethyl.}

Die zur Darstellung desselben angewandte Säure (von Schuchardt bezogen) wurde mittelst Alkohol und Salzsäure ätherificirt; das Produkt siedete unter gewöhnlichem Luftdrucke bei $282^{\circ}-286^{\circ}$. Wegen theilweiser Zersetzung wurde es unter vermindertem Drucke fractionirt. Das untersuchte Präparat siedete bei $251^{\circ}-253^{\circ}$ (Faden im Dampf) unter $320 \mathrm{Mm}$. Druck. Bestimmungen der Dichte ergaben:

$$
d \frac{15^{0}}{15^{0}}=0,98519, d \frac{25^{0}}{25^{0}}=0,97826 .
$$

Folgende Zablen wurden für die magnetische Rotation erhalten:

$\begin{array}{cccc}t & \text { Sp. Rotation. } & \text { Mol. Rotation. } \\ & 17,5^{\circ} & 0,9591 & 12,461 \\ & 17,5 & 0,9562 & 12,425 \\ & 17,5 & 0,9594 & 12,465 \\ & 11,0 & 0,9647 & 12,478 \\ & 11,0 & 0,9655 & 12,488 \\ & 11,6 & 0,9622 & 12,450 \\ & 11,6 & 0,9650 & 12,458 \\ \text { Mittel } 14,0 & 0,9617 & 12,461\end{array}$


d. Verbind. im Verhältn. zu deren chem. Constitut. etc. 563

\section{Sebacinaaures Aethyl.}

Die Sebacinsäure (von Kablbaum bezogen) wurde wie die Korksäure ätherificirt. Das angewandte Präparat siedete bei $307^{0}-308^{\circ}$ corr. und hatte das specifische Gewicht:

$$
d \frac{15^{0}}{15^{0}}=0,96824, d \frac{25^{0}}{25^{0}}=0,96049 \text {. }
$$

Das Messen der magnetischen Rotation dieser Substanz liess sich wegen Wärmeströmungen sehr schwierig ausführen.

Folgende Zahlen wurden für die magnetische Rotation erhalten:

\begin{tabular}{ccc}
$t$ & Sp. Rotation. & Mol. Rotation. \\
$10,7^{0}$ & 0,9790 & 14,444 \\
11,3 & 0,9826 & 14,505 \\
11,3 & 0,9807 & 14,477 \\
14,1 & 0,9793 & 14,488 \\
14,5 & 0,9806 & 14,511 \\
14,6 & 0,9806 & 14,512 \\
14,6 & 0,9811 & 14,520 \\
15,2 & 0,9789 & 14,495 \\
15,5 & 0,9787 & 14,495 \\
15,5 & 0,9793 & 14,504 \\
15,5 & 0,9807 & 14,524 \\
15,0 & 0,9777 & 14,474 \\
\hline Mittel 14,0 & 0,9799 & 14,496
\end{tabular}

Bernsteinsaures Isobutyl.

Ein Gemisch von Isobutylalkohol und Bernsteinsäure wurde mit Salzsäure gesättigt und einige Zeit stehen gelassen. Da ein Theil der Säure unverändert blieb, so wurde das Gemisch täglich ein oder zwei Mal erwärmt, und durch öftere Wiederholung dieses Processes die Säure vollständig ätherificirt. Nach Zusatz von Wasser wurde die ölige Schicht mit kohlensaurem Natron gewaschen, getrocknet und destillirt. Nach dem Fractioniren siedete der Aether bei $264,75^{0}-265,75^{\circ}$ corr.

Spec. Gewicht desselben: $d \frac{15^{0}}{15^{0}}=0,97374, d \frac{25^{0}}{25^{0}}=0,96670$.

Folgende Zahlen wurden für die magnetische Rotation erhalten: 
564 Perkin: Ueber magnetische Circular-Polarisation

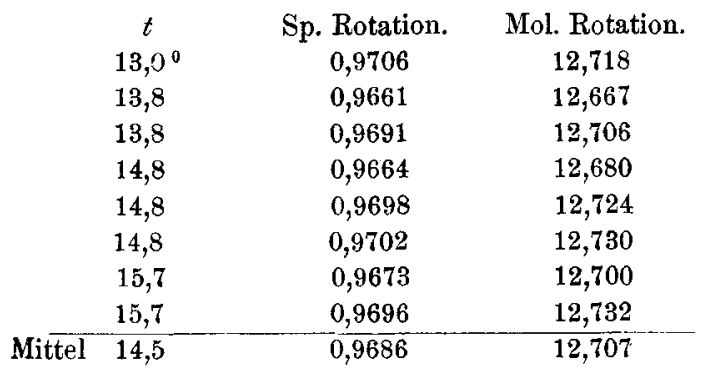

Alkylen-Bromide.

Methylenbromid.

Die Darstellung dieses Körpers wurde zuerst durch Erhitzen eines Gemisches von Methyljodid und Brom auf $230^{\circ}$ versucht, jedoch war es unmöglich, das Methylenbromid auf diese Weise genügend rein zu erhalten. Die ursprüngliche Methode Butlerow's: Behandeln von unter Wasser befindlichem Methylenjodid mit Brom wurde daher angewandt. Die von $\mathrm{Henry}{ }^{1}$ ) neuerdings veröffentlichten Vorschriften wurden eingehalten. Um alles Jod zu entfernen, wurde das Produkt nochmals mit wenig Brom behandelt, dann mit wasserfreiem kohlensaurem Kali getrocknet, und sorgfältig fractionirt, wozu ein langes Fractionsrohr diente. Das so erhaltene Präparat siedete bei $96,5^{\circ}-98,5^{\circ}$ (corr.) und ergab:

$$
d \frac{15^{0}}{15^{0}}=2,49922, d \frac{25^{0}}{25^{0}}=2,47849 .
$$

Da diese Zahlen von denen Henry's - bei $0^{0}, 2,4930$ (oder ca. $d \frac{15^{0}}{15^{0}}=2,4417$ ) - stark abweichen, so wurde die Substanz nochmals fractionirt und über Phosphorsäureanhydrid destillirt. Der zwischen $96,5^{\circ}-97,5^{\circ}$ corr. siedende Antheil wurde zur Untersuchung angewandt und ergab:

$$
d \frac{15^{0}}{15^{0}}=2,49850, d \frac{25^{0}}{25^{0}}=2,47745 \text {. }
$$

1) Ann. Chim. Phys. [5] 30, 267. 
d. Verbind. im Verhältn. zu deren chem. Constitut. ete. 565

Die folgenden Zahlen wurden für die magnetische Rotation erhalten:

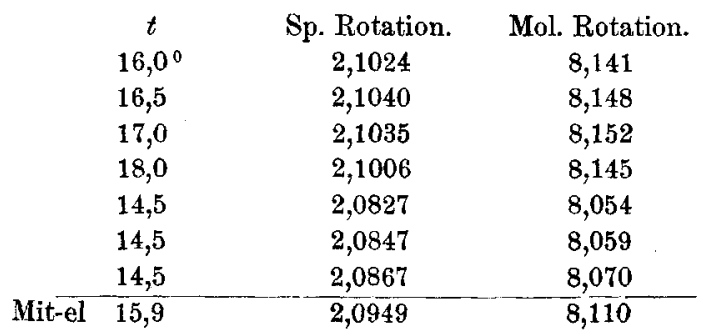

Aethylenbromid.

Das aus Alkohol und Schwefelsäure mittelst Brom auf bekannte Weise erhaltene Aethylenbromid wurde, um es noch weiter zu reinigen, sehr langsam abgekühlt, bis ungefähr die Hälfte erstarrt war, und sodann der krystallinische Theil gut abgepresst. Die Krystalle wurden dann geschmolzen, und die resultirende Flüssigkeit noch zweimal in obiger Weise behandelt. Die Krystalle schmolzen bei $8,2^{\circ}-8,4^{\circ}$. Die Substanz wurde schliesslich mit Phosphorsäureanhydrid getrocknet. Drei verschiedene Präparate wurden untersucht, zwei von eigner Darstellung, das dritte durch Reinigung des von Kahlbaum bezogenen Bromids erbalten. Die folgenden specifischen Gewichte wurden beobachtet:

$$
\begin{aligned}
& \text { I II III } \\
& d \frac{15^{0}}{15^{0}}=2,16061 \quad 2,16681 \quad 2,17507 .
\end{aligned}
$$

Daraus erhellt, dass diese Präparate nicht identisch sind.

Beim Destilliren des krystallisirten Bromids ging anfangs eine sehr kleine Quantität Wasser über, die Temperatur stieg dann, und beinahe alles destillirte zwischen $130^{\circ}$ und $181,5^{0}$ über. Da das Bromid sich beim Kochen mit Phosphorsäureanbydrid nicht zersetzte, so wurde es davon abdestillirt. Die zwischen $130,5^{\circ}$ und $131,5^{0}$ siedende Fraction wurde besonders aufgefangen. Die Temperatur blieb dann bei $131,5^{\circ}$ fast constant, und ca. ein Drittel des ursprünglichen Quantums ging bei dieser Temperatur über. Die Dichte-Bestimmungen der zwei Fractionen ergaben: 
566 Perkin: Ueber magnetische Circular-Polarisation

$\begin{array}{cc}\text { I } & \text { II } \\ 130,5^{0}-131,5^{0} & 131,5^{0} \\ d \frac{15^{0}}{15^{0}}=2,17334 & 2,18891 .\end{array}$

Auffallend gross ist die Differenz der Dichte zweier so nahe liegender Fractionen. Fraction II wurde nochmals über Phosphorsäureanbydrid destillirt; nur wenig kam unterhalb $131,5^{0}$ über; der Rest siedete zwischen $131,5^{\circ}-131,75^{0}$ corr. und ergab:

$$
d \frac{15^{0}}{15^{0}}=2,18934, d \frac{25^{0}}{25^{0}}=2,17271 \text {. }
$$

Die aus Kahlbaum's Präparat erhaltenen Krystalle wurden ebenfalls mit Phosphorsäureanhydrid fractionirt. Der grösste Theil destillirte bei $131,3^{0}-131,5^{\circ}$ und hatte das specifische Gewicht: $d \frac{15^{0}}{15^{0}}=2,18802$.

Die zwei letzten Fractionen wurden dann gemischt und ohne Zusatz von Phosphorsäureanhydrid fractionirt. Der Siedepunkt stieg bald auf $131,5^{0}$ und der Haupttheil ging zwischen $131,5^{\circ}$ und $131,6^{\circ}$ über. Die Bestimmungen dieses Produktes ergaben:

$$
d \frac{15^{0}}{15^{0}}=2,18859, d \frac{25^{0}}{25^{0}}=2,17197 .
$$

Das Mittel aus den specifischen Gewichten der drei letzten Fractionen wird sehr nahe die wahre Dichte des Aethylenbromids sein:

$$
\begin{aligned}
& \text { I . . . } d \frac{15^{0}}{15^{0}}=2,18891
\end{aligned}
$$

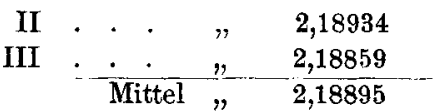

Diese Dichte $\left(2,19844\right.$ bei $\left.10^{\circ}\right)$ liegt der von Reboul gefundenen $\left(2,198\right.$ bei $\left.10^{\circ}\right)$ sehr nahe, aber höher als die von Thorpe ermittelte.

Die das Aethylenbromid verunreinigenden Produkte wurden nicht untersucht.

Folgende Zahlen wurden für die magnetische Rotation des Aethylenbromids erhalten: 
d. Verbind. im Verhältn. zu deren chem. Constitut. etc. 567

\begin{tabular}{rcc}
$t$ & Sp. Rotation. & Mol. Rotation. \\
$12,0^{\circ}$ & 2,0325 & 9,678 \\
12,0 & 2,0291 & 9,662 \\
18,0 & 2,0257 & 9,686 \\
18,0 & 2,0336 & 9,727 \\
13,1 & 2,0396 & 9,719 \\
13,1 & 2,0376 & 9,709 \\
13,1 & 2,0304 & 9,676 \\
17,2 & 2,0319 & 9,717 \\
17,5 & 2,0298 & 9,707 \\
17,8 & 2,0314 & 9,715 \\
\hline Mittel 15,2 & 2,0322 & 9,700
\end{tabular}

Aethylidenbromid - Methylmethylenbromid.

Dieser Körper wurde durch die Einwirkung von $\mathrm{PCl}_{3} \mathrm{Br}_{2}$ auf Paraldehyd erhalten. Da bei Zusatz des Paraldehyds zum Trichlorobromid eine sehr energische Einwirkung entsteht, so müssen kleine Portionen desselben zugegeben werden. Das Gemisch wurde allmählig mit Wasser versetzt und geschüttelt, um das entstandene Oxychlorid zu zersetzen. Das die Augen reizende Oel wurde mit Wasserdampf destillirt, das Oel vom Wasser getrennt, getrocknet und wiederholt destillirt. Nahezu rein, wurde es mit Phosphorsäureanhydrid geschüttelt, davon abfiltrirt und wieder fractionirt. Das zur Untersuchung angewandte Präparat siedete bei $108^{\circ}-110^{\circ}$ corr. und ergab:

$$
d \frac{15^{0}}{15^{0}}=2,10294, d \frac{25^{0}}{25^{0}}=2,08540 .
$$

Sowohl der Siedepunkt wie die Dichte ist niedriger als die Werthe Tawildarow's ${ }^{1}$ ), welcher den Siedepunkt $=115^{\circ}$, das specifische Gewicht $=2,129$ bei $10^{\circ}$ fand.

Den in grosser Zahl gemachten Bestimmungen der magnetischen Rotation dieses Körpers haftet ein Fehler an, welcher noch nicht eliminirt werden konnte. Die erhaltenen Zahlen variiren zwischen 9,1 und 9,2. Die Zahl 9,1 ist als die wahrscheinlichste anzunehmen.

\section{Propylenbromid - Methyläthylenbromid.}

Durch Einleiten von aus Thymol mit Phosphorsäureanhydrid erhaltenem Propylen in unter Wasser befindliches

1) Ann. Chem. Pharm. 176, 12. 
568 Perkin: Ueber magnetische Circular-Polarisation

Brom dargestellt, wurde das Bromid durch Fractioniren und Destillation üher Phosphorsäureanhydrid gereinigt; es siedete bei $142^{\circ}-142,3^{\circ}$ (corr.) und ergab:

$$
d \frac{15^{0}}{15^{0}}=1,94474, d \frac{25^{0}}{25^{0}}=1,93030 .
$$

Da möglicher Weise die Destillation über Phosphorsäureanhydrid schädlich war, so wurde das Bromid nochmals unter $330^{\circ} \mathrm{Mm}$. für sich fractionirt, und siedete unter diesem Drucke bei $121,8^{0}-122,5^{0}$ corr. Bestimmungen der Dichte ergaben:

$$
d \frac{15^{0}}{15^{0}}=1,94426, d \frac{25^{9}}{25^{0}}=1,93004 .
$$

Nach Linnemann ist $d \frac{15^{0}}{15^{0}}=1,9492$.

Magnetische Rotation des Propylenbromids:

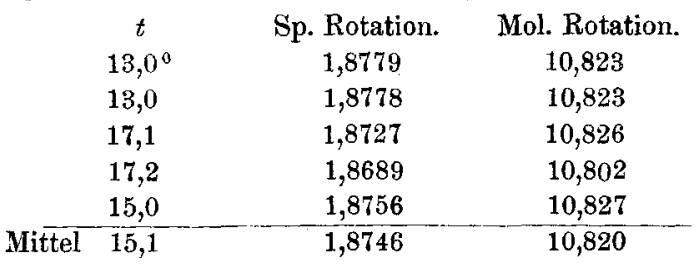

Bromacetol - Dimethylmethylenbromid.

Diese Verbindung wurde nach Reboull), dargestellt. Leider war die erhaltene Menge derselben sehr klein, sie siedete bei $114^{0}-116^{\circ}$ und hatte folgende spec. Gewichte:

$$
d \frac{15^{0}}{15^{0}}=1,84761, d \frac{25^{0}}{25^{0}}=1,83140 \text {. }
$$

Bestimmungen der magnetischen Rotation, die wegen Mangels an Substanz, in einem nur $35 \mathrm{Mm}$. langem Rohre ausgeführt werden mussten, ergaben:

\begin{tabular}{ccc}
$t$ & Sp. Rotation. & Mol. Rotation. \\
$20,8^{\circ}$ & 1,6664 & 10,176 \\
20,0 & $\mathbf{1 , 6 6 2 7}$ & 10,145 \\
20,5 & 1,6565 & 10,110 \\
Mittel 21,5 & $\mathbf{1 , 6 5 6 1}$ & 10,117 \\
\hline 20,7 & 1,6604 & 10,137
\end{tabular}

1) Ann. Chim. Phys. [o] 14, 479. 
d. Verbind. im Verbältn. zu deren chem. Constitut. ete. 569

\section{Trimethylenbromid.}

Von dieser durch fractionirte Destillation gereinigten Substanz wurde der unter $743 \mathrm{Mm}$. Druck bei $165,5^{\circ}-167^{\circ}$ corr. siedende Antheil _ur Untersuchung angewandt. Nochmals unter $350 \mathrm{Mm}$. Druck fractionirt, siedete dieselbe bei $135,5^{\circ}-136,5^{\circ}$ (Faden im Dampf).

Specif. Gewicht: $d \frac{15^{0}}{15^{0}}=1,98236, d \frac{25^{0}}{25^{0}}=1,96836$.

Magnetische Rotation des Trimethylenbromids:

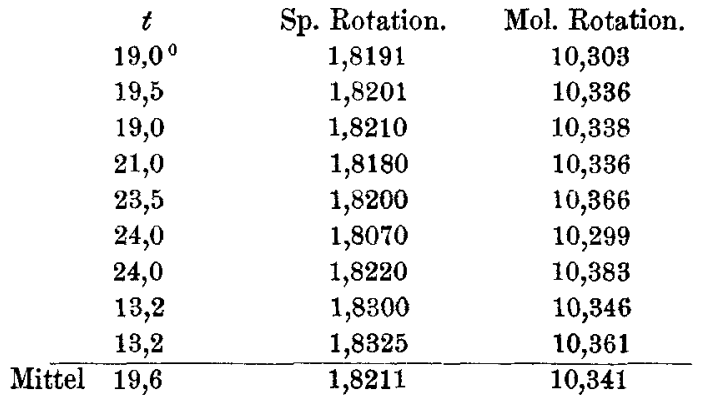

Isobutylenbromid - Dimethyläthylenbromid.

Von Kahlbaum bezogen, wurde dieser Körper mehrere Male fractionirt, und der zwischen $147^{\circ}$ und $150^{\circ}$ übergehende Antheil zur Untersuchung verwendet.

Specif. Gewicht: $d \frac{15^{0}}{15^{0}}=1,74343, d \frac{25^{0}}{2 \check{5}^{0}}=1,73083$.

Folgende Zahlen wurden für die magnetische Rotation erhalten:

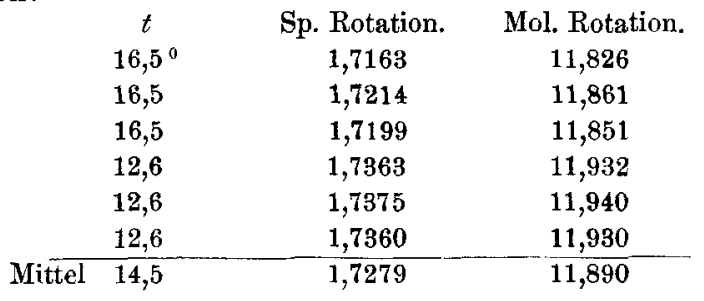

Das Isobutylenbromid erleidet bei der Destillation geringe Zersetzung. Nach Ausführung der obigen Bestimmungen wurde es nochrnals unter $313 \mathrm{Mm}$. Druck fractionirt 
570 Perkin: Ueber magnetische Circular-Polarisation und siedete dann bei $118^{\circ}-120^{\circ}$. Die Dichte war hierdurch erheblich verändert und betrug:

$$
d \frac{15^{0}}{15^{0}}=1,75586, d \frac{25^{0}}{25^{0}}=1,74294 \text {. }
$$

Diese specifischen Gewichte durften bei der Berechnung obiger Resultate nicht angewandt werden, weil das veränderte Produkt natürlicherweise andere Ablesungen geben würde, jedoch darf man annehmen, dass die oben angegebene molekulare Rotation nicht weit von der wahren abweicht.

Die letzte Dichte reiht sich in die aus den specifischen Gewichten der anderen Glieder dieser Reihe abgeleitete Curve am besten ein.

Isoamylenbromid - Trimethyläthylenbromid.

Zur Bereitung dieses Körpers diente das zwischen $36^{\circ}$ und $39^{\circ}$ siedende Amylen, welches in einer Kältemischung langsam mit Brom in Berührung gebracht wurde. Das Rohprodukt wurde erst mit verdünntem Alkali dann mit Wasser gewaschen und über wasserfreiem kohlensaurem Kali getrocknet. Unter vermindertem Drucke fractionirt, hatte es folgende Dichte:

$$
d \frac{15^{0}}{15^{0}}=1,64000, d \frac{25^{0}}{25^{0}}=1,62921 .
$$

Nochmals unter $215 \mathrm{Mm}$. Druck fractionirt, siedete es bei $126^{\circ}-127,5^{\circ}$ und ergab:

$$
d \frac{15^{0}}{15^{0}}=1,63699, d{\frac{25^{0}}{25^{0}}}^{0}=1,62595 .
$$

Folgende Zahlen wurden für die magnetische Rotation ermittelt:

\begin{tabular}{ccc}
$t$ & Sp. Rotation. & Mol. Rotation. \\
$10,4^{\circ}$ & 1,6628 & 12,941 \\
11,2 & 1,6634 & 12,952 \\
12,5 & 1,6602 & 12,938 \\
12,5 & 1,6624 & 12,955 \\
12,5 & 1,6618 & 12,950 \\
13,2 & 1,6581 & 12,928 \\
13,2 & 1,6653 & 12,983 \\
13,8 & 1,6598 & 12,945 \\
14,4 & 1,6578 & 12,943 \\
\hline Mittel 12,6 & 1,6613 & 12,947
\end{tabular}


d. Verbind. im Verhältn. zu deren chem. Constitut. etc. 571

$$
\text { Alkylen-Chloride. }
$$

Methylenchlorid.

Das durch Einwirkung von Chlor auf Methylchlorid dargestellte ${ }^{1}$ ), über Phosphorsäureanhydrid destillirte Methylenchlorid ging hauptsächlich bei $40^{\circ}$ über. Ein zweites, von Kahlbaum bezogenes Präparat siedete, ebenfalls über Phosphorsäureanhydrid fractionirt, fast constant bci $40^{\circ}$.

Specif. Gewicht: $d \frac{15^{0}}{15^{0}}=1,33771, d \frac{25^{0}}{25^{0}}=1,32197$.

Die von Thorp $\theta^{2}$ ) für diese Substanz angegebene Dichte ist bedeutend höher, als die von mir erhaltene. Aber aus dem von ihm gefundene Siedepunkt und seinem Bereitungsverfahren geht hervor, dass sein Produkt von Chloroform nicht vollständig befreit worden war.

Magnetische Rotation des Methylenchlorids:

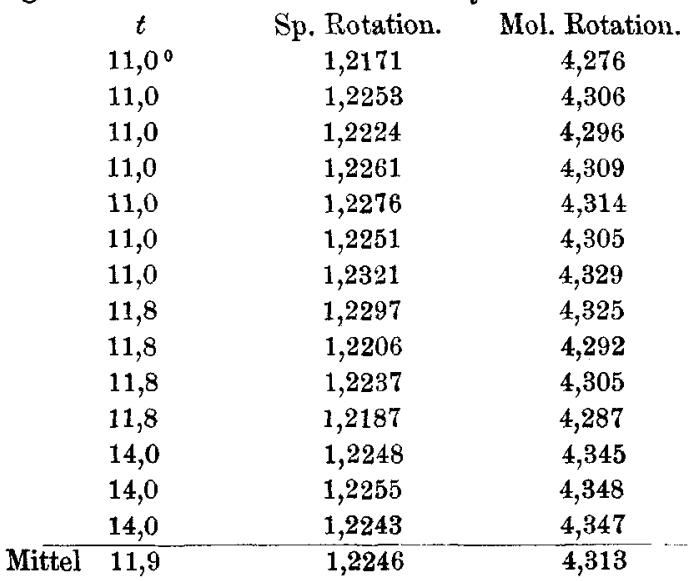

\section{Aethylenohlorid.}

Das über Phosphorsäureanhydrid destillirte und fractionirte Präparat siedete constant bei $83,7^{\circ}$ corr. und ergab:

$$
d \frac{15^{0}}{15^{0}}=1,25991, d \frac{25^{0}}{25^{0}}=1,24800 .
$$

1) Chem. Soc. Journ. 22, 260.

2) Das. 37, 195. 
572 Perkin: Ueber magnetische Circular-Polarisation

Thorpe giebt den Siedepunkt bei $83,5^{\circ}$, die auf $15^{0}$ umgerechnete Dichte zu 1,25984 an.

Magnetische Rotation des Aethylenchlorids.

\begin{tabular}{|c|c|c|}
\hline$t$ & Sp. Rotation. & Mol. Rotation. \\
\hline $16,25^{0}$ & 1,2576 & 5,496 \\
\hline 16,25 & 1,2576 & 5,496 \\
\hline 16,25 & 1,2576 & 5,496 \\
\hline 13,6 & 1,2568 & 5,476 \\
\hline 13,6 & 1,2559 & 5,471 \\
\hline 13,6 & 1,2562 & 5,473 \\
\hline 14,4 & 1,2569 & 5,485 \\
\hline
\end{tabular}

Aethylidenchlorid - Methylmethylenchlorid.

Dieser aus Paraldehyd dargestellte Körper wurde über Phosphorsäureanhydrid destillirt und fractionirt; er siedete bei $57^{\circ}-57,5^{\circ}$ und ergab:

$$
d \frac{15^{0}}{15^{0}}=1,18450, d \frac{25^{0}}{25^{0}}=1,17120 .
$$

Thorpe's Dichte auf $d \frac{15^{0}}{15^{0}}$ umgerechnet, beträgt 1,18161.

Magnetische Rotation des Aethylidenchlorids:

\begin{tabular}{rcc}
$t$ & Sp. Rotation. & Mol. Rotation. \\
$16,5^{\circ}$ & 1,1509 & 5,352 \\
16,5 & 1,1505 & 5,351 \\
12,5 & 1,1505 & 5,318 \\
13,0 & 1,1525 & 5,329 \\
13,5 & 1,1513 & 5,327 \\
\hline Mittel 14,4 & 1,1511 & 4,335
\end{tabular}

\section{Chloracetol - Dimethylmethylenchlorid.}

Diese durch Einwirkung von Phosphorpentachlorid auf reines Aceton bereitete Verbindung siedete nach mehrmaligem Fractioniren bei $68,5^{\circ}-69,5^{\circ}$ corr. und ergab:

$$
d \frac{15^{0}}{15^{0}}=1,09620, d \frac{25^{0}}{25^{0}}=1,08430 .
$$

Ueber Phosphorsäureanhydrid destillirt, siedete sie zwischen $69,7^{\circ}$ und $71,2^{\circ}$.

Specifisches Gewicht: $d \frac{15^{0}}{15^{0}}=1,09657, d \frac{25^{0}}{25^{0}}=1,08476$.

Diese Zahlen weichen von denen Linnemann's bedeutend $a b$ : er fand 1,0827 bei $16^{\circ}$. 
d. Verbind. im Verhältn. zu deren ehem. Constitut. ete. 573

Magnetische Rotation des Chloracetols:

\begin{tabular}{rcc}
\multicolumn{1}{c}{$t$} & Sp. Rotation. & Mol. Rotation. \\
17,5 & 1,1057 & 6,348 \\
17,5 & 1,1066 & 6,354 \\
17,5 & 1,1079 & 6,360 \\
17,5 & 1,1072 & 6,357 \\
16,0 & 1,1094 & 6,358 \\
13,5 & 1,1037 & 6,308 \\
14,6 & 1,1051 & 6,324 \\
\hline Mittel 16,3 & 1,1065 & 6,344
\end{tabular}

T r i c h l o r i d e.

Chloroform.

Durch fractionirte Destillation über Phosphorsäureanhydrid gereinigt, siedete das Chloroform constant bei $62^{\circ}$ corr. Die Bestimmungen des specif. Gewichts ergaben:

$$
d \frac{15^{0}}{15^{0}}=1,50027, d \frac{25^{0}}{25^{0}}=1,48432 \text {. }
$$

Thorpe fand $d \frac{15^{\circ}}{15^{\circ}}=1,49966$.

Obiges Präparat, nochmals über Phosphorsäureanhydrid fractionirt, ergab:

$$
d \frac{15^{0}}{15^{0}}=1,50085, d \frac{25^{0}}{25^{0}}=1,48492 .
$$

Folgende Zahlen wurden für die magnetische Rotation erhalten:

\begin{tabular}{cccc}
$t$ & Sp. Rotation. & Mol. Rotation. \\
& $13,5^{\circ}$ & 1,2647 & 5,587 \\
& 14,0 & 1,2610 & 5,574 \\
& 14,5 & 1,2552 & 5,551 \\
15,0 & 1,2599 & 5,574 \\
& 15,0 & 1,2601 & 5,575 \\
& 16,8 & 1,2510 & 5,546 \\
& 16,8 & 1,2468 & 5,540 \\
& 16,8 & 1,2466 & 5,526 \\
\hline Mittel & 15,3 & 1,2557 & 5,559 \\
& \multicolumn{3}{c}{ Methylchloroform. }
\end{tabular}

Von Kahlbaum bezogen und durch fractionirte Destillation über Phosphorsäureanhydrid gereinigt, siedete dasselbe bei $75,3^{0}-76,3^{0}$ corr. und ergab: 
574 Perkin: Ueber magnetische Circular-Polarisation

$$
d \frac{15^{0}}{15^{0}}=1,32466, d \frac{25^{0}}{25^{0}}=1,31144 .
$$

Magnetische Rotation des Methylchloroforms:

\begin{tabular}{|c|c|c|c|}
\hline & $t$ & Sp. Rotation. & Mol. Rotation. \\
\hline & $14,0^{0}$ & 1,2000 & 6,712 \\
\hline & 14,0 & 1,2028 & 6,728 \\
\hline & 14,0 & 1,2028 & 6,728 \\
\hline & 20,8 & 1,2007 & 6,762 \\
\hline & 21,2 & 1,1970 & 6,743 \\
\hline & 21,6 & 1,2007 & 6,767 \\
\hline Mittel & 16,7 & 1,2007 & 6,740 \\
\hline
\end{tabular}

Vinyltrichlorid - Monochloräthylenchlorid.

In gleicher Weise wie die vorige gereinigt, siedete die Substanz bei 114,8 $8^{\circ}-115,3^{\circ}$. Bestimmungen des specifischen Gewichtes ergaben:

$$
d_{\frac{15^{0}}{15^{0}}}=1,45527, d \frac{25^{0}}{25^{0}}=1,44303 \text {. }
$$

Magnetische Rotation des Vinyltrichlorids:

\begin{tabular}{cccc} 
& $t$ & Sp. Rotation. & Mol. Rotation. \\
& 13,0 & 1,3326 & 6,779 \\
& $\mathbf{1 3 , 0}$ & $\mathbf{1 , 3 3 9 0}$ & 6,796 \\
& $\mathbf{1 4 , 0}$ & 1,3346 & 6,795 \\
& $\mathbf{1 9 , 5}$ & $\mathbf{1 , 3 3 0 7}$ & 6,807 \\
& 20,0 & 1,3296 & 6,804 \\
& 20,5 & 1,3261 & 6,789 \\
\hline IIittel & $\mathbf{1 6 , 7}$ & 1,3321 & 6,796
\end{tabular}

Allyltrichlorid - Trichlorhydrin - Chlorotrimethylenchlorid.

Diese Substanz wurde durch Einleitung von Chlor in Allyljodid dargestellt. Das mit Wasser, wie auch mit wenig Alkali gewaschene und über kohlensaurem Kali getrocknete Produkt wurde dann fractionirt, und das bei $156^{\circ}$ $-157^{\circ}$ siedende Präparat zur Untersuchung verwendet. Bestimmungen der Dichte ergaben:

$$
d \frac{15^{0}}{15^{0}}=1,39805, d \frac{25^{0}}{25^{0}}=1,38753 .
$$

Dieses Präparat wurde nochmals über Phosphorsäureanhydrid fractionirt, und siedete dann bei $157^{\circ}-158^{\circ}$ corr. Sein specifisches Gewicht betrug: 
d. Verbind. im Verhältn. zu deren chem. Constitut. etc. 575

$$
d \frac{15^{0}}{15^{0}}=1,39836, d \frac{25^{0}}{25^{0}}=1,38783 .
$$

Folgende Zahlen wurden für die magnetische Rotation erhalten:

\begin{tabular}{|c|c|c|}
\hline$t$ & Sp. Rotation. & Mol, Rotation. \\
\hline $25,5^{0}$ & 1,3345 & 7,882 \\
\hline 25,5 & 1,3365 & 7,895 \\
\hline $2 \overline{0}, 5$ & 1.3375 & 7,899 \\
\hline 15,5 & 1,3485 & 9,905 \\
\hline 16,0 & 1,3478 & 7,904 \\
\hline 21,6 & 1,3410 & 7,897 \\
\hline
\end{tabular}

Carbontetrachlorid - Vierfach-Chlorkohlenstoff.

Ueber Phosphorsäureanhydrid fractionirt, siedete diese Verbindung bei $76,9^{\circ}$ corr. und ergab:

$$
d \frac{15_{1}^{0}}{15^{0}}=1,60500, d \frac{25^{0}}{25^{0}}=1,58873 .
$$

Thorpe's Bestimmungen ergeben $d \frac{15^{0}}{15^{0}}=1,60397$.

\begin{tabular}{|c|c|c|}
\hline$t$ & Sp. Rotation. & Mol. Rotation. \\
\hline $26,5^{\circ}$ & 1,2198 & 6,585 \\
\hline 27,5 & 1,2067 & 6,520 \\
\hline 23,5 & 1,2271 & 6,609 \\
\hline 23,5 & 1,2288 & 6,618 \\
\hline 24,5 & 1,2205 & 6,578 \\
\hline 25,1 & 1,2206 & 6,582 \\
\hline
\end{tabular}

Magnetische Rotation des Chlorids:

'lribromide.

Bromoform.

Da bei der Destillation dieses Körpers partielle Zersetzung zu beobachten war, so wurde er während des Winters durch fractionirte Krystallisation gereinigt. Die krystallinische Masse wurde sodann zerstossen, zwischen porösen Platten abgepresst, nochmals zerstossen und einige Stunden der Luft ausgesetzt. So gereinigt, war das Bromoform dem Naphthalin ähnlich und vollkommen farblos. Die Krystalle schmolzen bei $7,8^{\circ}$. Sie wurden dann geschmolzen, mit Phosphorsäureanbydrid behandet und unter vermindertem Luftdrucke destillirt. Unter $330 \mathrm{Mm}$. Druck siedete das 
576 Perkin: Ueber magnetische Circular-Polarisation

Bromoform bei $120,3^{0}$ corr., färbte sich aber schwach gelb. Bestimmungen seiner Dichte ergaben:

$$
d \frac{15^{0}}{15^{0}}=2,90246, d \frac{25^{0}}{25^{0}}=2,88253 .
$$

Da augenscheinlich eine geringe Zersetzung stattgefunden hatte, so wurde das Präparat nochmals abgekühlt, bis ungefähr zwei Drittel erstarrt war; die abgepresste, dann geschmolzene Masse hatte folgende specif. Gewichte:

$$
d \frac{15^{0}}{15^{0}}=2,90450, d \frac{25^{0}}{25^{0}}=2,88421 .
$$

Daraus ergiebt sich, dass dieser Körper selbst bei der Destillation unter vermindertem Drucke eine geringe Zersetzung erleidet. Dass er bei der unter dem gewöhnlichen Luftdruck ausgeführten Destillation bedeutende Zersetzung erfährt, wird aus den von von Thorpe ${ }^{1}$ ) erhaltenen Resultaten ersichtlich; denn derselbe erhielt für sein durch fractionirte Destillation gereinigtes Präparat, welches bei $2,5^{\circ}$ schmolz, folgende Zahlen:

$$
d \frac{15^{0}}{15^{0}}=2,79683, d \frac{25^{0}}{25^{0}}=2,78275 .
$$

\begin{tabular}{|c|c|c|c|}
\hline & $t$ & Sp. Rotation. & Mol. Rotation. \\
\hline & $15,6^{\circ}$ & 2,3980 & 11,616 \\
\hline & 15,6 & 2,3998 & 11,626 \\
\hline & 16,5 & 2,4023 & 11,644 \\
\hline & 18,4 & 2,3935 & 11,616 \\
\hline & 18,9 & 2,3980 & 11,642 \\
\hline & 19,5 & 2,3918 & 11,617 \\
\hline & 20,5 & 2,3911 & 11,611 \\
\hline Mittel & 17,9 & 2,3964 & $11, \overline{626}$ \\
\hline
\end{tabular}

Magnetische Rotation des Bromoforms:

Dieser durch Einwirkung von Brom auf Vinylbromid erhaltene Körper siedete bei $188,5^{\circ}-189,5^{\circ}$ corr.

Die von Ansch ütz ${ }^{2}$ ) angegebene Dichte desselben wurde der Berechnung der Resultate zu Grunde gelegt:

1) Chem. Soc. Journ. 37, 141.

2) Ann. Chem. Pharm. 221, 183. 
d. Verbind. im Verhältn. zu deren chem. Constitut. etc. 577

$$
d \frac{17,5^{0}}{17,5^{0}}=2,62027, d \frac{21,5^{0}}{21,5^{0}}=2,61418 .
$$

Folgende Zahlen wurden für die magnetische Rotation erhalten:

$\begin{array}{ccc}t & \text { Sp. Rotation. } & \text { Mol. Rotation. } \\ 12,0^{\circ} & 2,2902 & 12,924 \\ 12,0 & 2,2844 & 12,891 \\ 12,0 & 2,2799 & 12,860 \\ 11,4 & 2,2878 & 12,906 \\ 11,4 & 2,2862 & 12,897 \\ 11,4 & 2,2886 & 12,910 \\ 11,4 & 2,2854 & 12,893 \\ \text { Mittel } 11,7 & 2,2861 & 12,897\end{array}$

\section{Allyltribromid - Tribromhydrin.}

Von Kahlbaum bezogen, wurde diese Verbindung während des Winters durch Erstarrenlassen und Abpressen der krystallinischen Masse gereinigt. Letztere wurde geschmolzen, mit Phosphorsäureanhydrid behandelt und filtrirt. Specifisches Gewicht:

$$
d \frac{15^{0}}{15^{0}}=2,41344, d \frac{25^{0}}{25^{0}}=2,39856 .
$$

Folgende Zahlen wurden für die magnetische Rotation ermittelt:

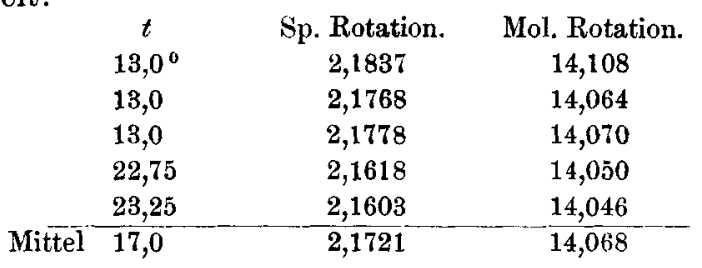

\section{Bromäthylenchlorid.}

Zur Gewinnung desselben wurde Vinylbromid in Chloroform, durch welches ein Chlorstrom ging, langsam einfliessen gelassen. So bereitet, siedete dieser mehrere Mal fractionirte Körper bei $139^{\circ}-140^{\circ}$. Specifisches Gewicht desselben:

$$
d \frac{15^{0}}{15^{0}}=1,86850, d \frac{25^{0}}{25^{0}}=1,85420 .
$$

Journal f. prakt. Chemie [2] Bd, 32. 
578 Perkin: Ueber magnetische Circular-Polarisation Magnetische Rotation des Bromäthylenchlorids:

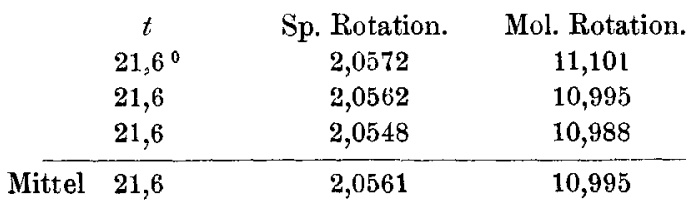

\section{Ungesättigte Verbindnngen.}

\section{Allylalkohol.}

Mittelst wasserfreiem schwefelsaurem Kupfer, sowie mit Kalk getrocknet, siedete der Allylalkohol bei $96,8^{\circ}$ corr. und ergab:

$$
d \frac{15^{0}}{15^{0}}=0,85778, d \frac{25^{0}}{25^{0}}=0,85067 .
$$

Folgende Zahlen wurden für die magnetische Rotation ermittelt:

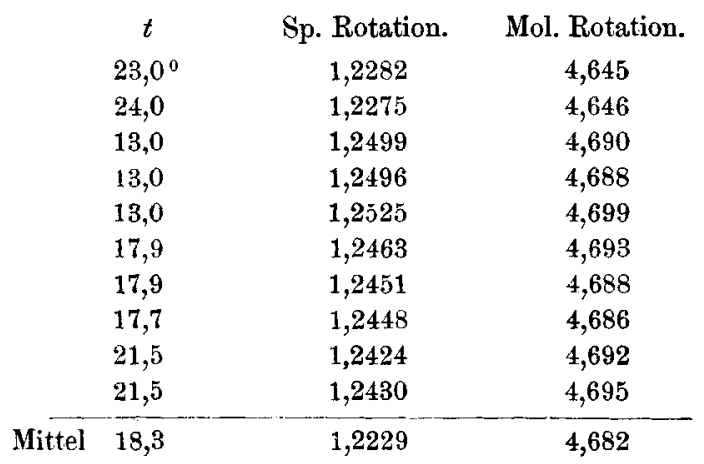

(-Crotonsaures Aethyl.

Die zur Bereitung dieses Aethers benutzte Säure (von Kahlbaum bezogen) war die $\alpha$-Säure und schmolz bei $72^{\circ}$ : sie wurde mittelst Alkohol und Salzsäure ätherificirt. Der Aether siedete bei $138^{\circ}-140^{\circ}$ corr. und ergab:

$$
d \frac{15^{0}}{15^{0}}=0,926 \diamond 0, d \frac{25^{0}}{25^{0}}=0,91846 .
$$

Magnetische Rotation des Crotonsäureäthers: 
d. Verbind. im Verhältn. zu deren chem. Constitut. etc. 579

\begin{tabular}{|c|c|c|}
\hline$t$ & Sp. Rotation. & Mol. Rotation. \\
\hline $22,5^{\circ}$ & 1,0998 & 7,567 \\
\hline 23,5 & 1,1034 & 7,601 \\
\hline 24,0 & 1,1030 & 7,599 \\
\hline 25,5 & 1,1052 & 7,624 \\
\hline 25,0 & 1,1009 & 7,591 \\
\hline 25,0 & 1,0980 & 7,571 \\
\hline 25,5 & 1,0970 & 7,568 \\
\hline $2 \overline{24,4}$ & 1,1010 & 7,589 \\
\hline
\end{tabular}

Oelsaures Aethyl.

Die zur Darstellung desselben verwendete Säure (von Kahlbaum bezogen) wurde mittelst Alkohol und Salzsäure ätherificirt. Das mit Wasser gewaschene, in Aether gelöste und über wasserfreiem kohlensaurem Kali getrocknete Produkt wurde, nach Abdestilliren des Aethers, mehrere Male unter vermindertem Drucke fractionirt. Das zur Untersuchung verwendete Präparat siedete bei $306^{\circ}-308^{\circ}$ (nur die Hälfte des Fadens im Dampf) unter $307 \mathrm{Mm}$. Druck. Bestimmungen der Dichte ergaben:

$$
d \frac{15^{0}}{15^{0}}=0,87589, d \frac{25^{0}}{25^{0}}=0,87041 .
$$

Unter gleichem Drucke und mit dem Thermometer in der gleichen Stellung wurde das Oel nochmals destillirt. Der Haupttheil siedete dann bei $304,75^{\circ}-307,25^{\circ}$ und ergab:

$$
d \frac{15^{0}}{15^{0}}=0,87525, d \frac{25^{0}}{25^{0}}=0,86991 .
$$

Der sehr geringe Unterschied zwischen den specifischen Gewichten zeigt, dass das Produkt rein genug war.

Magnetische Rotation des Oelsäureäthers:

$\begin{array}{ccc}t & \text { Sp. Rotation. } & \text { Mol. Rotation. } \\ 13,8^{0} & 1,1162 & 21,950 \\ 13,7 & 1,1135 & 21,886 \\ 14,4 & 1,1149 & 21,931 \\ 14,6 & 1,1137 & 21,910 \\ 17,8 & 1,1108 & 21,888 \\ 17,8 & 1,1103 & 21,888 \\ \text { Mittel } 15,0 & 1,1148 & 21,909\end{array}$

Allylmalonsaures Aethyl.

Nach der Methode Conrad's dargestellt, siedete derselbe bei $222^{\circ}-223^{\circ}$ corr. Daraus wurde dann die Säure 
gewonnen, vermitcelst des Calciumsalzes gereinigt, die freie Säure umkrystallisirt und dann wieder in ihren Aether übergeführt. So erhalten, siedete letzterer unter $330 \mathrm{Mm}$. Druck bei $193,5^{\circ}-195,5^{0}$ (Faden im Dampf).

Specif. Gewicht desselben: $d \frac{15^{0}}{15^{0}}=1,01397, d \frac{25^{0}}{25^{0}}=1,00620$.

Folgende Zahlen wurden für die magnetische Rotation erhalten:

\begin{tabular}{rcc}
$t$ & Sp. Rotation. & Mol. Rotation. \\
$14,1^{\circ}$ & 1,0298 & 11,277 \\
14,1 & 1,0284 & 11,261 \\
14,1 & 1,0281 & 11,258 \\
13,0 & 1,0342 & 11,315 \\
13,6 & 1,0310 & 11,285 \\
Mittel 13,6 & 1,0313 & 11,289 \\
\hline 13,7 & 1,0305 & 11,281
\end{tabular}

Diallylmalonsaures Aethyl.

Dieser Körper wurde nach Conrad's Methode dargestellt und unter vermindertem Drucke fractionirt: bei $225 \mathrm{Mm}$. Druck siedete er zwischen $201^{\circ}$ und $204^{\circ}$ (Faden im Dampf). Specif. Gewicht desselben: $d \frac{15^{0}}{15^{0}}=0,99997, d \frac{25^{0}}{25^{0}}=0,99301$.

Folgende Zahlen wurden für die magnetische Rotation erhalten:

\begin{tabular}{cccc} 
& $t$ & Sp. Rotation. & Mol. Rotation. \\
$22,0^{\circ}$ & 1,1237 & $\mathbf{1 5 , 0 5 2}$ \\
$\mathbf{2 2 , 0}$ & 1,1170 & $\mathbf{1 4 , 9 6 6}$ \\
& $\mathbf{2 2 , 0}$ & 1,1178 & $\mathbf{1 4 , 9 7 7}$ \\
\hline Mittel 22,0 & 1,1195 & $\mathbf{1 4 , 9 9 8}$
\end{tabular}

Da das zu dieser Bestimmung verwendete Produkt in der oben beschriebenen Weise nicht gereinigt worden war, so wurde der Aether zu dem Zwecke mit alkoholischem Kali verseift, der nach Abdampfen des Alkohols bleibende Rückstand in wenig Wasser gelöst und mit Salzsäure neutralisirt. Durch Zusatz von Chlorcalcium entstand eine Fällung von diallylmalonsaurem Calcium. ${ }^{1}$ ) Mit starker Salzsäure behan-

1) Die Angabe Conrad's, dass unter diesen Bedingungen das diallylmalonsaure Calcium nicht gefällt wird, beruht darauf, dass die von ihm angewandten Lösungen nicht concentrirt genug waren. 
d. Verbind. im Verhältn. zu deren chem. Constitut. etc. 581

delt, lieferte letzteres einen krystallinischen Brei der Diallylmalonsäure, welche aus wenig siedendem Wasser in schönen, langen, dicken Prismen krystallisirte. Die Säure ist in kaltem Wasser nur mässig löslich und schmilzt bei $134^{\circ}$.

Zur Aetherificirung der Säure wurde sie in Alkohol gelöst, mit Salzsäure gesättigt und 24 Stunden stehen gelassen. Auf diese Weise gelang es nicht, den gesuchten Aether darzustellen, denn das entstandene Oel wurde von Sodalösung aufgenommen; wahrscheinlich hat sich der saure Aether gebildet.

\section{Allylacetessigäther.}

In der gewöhnlichen Weise aus Acetessigäther dargestellt, siedete derselbe bei $213^{\circ}-214^{0}$ corr. unter $720 \mathrm{Mm}$. Druck.

Specif. Gewicht: $d \frac{15^{0}}{15^{0}}=0,99272, d \frac{25^{0}}{25^{0}}=0,98542$.

Die folgenden Zahlen wurden für die magnetische Rotation erhalten:

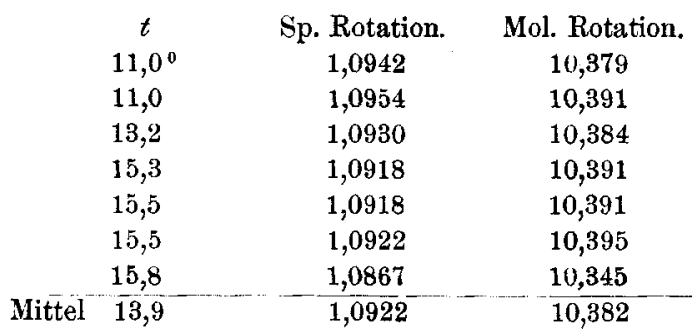

Ungesättigte Halogen-Verbindungen.

Bromäthylen - Vinylbromid.

In der gewöhnlichen Weise durch Einwirkung von alkoholischem Kali auf Aethylenbromid dargestellt, nach dem Waschen getrocknet, und über Phosphorsäureashydrid fractionirt, siedete das Bromäthylen bei $16^{\circ}$ corr. Die folgende Bestimmung des specif. Gewichts wurde mit einem frisch destillirtem Präparat ausgeführt, weil der Körper sich sehr bald polymerisirt.

$$
d \frac{9,6^{0}}{9,6^{0}}=1,52 \mathrm{j} 04 .
$$

Andere Bestimmungen waren schon früher in einem gewöhnlichen Sprengel'schen Rohre gemacht worden und 


\section{Perkin: Ueber magnetische Circular-Polarisation}

hatten ein wenig niedrigere Resultate ergeben, wahrscheinlich in Folge eines Verlustes durch Verdampfen. Ich habe aber die aus diesen früheren Bestimmungen berechnete Veränderung der Dichte, nämlich 0,00227 für $1^{0}$, bei der $\mathrm{Be}$ rechnnng der Resultate benutzt.

Folgende Zahlen wurden für die magnetische Rotation von frisch destillirtem Bromäthylen erhalten:

\begin{tabular}{rrrr} 
& \multicolumn{1}{c}{$t$} & Sp. Rotation. & Mol. Rotation. \\
$5,5^{0}$ & 1,6109 & 6,241 \\
5,5 & 1,6112 & 6,242 \\
5,5 & 1,6114 & 6,243 \\
8,5 & 1,5892 & 6,188 \\
11,0 & 1,5894 & 6,208 \\
11,0 & 1,5868 & 6,198 \\
\hline Mittel $\quad 7,8$ & 1,5998 & 6,220
\end{tabular}

Chlorpropylen - AllylchIorid.

Zur Darstellung dieses Körpers wurde Allylalkohol mit Phosphortrichlorür erhitzt. Beim Erwärmen dieses Gemisches auf dem Wasserbade beginnt das Allylchlorid bald überzudestilliren. ${ }^{\mathrm{I}}$ ) Das Produkt wurde gewaschen, getrocknet und über Phosphorsäureanhydrid destillirt; es siedete bei $45^{\circ}$ $46^{\circ}$ corr. und ergab:

$$
d \frac{15^{0}}{15^{0}}=0,94366, d \frac{25^{0}}{25^{0}}=0,93228 .
$$

Magnetische Rotation des Allylchlorids:

\begin{tabular}{cccc}
\multicolumn{1}{c}{$t$} & Sp. Rotation. & Mol. Rotation. \\
$26,0^{\circ}$ & 1,3181 & 6,017 \\
26,0 & 1,3111 & 5,986 \\
26,0 & 1,3168 & 6,010 \\
17,6 & 1,3359 & 6,036 \\
18,4 & 1,3362 & 6,043 \\
14,3 & 1,3319 & 5,994 \\
14,3 & 1,3319 & 5,994 \\
Mittel & 14,3 & 1,3303 & 5,987 \\
\hline
\end{tabular}

1) Das in der Retorte befindliche Gremisch wird undurchsichtig und färbt sich orange, nach kurzer Zeit scheidet sich ein feines, dem amorphen Phosphor ähnliches Pulver reichlich ab. Nach etwa einer halben Stunde erfolgt unter Gasentwickelung eine heftige Explosion. Dieses Verhalten ist ganz verschieden von dem, welches bei der gleichartigen Darstellung anderer Chloriden beobachtet wird, obwohl auch hjer, bei höheren Temperaturen, Phosphorwasserstoff - wahrscheinlich durch die Zersetzung der phosphorigen Säure - gebildet wird. 
d. Verbind. im Verhältn. zu deren chem. Constitut. ete. 583

Brompropylene: I. Methylvinylbromid $\mathrm{CH}_{3}$. $\mathrm{CH}$ : $\mathrm{CHBr}$.

Nach der Vorschrift Reboul's ${ }^{1}$ ) dargestellt, siedete das Methylvinylbromid bei $59^{0}-63^{0}$ corr. Reboul giebt den Siedepunkt: $59,5^{\circ}-60^{\circ}$ an. Leider war die erbaltene Menge zu klein, um weiter gereinigt zu werden. Bestimmungen der Dichte ergaben:

$$
d_{15^{0}}^{15^{0}}=1,42077, d \frac{25^{0}}{25^{0}}=1,40527 .
$$

Folgende Zahlen wurden für die magnetische Rotation ermittelt:

$\begin{array}{ccc}t & \text { Sp. Rotation. } & \text { Mol. Rotation. } \\ 27,5^{0} & 1,5254 & 7,318 \\ 27,5 & 1,5217 & 7,299 \\ 26,5 & 1,5221 & 7,293 \\ 22,0 & 1,5290 & 7,289 \\ 22,0 & 1,5286 & 7,289 \\ 22,0 & 1,5253 & 7,272 \\ 22,0 & \mathbf{1 , 5 3 2 5} & \mathbf{7 , 3 0 7} \\ \text { Mittel } 24,2 & \mathbf{1 , 5 2 6 4} & \mathbf{7 , 2 9 5}\end{array}$

II. Allylbromid: $\mathrm{CH}_{2}: \mathbf{C H}$. $\mathrm{CH}_{2} \mathrm{Br}$.

Von Kahlbaum bezogen, wurde es über Phosphorsäureanbydrid fractionirt und siedete bei $70^{\circ}-71^{\circ}$ corr.

Specif. Gewicht: $d \frac{15^{0}}{15^{0}}=1,42532, d \frac{25^{0}}{25^{0}}=1,41057$.

Magnetische Rotation des Allylbromids:

\begin{tabular}{ccc}
$t$ & Sp. Rotation. & Mol. Rotation. \\
$17,0^{\circ}$ & 1,7413 & 8,230 \\
17,5 & $\mathbf{1 , 7 4 0 1}$ & 8,228 \\
$\mathbf{1 8 , 2}$ & $\mathbf{1 , 7 4 2 1}$ & 8,247 \\
$\mathbf{1 8 , 3}$ & 1,7439 & 8,255 \\
19,0 & 1,7367 & 8,225 \\
19,0 & $\mathbf{1 , 7 3 7 8}$ & 8,230 \\
18,0 & 1,7321 & 8,194 \\
$\mathbf{1 3 , 8}$ & $\mathbf{1 , 7 4 0 6}$ & 8,199 \\
13,8 & $\mathbf{1 , 7 4 0 9}$ & 8,201 \\
13,8 & $\mathbf{1 , 7 4 1 7}$ & 8,206 \\
\hline 16,8 & $\mathbf{1 , 7 3 9 8}$ & 8,221
\end{tabular}

1) Ann. Chim. Phys. [5] 14, 477. 
584 Perkin: Ueber magnetische Circular-Polarisation

Jodpropylen - Allyljodid: $\mathrm{CH}_{2}: \mathrm{CH} . \mathrm{CH}_{2} \mathrm{~J}$.

Dieses Jodid wurde durch kurzes Schütteln mit Quecksilber gereinigt, über Phosphorsäureanhydrid getrocknet und unter vermindertem Drucke fractionirt. Dasselbe ist eine blassgelbe Flüssigkeit, welche unter $330 \mathrm{Mm}$. Druck bei $70^{0}-71,5^{0}$ corr. siedete:

Specif. Gewicht: $d \frac{15^{0}}{15^{0}}=1,82403, d \frac{25^{0}}{25^{0}}=1,80776$.

Folgende Zahlen wurden für die magnetische Rotation eines frisch destillirten Präparates erhalten:

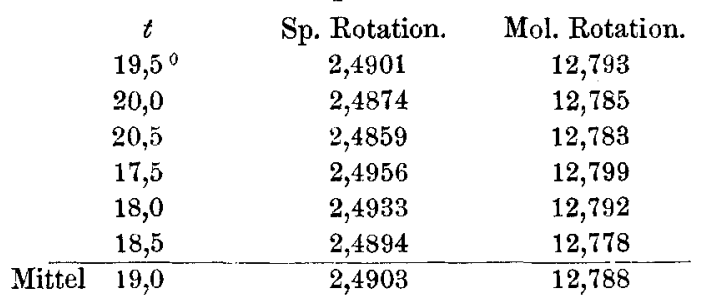

\section{Bemerknngen über die speciflschen Gewichte und die specifischen magnetischen Rotationen der unter- suchten Körper.}

Ehe die molekularen Rotationen der untersuchten Substanzen besprochen werden, ist es von Interesse, die gegenseitigen Beziehungen der verschiedenen Dichten und der specifischen Rotationen bei einer bestimmten Temperatur zu betrachten.

Die ausgedehntesten und für diesen Zweck passendsten Reihen von Verbindungen sind die der Fettsäuren und ihrer Aethyläther. In der beigegebenen Tafel $\mathrm{V}$ sind die in dem vorhergehenden Theile dieser Abhandlung angegebenen, aber für $20^{\circ}$ umgerechneten Resultate graphisch dargestellt. Auf der Abscisse ist die Zahl der in der Verbindung enthaltenen Kohlenstoffatome angegebenen, während die Ordinaten eine Zahlenscala bilden, welche die Dichten und specifischen Rotationen der betreffenden Verbindungen umfasst.

Man erkennt, dass die Dichten, sowohl der Säuren wie 
auch ihrer Aethyläther, regelmässige Curven bilden und dass die der Aether gekrümmter sind, als die der Säuren.

Sodann schien es von Interesse, zu prüfen, welche Curve einer Reibe entspricht, in welcher das Säureradical constant bleibt, das Alkyl aber variirt. Ein Vergleich wurde daher zwischen den folgenden Körpern gemacht:

$$
\begin{array}{ccc}
\text { Essigsaures } & \text { Methyl, } \\
" & \quad & \text { Aethyl, } \\
" & \quad & \text { Propyl, } \\
" \quad & \quad & \text { Octyl, } \\
" \quad & \text { Cetyl. }
\end{array}
$$

Diese Körper bilden nicht genau die gleiche Curve wie die Aethyläther, sondern eine, welche diese schneidet und ein wenig gekrümmter ist.

Ein ähnlicher Vergleich, bei welchem Säure- und Alkohol-Radicale gleichartig variiren, wurde ebenfalls angestellt. Folgende Verbindungen wurden zu diesem Zwecke gewählt:

Ameisensaures Methyl,

Essigsaures Aethyl,

Propionsaures Propyl,

Oenanthylsaures Heptyl.

In diesem Falle ist die Curve etwas offener als die der Aethyläther.

Bei der Bestimmung der Dichte von Körpern der homologen Reihen wurde bemerkt, dass sich der AusdehnungsCoëfficient um so mehr verringerte, je höher das Molekulargewicht war; und dass diese Abnahme eine regelmässige war. Dies wird aus der auf Taf. $V$ befindlichen kleinen Zeichnung ersichtlich. Diese zeigt der Aenderung-Coëfficient der Fettsäuren und ihrer Aether zwischen $15^{\circ}$ und $25^{\circ}$. Hieraus erkennt man, dass die zwei Curven nahezu parallel laufen. Die grösste Abweichung einer gefundenen Zahl von der ihr zugehörigen Curve beträgt nur 0,0003.

Aus dem Vorhergehenden scheint hervorzugehen, dass die Dichten von homologen Körpern in einer ganz bestimmten Weise aufeinander folgen und einer Regel gehorchen. Auch für die Ausdehnungscoëfficienten scheint dies zu gelten. Nach diesen Beobachtungen sollten solche 
Bestimmungen mit möglichster Sorgfalt gemacht werden, besonders da sie vielleicht für die Entscheidung der Constitution der Verbindungen werthvoll werden können.

Mit den gegenwärtigen Bestimmungen der Dichten der normalen primären Alkohole kann keine Curve erhalten werden. Dies beruht wahrscheinlich auf ungenügender Reinheit der untersuchten Präparate, da viele dieser Alkohole sehr schwer in genügender Menge zu erhalten sind. Aber mit Aethyl-Alkohol anfangend und diesen mit Propyl-, Butyl(Linnemann's Bestimmung) und Octyl-Alkohol vergleichend, kann man doch eine sie alle umfassende Curve entwerfen. Heptyl-Alkohol weicht auch nicht weit davon ab; und es ist kaum zu bezweifeln, dass dieser aus Oenanthol dargestellte Alkohol immer noch eine Verunreinigung enthält, da seine Dichte höher als die des Octyl-Alkohols ist, obwohl bei den Alkoholen die Dichte stets mit dem Molekulargewicht wächst.

Der Vergleich der specifischen Gewichte bei einer bestimmten Temperatur wird zuweilen für nutzlos gehalten; aber in einer Reihe homologer Verbindungen sind solche Dichten doch vergleichbar, weil zwischen jedem Glied der Reihe die gleiche Differenz der Zusammensetzung, annähernd die gleiche Differenz des Siedepunktes, und ein sich regelmässig ändernder Ausdehnungscoëfficient vorhanden sind. Auf der Tafel V sind einige, von Elsässer ${ }^{l}$ ) bei deren Siedepunkten bestimmte Dichten von Aethern graphisch dargestellt.

Diese Bemerkungen gelten auch für die specifischen Rotationen, welche, wie aus der Tafel ersichtlich, auch Curven - natürlicherweise in der entgegengesetzten Richtung bilden. Ameisensäure aber fügt sich in die Curve nicht ein, und bei den Aethern sieht man, dass eine kleine Aenderung der Richtung zwischen Ameisensäureäthyl- und Essigsäureäthyläther statt findet.

Die Regelmässigkeit dieser Curven beweist, dass die bei der Bestimmung der magnetischen Rotation erhaltenen Zahlen, aus denen die specifischen Ratationen berechnet wurden, der Wahrheit sehr nahe kommen, oder mindestens unter einander harmoniren.

1) Ann. Chem. Pharm. 218, 302. 
d. Verbind. im Verhältn. zu deren chem. Constitut. etc. 587

\title{
Molekulare Rotation.
}

\author{
Normale Verbindungen.
}

In der kurzen Mittheilung ${ }^{1}$ ) die ich i. J. 1882 über diesen Gegenstand veröffentlichte, sprach ich, mich auf meine bis dahin erhaltenen Daten stützend, die Vermuthung aus, dass die molekulare magnetische Rotation eines Körpers in einer regelmässigen Weise mit der chemischen Zusammensetzung desselben variirt, und dass für jede Zunahme um $\mathrm{CH}_{2}$ eine Vermehrung der molekularen Rotation von 1,0-1,2 stattfindet. Da die Reihen der Fettsäuren und ihrer Aether am umfassendsten sind, so sollen sie zuerst besprochen werden.

Bei der Prüfung der durch die sorgfältige Untersuchung dieser Reihen erhaltenen Zahlen war ich zu der Ueberzeugung gekommen, dass jene Differenz genau 1,0 beträgt und dass die kleinen $A b w e i c h u n g e n$ den Beobachtungsfehlern zuzuschreiben sind. Bei der Bestimmung der Oenanthylsäure und ihrer Aether wurden aber Zahlen erhalten, welche sich mit dieser Annahme nicht vereinigen liessen. Da die Rotation dieser Verbindungen in Folge der leichten Bildung von Wärmeströmungen durch geringe Temperatur-Unterschiede schwer zu messen war, so lag der Gedanke nahe, diesen scheinbaren Widerspruch auf die durch diese Schwierigkeit verursachten Beobachtungsfehler, oder auf in den benutzten Präparaten enthaltene Verunreinigungen zurückzuführen. Die Substanzen wurden daher nochmals gereinigt und fractionirt. Da hierdurch die Resultate nicht geändert wurden, so nahm ich einige andere höhere Säuren und Aether zur Messung. Das Resultat war, dass der Werth für die Zusammensetzungsdifferenz von $\mathrm{CH}_{2}$ grösser als 1,0 ist. Aus einer sehr grossen Anzahl Bestimmungen ist derselbe zu 1,023 ermittelt worden.

Nach Bestimmung dieser Zahl kann man die molekulare Rotation irgend eines Gliedes einer homologen Reihe berechnen, wenn nur die Rotation eines Gliedes gut gemessen worden ist. Nehmen wir als Beispiel die Oenanthylsäure:

1) Ber. Berl. chem. Ges. 15, 1363. 
588 Perkin: Ueber magnetische Circular-Polarisation

Wenn wir $1,023 \times 7$ von deren molekularen Rotation wegnehmen, so erhalten wir einen Rest:

$$
\begin{aligned}
& \text { Mol. Rotation der Oenanthsäure 7,552 } \\
& 1,023 \times 7 \quad \cdot \quad \cdot \quad \cdot \quad \cdot \quad \cdot \frac{7,161}{0,391}
\end{aligned}
$$

Ich schlage vor, diese übrigbleibende Zahl die ReihenConstante zu nennen und dieselbe mit $s$ zu bezeichnen. So können wir folgende Formel für die Fettsäuren dieser Reihe (bei Propionsäure anfangend) aufstellen:

Mol. Rotation von $\mathrm{C}_{n} \mathrm{H}_{2 n} \mathrm{O}_{2}=0,391+\mathrm{n}(1,023)$.

Im Folgenden sind die gefundenen molekularen Rotation

\begin{tabular}{|c|c|c|}
\hline & Gefunden & Berechnet \\
\hline Propionsäure. & 3,462 & 3,462 \\
\hline Buttersäure . & 4,472 & 4,485 \\
\hline $\begin{array}{l}\text { Isobuttersäure oder Dime- } \\
\text { thylessigsäure }\end{array}$ & 4,479 & 4,485 \\
\hline Valeriansäure . . & 5,513 & 5,508 \\
\hline Oenanthsäure & 7,552 & 7,554 \\
\hline Caprylsäure . & 8,565 & 8,577 \\
\hline Nonylsäure . & 9,590 & 9,600 \\
\hline
\end{tabular}
der Säuren der Fettreihe mit den berechneten verglichen:

Für die Aether dieser Säuren ist $s=0,337$; unten sind

\begin{tabular}{|c|c|c|}
\hline & Gefunden & Berechnet \\
\hline Propionsaures Aethyl & 5,452 & 5,452 \\
\hline Buttersaures $\quad "$ & 6,477 & 6,475 \\
\hline Dimethylessigsaures Aethy & 6,479 & 6,475 \\
\hline Capronsaures Aethyl . . & 8,509 & 8,521 \\
\hline Oenanthsaures Aethyl & 9,541 & 9,544 \\
\hline Nonylsaures Aethyl. & 11,571 & 11,590 \\
\hline Oenanthsaures Heptyl & 14,655 & 14,659 \\
\hline
\end{tabular}
die gefundenen mit den berechneten Zahlen verglichen:

Man erkennt hieraus, dass die gefundenen Zahlen sehr gut bei Annahme des Werthes 1,0231 für die Differenz $\mathrm{CH}_{2}$ stimmen.

Ameisen- und Essigsäure und ihre Aether gehören nach ihren molekularen Rotationen den homologen Reihen nicht an.

Für die Aether der Essigsäure ist die Reihen-Constante 0,370 ; unten sind die gefundenen Zahlen mit den berechneten verglichen: 
d. Verbind. im Verhältn. zu deren chem. Constitut. etc. 589

\begin{tabular}{|c|c|c|c|c|}
\hline \multirow{2}{*}{ Essigsaures } & & & Gefunden & Berechnet \\
\hline & Aethyl & • & 4,462 & 4,462 \\
\hline$"$ & Propyl & - & 5,487 & 5,485 \\
\hline$"$ & Oetyl. & $\cdot$ & 10,601 & 10,600 \\
\hline$n$ & Cetyl. & . & 18,772 & 18,784 \\
\hline
\end{tabular}

Um die erhaltenen Resultate verständlicher zu machen, sind sie graphisch dargestellt worden. In den Tafeln (VI u. VII) und Figuren geben die Abscissen die Anzahl der Kohlenstoffatome der Verbindungen, die Ordinaten die Decimalzahlen der molekularen Rotationen an. Die ganzen Zahlen sind weggelassen dadurch werden die Zahlen bis zur dritten Decimalstelle angezeigt; wollte man die ganzen Zahlen anführen, so würde man zehnmal grössere Figuren wie die beigegebenen brauchen. Um das Nachschlagen nach der Mittheilung selbst zu ersparen sei erwähnt, dass wenn man die molekulare Rotation irgend einer aus Kohlenstoff und Sauerstoff bestehenden Verbindung wissen will, es nur nöthig ist, die ihr entsprechenden Abscissen und Ordinaten zu addiren. Wenn die Rotationen höher sind, wie es bei den Halogen-Verbindungen der Fall ist, so werden die Zahlen in derselben Weise gefunden, nur muss die oben links an der Figur stehende Zahl noch hinzugefügt werden.

Aus Fig. 3 (Taf. VI), welche die Säuren und ihren Aether betrifft, sieht man, wie die molekulare Rotation von der Ameisensäure bis zur Essigsäure, und weiter, wenn schon in kleinerem Maassstabe, zur Propionsäure sinkt, die Linie wird dann gerade und aufsteigend. Dies trifft auch für die Aether zu, welche den Säuren fast parallel laufen: das Sinken vom ersten zum zweiten Glied ist aber etwa ein Viertel geringer, als bei den Säuren. Man erkennt ferner, dass die Acetate eine besondere Linie bilden, die in gleicher Richtung, aber nicht in gleichem Maassstabe von denen der anderen Aether abweicht, wie die Essigsäure von ihren Homologen.

Nachdem wir gefunden haben, dass bei den Fettsäuren und deren Aethern der Unterschied für $\mathrm{CH}_{2}$ eine constante Grösse ist, und dass die molekularen Rotationen -- wie aus den Zahlen ersichtlich - für alle normalen Aether von gleicher Zusammensetzung, welche Aethyl oder höhere 
Radicale enthalten, die nämlichen sind, wird es von Interesse sein, zu erfahren, ob dies auch für andere Reihen gilt. Als Beispiel mögen die Paraffine dienen.

In dieser Reihe wurde Heptan aus Pinus sabiniana am sorfältigsten untersucht, da dieser Körper in Bezug auf Reinheit der sicherste war. Die Reihenconstante wurde aus den erhaltenen Zahlen zu 0,508 berechnet.

Folgendes ist ein Vergleich der gefundenen und berechneten Zahlen (siehe Fig. 2, Taf. VI) :

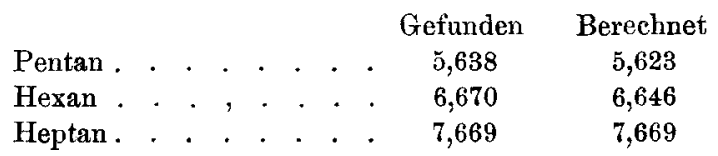

Diese Resultate stimmen genügend nahe, wenn man die Schwierigkeit der Reindarstellung des Pentans und Hexans bedenkt; man darf wohl annehmen, dass auch diese Verbindungen derselben Regel folgen, wie die schon besprocheneu Säuren und deren Aether.

Das Gleiche findet man auch bei der Reihe der mit Propylalkohol anfangenden normalen Alkohole. In diesem Falle ist die Reihen-Constante 0,699. Die folgenden Resultate wurden gefunden (siehe Fig. 1, Taf. VI):

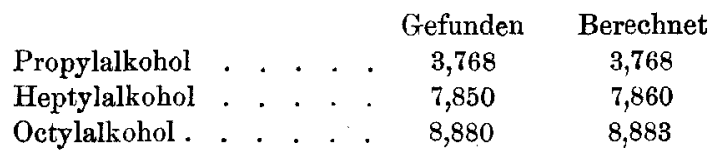

Die Aldehyde (mit Propylaldehyd anfangend) scheinen auch derselben Gesetzmässigkeit zu folgen. (Siehe Fig. 2). Die Reihen-Constante beträgt 0,263 :

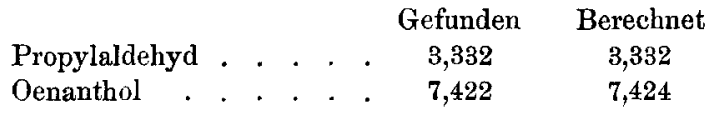

In der Bernsteinsäure-Reihe erhalten wir die folgenden Zahlen. (Siehe Fig. 7, Taf. VI). Die Reihen-Constante ist $=0,196$ :

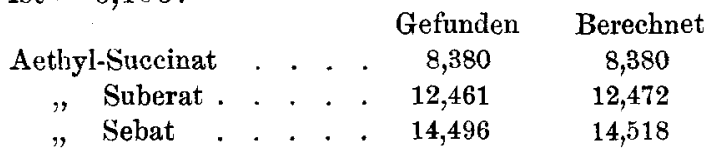


d. Verbind. im Verhältn. zu deren chem. Constitut. etc. 591

Die einbasischen ungesättigten Säuren scheinen ebenfalls dieser Gesetzmässigkeit unterworfen zu sein. Nur zwei sind untersucht worden, aber diese liegen ziemlich weit aus einander, so dass die Resultate, zur Bestätigung des Werthes von $\mathrm{CH}_{2}$ wichtig sind. Die Reihenconstante beträgt 1,451 :

\begin{tabular}{|c|c|c|}
\hline ethyl-Crotonat & $\begin{array}{c}\text { Gefunden } \\
\mathbf{7 , 5 8 9}\end{array}$ & $\begin{array}{c}\text { Berechnet } \\
7,589\end{array}$ \\
\hline$" \quad$ oleat & 21,909 & 21,897 \\
\hline
\end{tabular}

Die Chloride, Bromide und Jodide der normalen Alkyle geben auch ähnliche Resultate wenn man mit den Propyl-Verbindungen anfängt. Die Reihen-Constanten sind für die

$$
\begin{aligned}
& \text { Bromide . . . . . . } s=1,988 \\
& \text { Chloride . . . . . . . } s=3,816 \\
& \text { Jodide . . . . . . . . } s=8,011
\end{aligned}
$$

Da die höheren Glieder dieser Reihen schwer rein zu erhalten sind, so stimmen die Zahlen nicht ganz so nahe mit einander überein, als in den früheren Fällen.

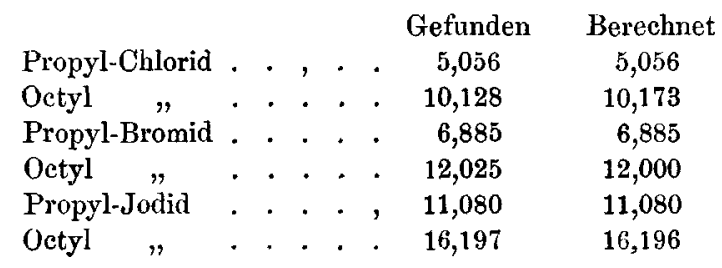

Einfluss des Ersatzes von Wasserstoff durch Methyl in normalen homologen Verbindungen.

\section{Isoparaffine.}

Diese können als normale Paraffine, in welchen ein Atom Wasserstoff des Aethyls: $\mathrm{CH}_{2} . \mathrm{CH}_{3}$ durch Methyl ersetzt ist, angesehen werden. Z. B.:

$$
\begin{aligned}
& \mathrm{CH}_{3} \cdot \mathrm{CH}_{2} \cdot \mathrm{CH}_{2} \cdot \mathrm{CH}_{3} \quad\left(\mathrm{CH}_{3}\right)_{2} \cdot \mathrm{CH} \cdot \mathrm{CH}_{2} \cdot \mathrm{CH}_{3} \\
& \text { Butan Methylbutan oder Isopentan } \\
& \mathrm{CH}_{3} \cdot \mathrm{CH}_{2} \cdot \mathrm{CH}_{2} \cdot \mathrm{CH}_{2} \cdot \mathrm{CH}_{3}\left(\mathrm{CH}_{3}\right)_{2} \cdot \mathrm{CH} \cdot \mathrm{CH}_{2} \cdot \mathrm{CH}_{2} \cdot \mathrm{CH}_{3} \\
& \text { Pentan } \\
& \text { Methylpentan oder Isohexan. }
\end{aligned}
$$


Der Einfluss des Methyls auf die molekulare Ratation ist sehr auffallend; denn letztere wird dadurch bedeutend mehr erhöht, als durch die Einführung der $\mathrm{CH}_{2}$-Gruppe, wie aus folgenden Beispielen ersichtlich ist. Die ReihenConstante der Isoparaffine ist 0,631. (Siehe Fig. 2):

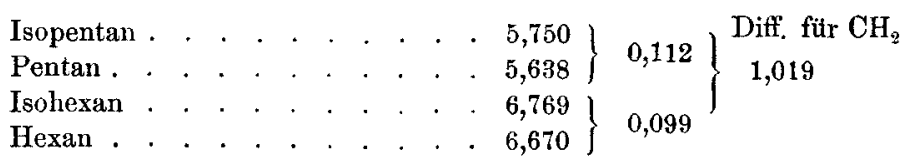

Demnach ist die der Zunahme von $\mathrm{CH}_{2}$ zwischen den zwei Isoverbindungen entsprechende Differenz eigentlich mit der in den anderen Reihen gefundenen identisch.

\section{Isoalkohole.}

Die zwischen den normalen und Iso-Alkoholen gefundenen Differenzen sind folgende (siehe Fig. 1):

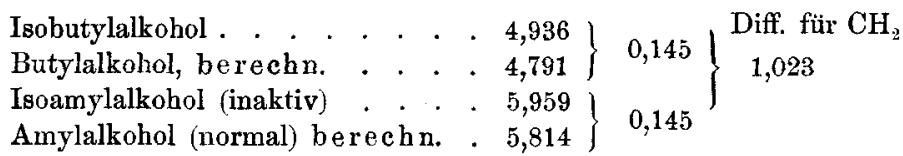

Die Reihen-Constante ist für diese $=0,844$. Die $\mathrm{Zu}$ nahme der Rotation gegenüber den normalen Körpern ist hier etwas grösser, als bei den Isoparaffinen. Auch hier ist der zwischen den zwei Isoalkoholen beobachtete Unterschied für $\mathrm{CH}_{2}$ genau derselbe, wie bei den anderen Reihen.

Isoamyläther, welcher zweimal Isoamyl enthält, zeigt, wie zu erwarten, ungefähr die doppelte Differenz wie der Alkohol:

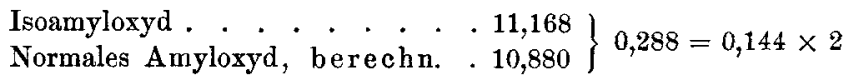

Die für das normale Amyloxyd berechnete $Z a h l$ ergiebt sich aus der Annahme, dass die Reihen-Constante des normalen Amyloxyds in demselben Verhältnisse zu der des normalen Amylalkohols steht, als die des Aethyloxyds zu der des Aethylalkols. (Siehe Fig. 1). 
d. Verbind. im Verhältn. zu deren chem. Constitut. etc. 593

Isosäuren und deren Aether.

Folgende Substanzen sind untersucht worden:

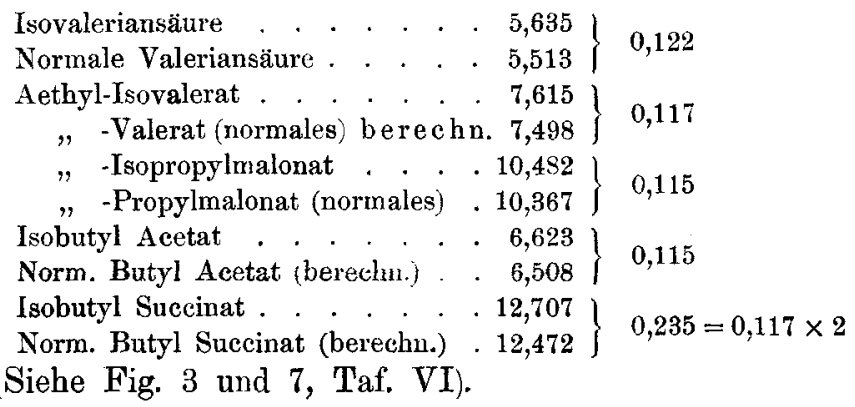

Aldehyde.

Von den Aldehyden kann nur ein einziges Beispiel gegeben werden. (Siehe Fig. 2).

Isovaleraldehyd . . . . . . . 5,487

Norm. Valeraldehyd (berechn.) . $\cdot 5,376\} 0,111$

Die mitgetheilten Resultate beweisen, dass die Zunahme der molekularen Rotation in Folge Eintritt eines Methyls und Bildung einer Isoverbindung grösser ist, als die durch die gewöhnliche Zunahme von $\mathrm{CH}_{2}$ hervorgerufene, und zwar ist dieselbe durch folgende Zahlen ausdrückbar:

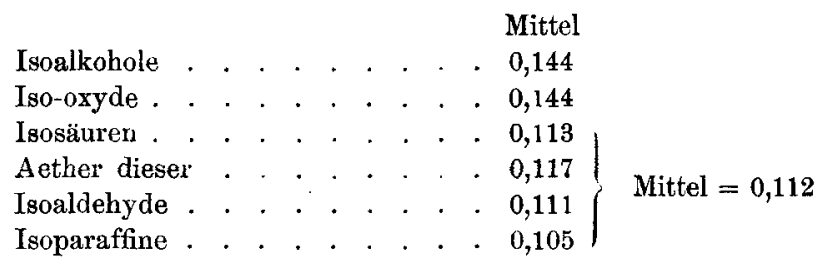

Bei den Isoalkoholen und Iso-oxyden ist diese Differenz offenbar grösser, als bei den anderen Verbindungen. Die geringen Unterschiede der bei den vier letzten Reihen gefundenen Zahlen rühren wahrscheinlich von Beobachtungsfehlern her, ihr Mittel: 0,112 ist vermuthlich auf alle anwendbar.

Die Vergleichung einer Isosäure (die Isobuttersäure), deren Aether und Aldehyde mit den entsprechenden Normalverbindungen, ist übergangen worden. Diese Verbindungen 


\section{Perkin: Ueber magnetische Circular-Polarisation}

ergaben Zahlen, die beinahe genau mit den entsprechenden normalen Verbindungen übereinstimmen. (Siehe Fig. 2 u. 3):

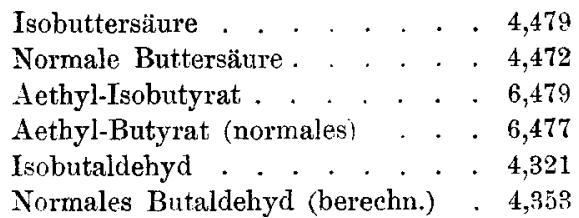

Im Betreff dieser Verbindungen müssen mehrere Punkte berücksichtigt werden, wie z. B. der Einfluss des Carboxyls auf die damit verbundenen Complexe, und die Frage, wo eine homologe Reihe eigentlich anfängt. Der zweite Punkt möge gleich besprochen werden. Nach den erhaltenen Zahlen scheint es, dass ein Körper, um das erste Glied einer homologen Reihe zu sein, den Complex $\mathrm{CH}_{2}$ enthalten müsse, denn durch die Bildung weiterer solcher Gruppen entstehen die homologen Reihen. Propionsäure sollte demnach als erstes Glied der homologen Fettsäure - Reihe angesehen werden. Weder Ameisensäure noch Essigsäure enthalten den Complex $\mathrm{CH}_{2}$ und bekanntlich besitzen sie Eigenschaften, die denen der anderen Fettsäuren gar nicht vergleichbar sind. Wie schon erwähnt, weist die magnetische Rotation dieser Verbindungen auf ähnliche Unterschiede hin.

In obigen drei Verbindungen haben wir Körper, welche den Complex $\mathrm{CH}_{2}$ nichtenthalten und daher der eigentlichen homologen Reihe der Iso-Verbindungen nicht angehören. Sobald sie aber durch Einführung einer $\mathrm{CH}_{2}$-Gruppe in die Valerian-Verbindungen übergeführt werden, verhalten sie sich wie wahre Iso-Körper. Die in Fig. 2 und 3, die Isobuttersäure- und Isovaleriansäure-Derivaten verbindenden, punktirten Linien sind bestimmt auf diese Thatsache aufmerksam zu machen.

Ersatz von Wasserstoff in normalen Körpern unter Bildung secundärer Verbindungen.

Der Ersatz findet in dem mit dem Hydroxyl oder anderen negativen Radicalen verbundenen Atomcomplexe statt, z. B.: 
d. Verbind. im Verhältn. zu deren chem. Constitut. etc. 595

$\mathrm{CH}_{3},\left(\mathrm{CH}_{2}\right)_{5} \cdot \mathrm{CH}_{2} \mathrm{OH}$

Heptylalkohol
$\mathrm{CH}_{3} \cdot\left(\mathrm{CH}_{2}\right)_{5} \cdot \mathrm{O}\left(\mathrm{CH}_{3}\right) \mathrm{H} . \mathrm{OH}$

Methylheptylalkohol oder secundärer Octylalkohol

Der secundäre Octylalkohol ist die einzige Kohlenstoff, Wasserstoff und Sauerstoff enthaltende Verbindung, welche ich in dieser Hinsicht untersucht habe. Die hierher gehörigen Halogen-Verbindungen werden später besprochen werden.

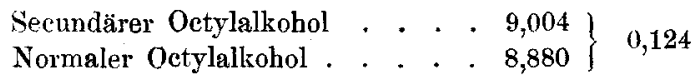

Diese Differenz weicht von der für Isoalkohole ermittelten nur um 0,023 ab; eine Abweichung, die leicht von Beobachtungsfehlern herrühren mag.

Isopropylalkohol ist auch eine secundäre Verbindung, wird aber, aus den oben angeführten Gründen, nicht als ein Glied einer homologen Reihe betrachtet. Die Rotation ist auffallend hoch.

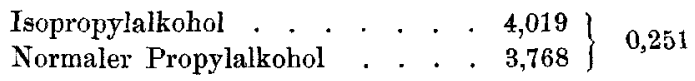

Nach den bisherigen Versuchen übt die Einführung des Methyls in primäre Verbindungen fast gleichen Einfluss aus, einerlei ob hierbei Iso-oder secundäre Verbindungen entstehen. (Siehe Fig. $i$ und 3).

Ersatz des Wasserstoffs in Aldehyden durch Methyl unter Bildung von Ketonen.

Aceton und Methylpropylketon bilden zwei Fälle, welche untersucht worden sind. Da das Acetaldehyd, mit dem das Aceton zu vergleichen ist, kein wahres Homologes hat, so ist es nöthig, 1,023 zu dessen Rotation zu addiren, um die Zunahme des $\mathrm{CH}_{2}$ in Rechnung zu bringen.

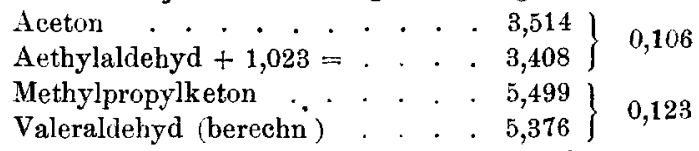

Man erkennt, dass das Methylpropylketon eigentlich dieselbe Rotation hat, wie das Isovaleraldehyd. In der That scheint es, dass diese Art der Einführung von Methyl die molekulare Rotation in demselben Maasse erhöht, wie bei der Ueberführung der normalen in die Iso-Aldehyde. (Siehe Fig.2). 
596 Perkin: Ueber magnetische Circular-Polarisation

Ersatz des Wasserstoffs im Methylalkohol durch Methyl und Aethyl.

Durch Ersatz eines Atoms Wasserstoff im Methyl wird Methylalkohol in Aethylalkohol übergeführt, wobei sich die Rotation erhöht:

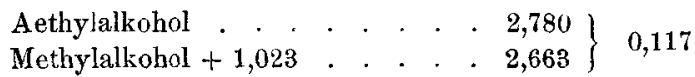

Die Rotation des Aethylalkohols ist verhältnissmässig um etwa 0,035 höher als die seines Homologen.

Die Einführung eines zweiten Methyls verursacht die Bildung von secundärem oder Iso.Propylalkohol. Hier finden wir, wie schon erwähnt, eine auffallend grosse Zunahme der Rotation.

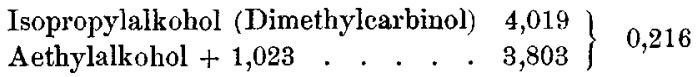

Durch die Einführung eines dritten Methyls, Bildung des tertiären Butylalkohols, wird noch eine weitere Zunahme der Rotation hervorgerufen:

$\begin{array}{lr}\text { Tertiärer Butyalalkol (Trimethylearbinol) } & 5,122 \\ \text { Isopropylalkohol }+1,023 & 0,080\end{array}$

Der Ersatz von Wasserstoff durch Aethyl kann nur an einem Beispiel erläutert werden. Der untersuchte Körper war Dimethyläthylcarbinol, welches als Aethylisopropylalkohol angesehen werden kann. Dieser Körper hat merkwürdiger W eise eine verhältnissmässig niederere Rotation, als der Isopropylalkohol selbst:

Tertiärer Amylalkohol (Dimethyläthylcarbinol) $5,98 \pi$

Isopropylalkohol $+(1,023 \times 2) \quad . \quad . \quad . \quad . \quad$. 6,06\%

Die Rotation ist fast identisch mit der des Isoamylalkohols, die 5,959 beträgt. Da der Isopropylalkohol eine abnorm hohe Rotation besitzt, so eignet er sich kaum zu Vergleichszwecken, besonders da Dimethylcarbin sich in anderen Verbindungen in einer normaleren Weise verhält. Bis wir aber bessere Auskunft im Betreff des Ersatzes von Wasserstoff in den Radicalen durch Aethyl besitzen, kann nur wenig aus diesem einzigen Falle gefolgert werden.

Alle diese Derivate des Methylalkohols stehen allein und sind hauptsächlich von Interesse, wenn sie unter einander verglichen werden. Sie bestätigen aber doch, was schon in 
d. Verbind. im Verhältn. zu deren chem. Constitut. etc. 597 anderen Fällen beòbachtet wurde, dass der Ersatz von Wasserstoff durch Methyl die molekulare Rotation erhöht. (Siehe Fig. 1).

Es giebt noch einen Fall des Ersatzes von Wasserstoff durch Methyl, der hier erwähnt werden mag, nämlich im Aethylenalkohol oder Glycol. Das Substitutionsprodukt ist Pinakon oder Tetramethylglycol

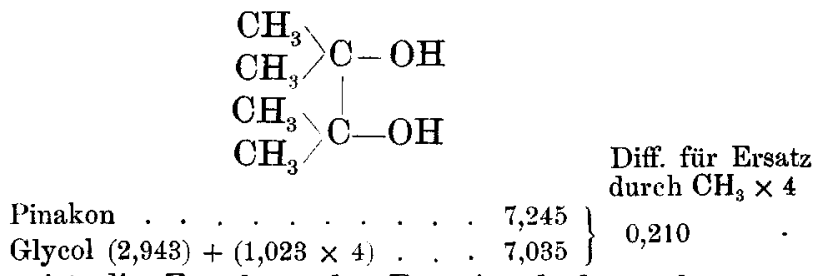

Hier ist die Zunahme der Rotation bedeutend grösser als die für die Zusammensetzungsdifferenz gewöhnliche; dieser Ueberschuss ist doch bei weitem nicht viermal so gross, wie der beim Ersatz des einen Wasserstoffatoms in den gewöhnlichen Alkoholen. Aus der Untersuchung der Mono-, Diund Trimethylderivate des Aethylenbromids erkennt man aber, dass der Einfluss dieses Ersatzes successiv kleiner wird; graphisch dargestellt, geben die Resultate eine gekrümmte Linie. Es ist wohl möglich, dass die Einführung des ersten Methyls in das Glycol mindestens beinahe eben so grossen Einfluss haben wird, wie es bei den einwerthigen Alkoholen der Fall ist.

Ersatz des Hydroxyl-Wasserstoffs durch Methyl, Aethyl und andere normale Alkyle.

I. Aethyläther von Säuren.

Durch Ueberführung einer Säure in ihre Aether wird die magnetische Rotation erniedrigt.

\begin{tabular}{|c|c|}
\hline Ameisensäure $(1,671)+(1,023 \times$ & \\
\hline Ameisensaures Aethyl & 3,564 \\
\hline Essigsäure $(2,525)+(1,023 \times 2)$. & \\
\hline
\end{tabular}

Wenn wir die Säuren und Aether der homologen Säuren vergleichen, so erhalten wir für:

$\left.\begin{array}{lll}\text { Propionsäure }(3,462)+(1,023 \times 2) & 5,508 \\ \text { Propionsaures Aethyl . . . . . } & 5,452\end{array}\right\} \quad 0,056$ 
598 Perkin: Ueber magnẹtische Circular-Polarisation

Diese letzte Zahl 0,056 scheint eine constante, zwischen den Reihen der Säuren und denen ihrer Aether bestehende Differenz zu sein.

II. Andere, die normalen Alkyle enthaltende Aether.

Obwohl das Aethyl wahrscheinlich nicht ein wahres Glied der homologen Reihe ist, so übt dasselbe doch auf die magnetische Rotation in der Mehrzahl der Fälle einen normalen Einfluss aus. Aethylalkohol, bei welchem der Einfluss circa 0,035 höher ist als er sein sollte, bildet die Hauptausnabme. Dies ist anch bei der Reihe der Fettsäureäther der Fall, so dass - aus einem Vergleich des Propylacetats mit dem Aethylacetat zu schliessen - mit Ausnahme der Methyläther, alle die normalen Alkyle enthaltenden Säureäther dieselbe Reihen-Constante zu haben scheinen, und daher ihre Rotation durch dieselbe Formel $^{1}$ ) ausgedrückt werden kann. (Siehe Fig. 3).

\section{Methyläther.}

Der Ersatz vom Hydroxyl-Wasserstoff einer Säure durch Methyl verursacht eine weit grössere Abnahme der magnetischen Rotation, als die Substitution durch Aethyl.

Nochmals die Säuren, die keine Homologen besitzen, als Beispiele nehmend, haben wir:

$$
\left.\begin{array}{llll}
\text { Ameisensäure }(1,671)+1,023 & . & 2,694 \\
\text { Ameisensaures Methyl . . . . . } & . & 2,495
\end{array}\right\} 0,199
$$

In Fig. 3 sind Linien für die Methyläther denen der Aethyläther parallel gezogen worden. Man wird aber bemerken, dass die für ameisensaures und essigsaures Methyl gefundenen Resultate mit diesen Linien nicht genau zusam-

1) Nachdem dieses geschrieben, sind Bestimmungen der magnetischen Rotation des Propylpropionats und Propylformiats ausgeführt und dieser Mittheilung hinzugefügt worden. Man bemerkt, dass diese Körper wirklich niedrigere Zahlen ergeben, als die entsprechenden Aethyläther. Es ist daher wahrscheinlich, dass die in Fig. 3 für Propylund höhere Alkyläther angegebene Linie etwa 0,02 bis 0,03 niedriger sein sollte, als die der Aethyläther. 
d. Verbind. im Verhältn. zu deren chem. Constitut. ete. 599

menfallen. Der Unterschied ist so klein, dass er von den Beobachtungsfehlern herrühren mag. Da aber die Methyläther viel mehr als die Aethyläther von den Säuren abweichen, so ist es auch möglich, dass die zwei in Frage stehenden Aether sich den Aethyläthern doch nicht genau parallel verhalten.

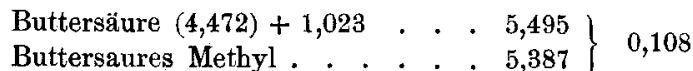

Diese Differenz würde ohne $Z$ weifel auch für die anderen Methyläther der Fettsäuren gefunden werden. Die Reihen-Constante beträgt für dieselben 0,273 .

Die weitere Betrachtung der Methylester muss im Zusammenhange mit den Aethylestern gesshehen, weil sie sich auf die Ester der Oxalsäurereihe bezieht. Hier sind die Säuren selbst feste Körper und konnten daher nicht untersucht werden. Man wird bemerken, dass die Reihen-Constante der Methylester um 0,052 niedriger ist, als die der Aethylester.

Da die Säuren der Oxalsäurereihe zweiwerthig sind, so ist zu erwarten, dass der Ersatz aer zwei Hydroxyl-Wasserstoffatome durch Alkyle eine circa zweifach so grosse Differenz der magnetischen Rotation hervorrufen werde, als bei den einwerthigen Säuren.

Folgende vergleichbare Verbindungen sind untersucht worden. (Giehe Fig. 7).

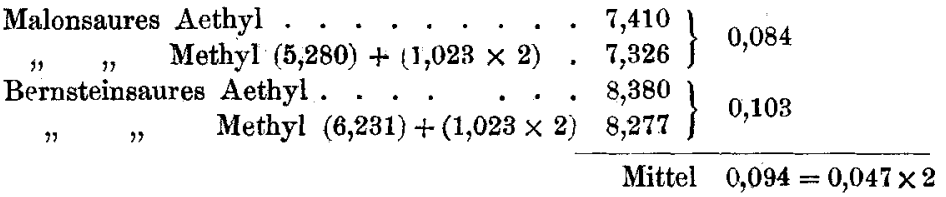

Hieraus folgt, dass die Einführung zweier Methyle an Stelle der Hydroxyl-Wasserstoffatome der zweiwerthigen Säuren in der That die magnetische Rotation fast zweimal so weit herabdrückt, als die Einführung des einen Methyls in den Fettsäuren. Wahrscheinlich ist die etwas niedri re Zahl, die erhalten wurde, nicht zufällig, vielmehr wird i as zweite Methyl einen etwas kleineren Einfluss ausüben, ds das erste. 
600 Perkin: Ueber magnetische Circular-Polarisation

IV. Oxyde (Aether).

Der Ersatz des Hydroxyl-Wasserstoffs der Alkohole durch Alkyle, scheint demselben Gesetz zu folgen, wie der bei den Säuren.

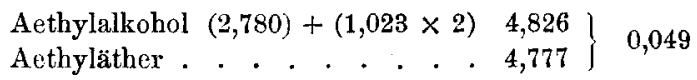

Diese Zahl weicht nur um 0,007 von der bei den Fettsäureäthern gefundenen Differenz ab. (Siehe Fig. 1).

Einfluss des Carboxyls auf die magnetische Rotation der Verbindungen.

Die Rotation dieses Complexes ( $\mathrm{COOH}$ ) ist offenbar gross, doch übt sie merkwürdigerweise einen verringernden Einfluss auf die magnetische Rotation mit ihr verbundener Alkyle aus. So sinkt - wenn man natürlich dem Unterschiede der Zusammensetzung Rechnung trägt - die Rotation der Ameisensäure um 0,169 in Folge des Ersatzes von deren Wasserstoffatom durch Methyl bei der Bildung der Essigsäure und nochmals um 0,086 durch die weitere Einführung von Methyl zur Bildung von Propionsäure. Der Einfluss ist kleiner, wenn der Wasserstoff des $\mathrm{CO} . \mathrm{OH}$ durch Aethyl ersetzt wird, die Differenz zwischen der Rotation des Ameisensäureäthers und der des Essigsäureäthers beträgt nur 0,125; die weitere Abnahme für Propionsäureäther nur 0,033. (Siehe Fig. 3).

Die molekulare Rotation des Oxalsäureäthers lässt erkennen, dass die Differenzen hier etwa zweimal so gross sind als bei den einbasischen Säuren. Zwischen Aethyloxalat und Aethylmalonat beobachtet man z. B. eine Abnahme der Reihen-Constante von 0,269, welche der doppelten, zwischen Aethylformiat und Aethylacetat stattfindenden $\mathrm{Ab}$ nahme entspricht, und zwischen Aethylmalonat und Aethylsuccinat ist eine weitere Abnahme von 0,053, die ein wenig kleiner ist, als die doppelte Differenz zwischen Aethylacetat und Aethylpropionat.

Der Einfluss des Carboxyls ist sehr merkwürdig, da er dem der Halogene und des Hydroxyls, welche die Reihen- 
d. Verbind. im Verbälț. zu deren chem. Constitut. ete. 601

Constante erhöhen, entgegengesetzt ist. Bei den Aethern der zweibasischen Säuren scheint diese Gruppe ihren Einfluss viel weiter hinauf geltend zu marhen, als bei den einbasischen Säuren, insofern die successive Einführung von Methyl, Aethyl oder anderer Alkyle in das Methylen des Malonsäureäthers oder in das Aethylen des Bernsteinsäureäthers die relative Rotation continuirlich herabdrückt. Dies ist in Fig. 7 (Taf. VI) graphisch dargestellt, woraus man erkennt, dass die Einführung von Methyl in Succinsäureäther zur Bildung des Brenzweinsäureäthers die Reihen-Constante oder die relative Rotation um 0,056 verringert.

Dieser eigenthümlichen Eigenschaft des Carboxyls, die Rotation der Alkyle, besonders der mit demselben in unmittelbarer Verbindung stehenden, herabzudrücken, ist wahrscheinlich die niedrige Rotation der Isobuttersäure und ihrer Derivate zuzuschreiben.

\section{Einfluss des Ersatzes von Wasserstoff durch Hydroxyl.}

Die Alkohole in ihrem Verhältniss zu den Paraffinen kommen zuerst in Betracht; Heptan und Heptylalkohol, sowie Isopentan und Isoamylalkohol seien als Beispiele gewählt:

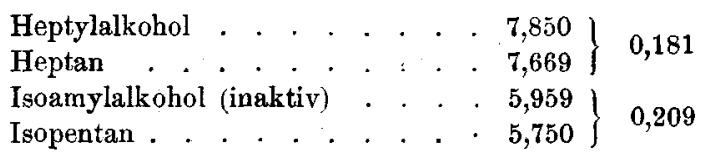

Für weitere Vergleiche müssen die berechneten Werthe der Paraffine benutzt werden:

Propylalkohol . . . . . . . . 3,768

Pentan (berechn.) . . . . . . . 3,377$\}$ 0,191

Das Mittel dieser drei Zahlen ist 0,194. Zwei weitere Beispiele bieten das Glycol und Glycerin dar:

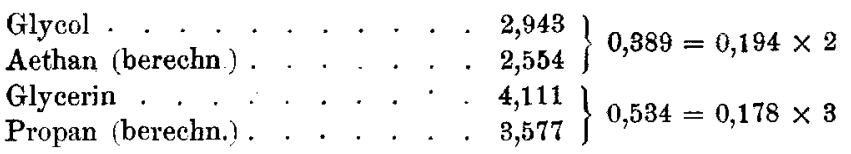

Diese Zahlen beweisen, das der Einfluss des Hydroxyls auf die molekulare Rotation mit der successiven Einführung 
desselben stetig abnimmt. Dies geht auch daraus hervor, dass durch Abziehen des Werthes für Aethylalkohol von dem für das Glycol nur 0,163 für den Einfluss des zweiten Hydroxyls resultirt, gegen 0,226 für das erste. Da aber der Aethylalkohol in seiner Rotation etwas abnorm ist, so muss noch ein anderer Vergleich angestellt werden. Wie erwähnt, beträgt die den Einfluss der Einführung des ersten Hydroxyls in die Paraffine ausdrückende Mittelzahl: 0,194. Wenn man diese Zahl von dem aus dem Vergleich des Propans mit dem Glycerin gewonnenen Werthe für drei Hydroxyle abzieht, so erhält man 0,340 für den Einfluss des zweiten und des dritten Hydroxyls.

Der Einfluss der Ersetzung des Wasserstoffs der Aldehyde durch Hydroxyl zur Bildung der Säuren wird aus dem folgenden Vergleiche ersichtlich:

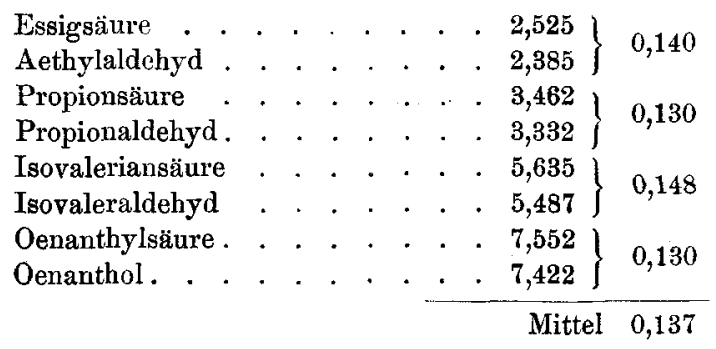

Man erkennt daraus, dass sowohl bei den Paraffinen wie bei den Aldehyden die Einführung eines Hydroxyls an der Stelle eines Wasserstoffatoms die molekulare Rotation erhöht. In dem letzteren Fall ist der Einfluss etwas kleiner als in dem ersten, ein Resultat, welches aller Wahrscheinlichkeit nach dem Vorhandensein von $\mathrm{CO}$ in der Verbindung zuzuschreiben ist. (Siehe Fig. 11, Taf. VII).

Einfluss des Sauerstoffs auf die magnetische Rotation der Verbindungen.

Der Einfluss des Ersatzes von 2 At. Wasserstoff durch 1 At. Sauerstoff kann durch den Vergleich eines Aldehydes mit einem Yaraffine erkannt werden:

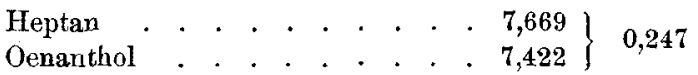


d. Verbind. im Verhältn. zu deren chem. Constitut. etc. 603

Hier zeigt sich eine bedeutende Verringerung, ein Resultat, welches anscheinend dem bei der Einführung des Sanerstoffs zur Bildung von Hydroxyl erhaltenen entgegengesetzt ist. Wir müssen aber den Werth der zwei weggenommenen Wasserstoffatome (s. w. u.) in Betracht ziehen; wir werden dann sehen, dass der zwei Wasserstoffatome an demselben Kohlenstoffatome ersetzende Sauerstoff fast den doppelten Einfluss ausübt, im Vergleich mit dem zugleich mit Kohlenstoff und Wasserstoff verbundenen At. Sauerstoff.

Ersatz des Wasserstoffs durch Acetyl.

Zwei Acetylderivate, der Acetessigäther und der Acetsuccinsäureäther, sind untersucht und mit den nicht-acetylirten Verbindungen verglichen worden:

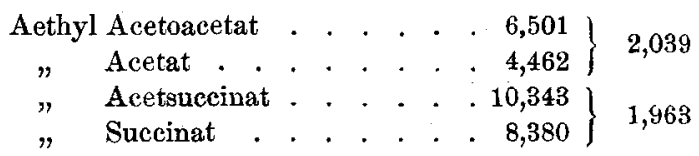

Dieser Zuwachs ist etwas geringer als einer Zunahme von $\mathrm{CH}_{2} \times 2=2,046$ entspricht, obwohl das Acetyl Methyl enthält, ein Resultat, das ohne Zweifel dem Vorhandensein von Carbonyl: $\mathrm{CO}$ in dem Acetyl zugeschrieben werden muss.

Man sieht, dass der Einfluss des Acetyls um 0,07 kleiner ist bei dem Acetosuccinat als bei dem Acetessigäther. Bis diese Körper eingehender untersucht worden sind, wäre es gewagt $\mathrm{zu}$ sagen, ob dieser Unterschied zufällig oder grösser ist, als er sein sollte. Das letzte wird für das wahrscheinlichste gehalten.

\section{Unges ät tigte Verbindungen.}

I. Gesättigte Verbindungen $-2 \mathrm{H}$.

Der einzige bis jetzt untersuchte Kohlenwasserstoff dieser Reihe ist das Amylen (Trimethyäthylen); die molekulare Rotation wurde $=6,121$ gefunden.

Wenn wir annehmen, dass die Rotation der normalen Olefine in demselben Grade von der der Paraffine abweicht, wie die des Allylalkohols von der Rotation des Propyl- 
604 Perkin: Ueber magnetische Circular-Polarisation

alkohols, so wird die des normalen Amylens 6,541 sein, Das Vorhandensein der Methyle würde also in diesem Falle die Rotation erniedrigen anstatt erhöhen. Dies wäre sehr merkwürdig; ehe jedoch andere Olefine untersucht worden sind, können wir keine sicheren Schlüsse daraus ziehen.

Die Differenz der magnetischen Rotation gesättigter und ungesättigter Verbindungen ergiebt sich aus den folgenden Beispielen:

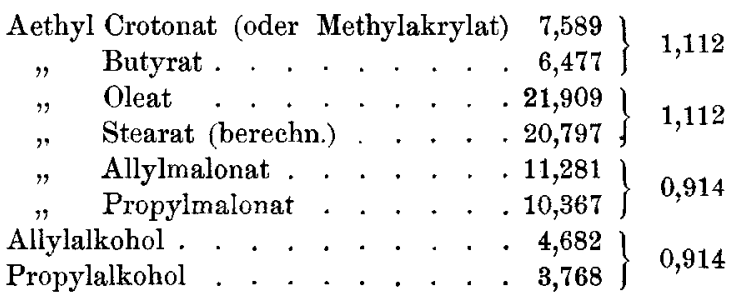

Diese Differenzen der Rotation lassen erkennen, ob ein Körper ein gesättigter wäre oder nicht. Man wird sehen, dass die einbasischen Säuren einen etwas grösseren Unterschied aufweisen, als der Allylalkohol und Allylmalonsäureäther. Die Halogen-Derivate sind weiter unten besprochen. (Siehe Fig. 6, Taf. VI).

II. Gesättigte Verbindungen $-4 \mathrm{H}$.

Ein Beispiel dieser Art ist untersucht worden, aber die Reinheit des verwendeten Präparats war nicht ganz sicher:

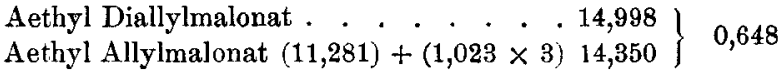

Es ist nicht zweifelhaft, dass Körper dieser Natur bedeutend grössere Rotationen besitzen als die der oben besprochenen Gruppe I.

Halogen enthaltende Verbindungen.

I. Chloride der normalen Alkyle.

Der Einfluss des Chlors besteht in der Erhöhung der magnetischen Rotation der dasselbe enthaltenden Körper.

Folgende normale Verbindungen sind untersucht worden: 
d. Verbind. im Verbältn. zu deren chem. Constitut. etc. 605

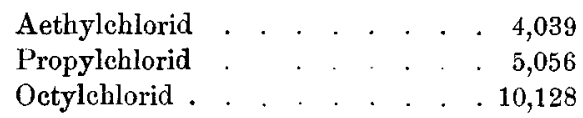

Das Aethylchlorid konnte wegen seiner niedrigen Siedetemperatur nicht so genau untersucht werden, wie zu wünschen gewesen wäre.

Die Rotatıon der Chloride ist circa 1,480 höher als die der entsprechenden Paraffine: die Reihen-Constante ist 1,988 gegen 0,508 für die Paraffine. (Siehe Fig. 10, Taf. VII).

II. Bromide der normalen Alkyle.

Diese Verbindungen haben stärkere Rotationen als die Chloride. Folgende $W$ erthe wurden erhalten:

Methylbromid . . . . . . . . . 4,644

Aethylbromid . . . . . . . . . 5,851

Propylbromid . . . . . . . . . 6,885

Octylbromid . . . . . . . . . 12,025

Neue Bestimmungen des Methylbromids sind wünschenswerth. Die Rotation dieser Reihe ist um 3,308 höher, als die der entsprechenden Paraffine: die Reihen-Constante beträgt 3,816. (Siehe Fig. 9, Taf. VII).

III. Jodide der normalen Alkyle.

Die Rotationen dieser Körper sind sehr gross:

Methyljodid . . . . . . 9,009

Aethyljodid . . . . . . . . . 10,075

Propyljodid . . . . . . . . . 11,080

Octyljodid . . . . . . . . . . 16,197

Die Reihen-Constante ist 8,011, also 7,503 höher als die der Paraffine. Man erkennt, dass die Rotation des Jodäthyls im Verhältniss ein wenig höher ist, als die des Jodpropyls. Obwohl die Differenz sehr gering ist, so scheint es doch, wenn man die andern Reihen in Betracht zieht, als wenn die Halogen-Derivate des Aethyls streng genommen der homologen Reihe nicht angehören. (Siehe Fig. 8, Taf. VII).

Einfluss des Ersatzes von Wasserstoff der HalogenDerivate normaler Alkyle durch Methyl.

Hier ist der Einfluss auf die magnetische Rotation dem der früher besprochenen Fälle ähnlich. Im Folgenden ist 
606 Perkin: Ueber magnetische Circular-Polarisation

ein Vergleich zwischen den normalen, Iso-, und secundären Verbindungen angestellt:

Chloride.

Isopropylchlorid . . . . . . . 5,159

Normales Propylchlorid . . . . 5,056$\} 0,103$

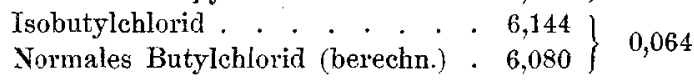

Isoamylchlorid . . . . . . . . 7,168 0,065

Normales Amylchlorid . . . . . 7,103 0,065

$\left.\begin{array}{lll}\text { Secundäres Octylchlorid . . . } & .10,248 \\ \text { Normales Octylchlorid (berechn.) } & .10,172\end{array}\right\} 0,076$

Reihen-Constante $=2,068$.

Mittel $\quad 0,077$

Bromide.

$\left.\begin{array}{llllll}\text { Isopropylbromid . . } & \cdot & \cdot & \cdot & 7,003 \\ \text { Nortmales Propylbromid } & . & \cdot & \cdot & . & 6,885\end{array}\right\} 0,118$

$\left.\begin{array}{llll}\text { Isobutylbromid . } \cdot \cdot \cdot \cdot \cdot \cdot \cdot \cdot & \cdot & 8,003 \\ \text { Normales Butylbromid (berechn.) } & . & 7,908\end{array}\right\} 0,095$

Isoamylbromid . . . . . . . $\cdot \begin{gathered}9,042 \\ 0,111\end{gathered}$

Reihen-Constante $=3,924$.

Mittel 0,108

\section{Jodide.}

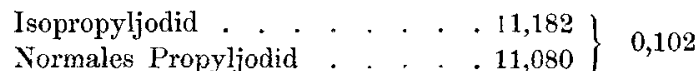

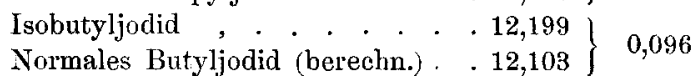

Isoamyljodid . . . . . . . . . 13,200 0,074

Normales Amyljodid (berechn.) . . 13,126 $\}$ 0,074

Reihen-Constante $=8,099$.

Mittel 0,088

In diesen Tabellen sind die Halogen-Derivate des Isopropyls mit aufgeführt. Dies ist der Bequemlichkeit wegen geschehen; doch scheint es zweifelhaft, ob sie eigentlich mit den anderen zusammen classificirt werden sollten, da sie das Radical $\mathrm{CH}_{2}$ nicht enthalten. Man sieht auch, dass die für sie erhaltenen Rotationen ein wenig grösser sind, als die für die anderen Isokörper gefundenen. (Siehe Fig. 8, 9, 10). 
d. Verbind. im Verhältn. zu deren chem. Constitut. ete. 607

Die weitere Einführung des Methyls ist nur in dem Falle der tertiären Chloride und Bromide des Trimethylcarbins untersucht worden. Diese aber verursacht, wie bei den Alkoholen, eine weitere Zunahme der Rotation:

Tertiäres Butylchlorid - Trimethyl-

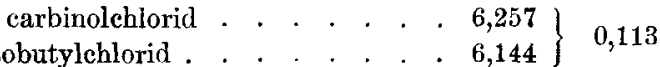

$\left.\begin{array}{llll}\text { Tertiäres Butylbromid . . . . } & 8,238 \\ \text { Isobutylbromid . . . } & 8,003\end{array}\right\} \quad 0,235$

(Siehe Fig. 9 und 10).

Bei den Alkoholen wurde bemerkt, dass der Propylalkohol sich in einer abnormen Weise verhielt, indem er weit höhere Differenzen der Rotation, als die erwarteten, ergab. Unter den Bromiden finden wir eine gleich grosse Anomalie bei dem Trimethylcarbinbromid. 'Bei der Betrachtung der für die vorhergehenden Halogenverbindungen erhaltenen Zahlen finden wir, dass die Iso- und secundären Chloride und Jodide nicht ganz so grosse Abweichungen von den normalen zeigen, wie in den schon besprochenen Fällen. Die Bromide aber geben Differenzen, welche grösser sind, als die der Chloride und Jodide, denen der anderen Verbindungen aber fast gleich kommen. (Vergl. Fig. 1, 2, $3,8,9,10$ ).

Einfluss des Ersatzes von Wasserstoff im Isopropylchlorid durch Aethyl.

Bei der Betrachtung des tertiären Amylalkohols (Dimethyläthylcarbinol) wurde erwähnt, dass die Rotation durch Einführung von Aethyl, statt erhöht zu werden, bis zu der eines secundären oder Iso-Alkohols herabgedrückt wird. Dasselbe findet man bei dem Dimethyläthylcarbinchlorid, dessen Rotation fast die nämliche ist wie die des Isoamylchlorids (Siehe Fig. 10):

$\left.\begin{array}{l}\text { Dimethyläthylcarbinylchlorid . . . } 7,782 \\ \text { Isoamylchlorid . . . . . . . . } 7,168\end{array}\right\} \quad 0,013$ 
608 Perkin: Ueber magnetische Circular-Polarisation

Chlor-, Brom- und Jod-Substitutionsderivate der Monocarbonverbindungen.

Chlormethyl, als Gas, konnte nicht untersucht werden:

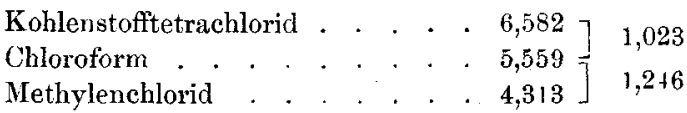

Aus diesen Werthen erkennt man, dass, mit Methylenchlorid anfangend, die successive Einführung des Chlors keine gleichartige Erhöhung der Rotation hervorruft, sondern dass diese Erhöhung zwischen Chloroform und Kohlenstofftetrachlorid kleiner wird.

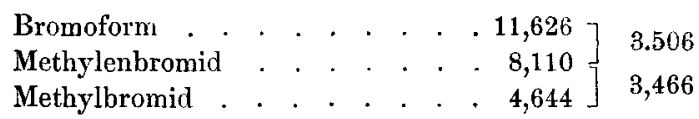

In diesem Falle ist nur eine sebr kleine Differenz des Ersetzungswerthes bemerkbar; das letzte Bromatom übt den grösseren Einfluss aus.

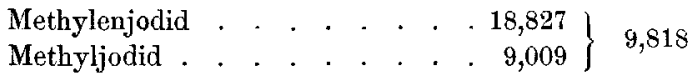

Der durch Eintritt des zweiten At. Jod geübte Einfluss ist grösser als die Rotation des Methyljodids selbst. Jod wirkt also wie das Brom, aber noch energischer. (Siehe Fig. 12, 13, 14, Taf. VIT).

Einfluss der Einführung von Methyl in die Monocarbonhalogenverbindungen.

Wir haben hier die folgenden Beispiele zum Vergleiche:

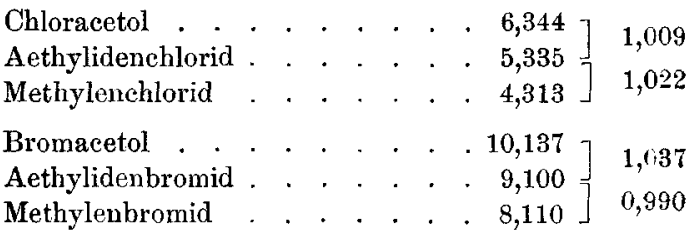

(Siehe Fig. 4, Taf. VI).

Hier erhalten wir ein sehr merkwürdiges Resultat, Das Methyl übt nur den nämlichen Einfluss aus, wie die Zunahme von $\mathrm{CH}_{2}$ in den homologen Reihen. Dies ist jedoch nur bei solchen Derivaten der Monocarbonverbindungen der Fall, 
d. Verbind. im Verbältn. zu deren chem. Constitut. etc. 609

in denen die zwei Halogenatome mit demselben Kohlenstoffatom verbunden sind. Der einzige andere Fall dieser Art, der untersucht wurde, ist folgender:

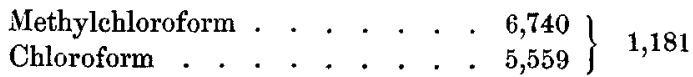

Nach Abzug der für die Zusammensetzungs-Differenz gewöhnlichen Zunahme von 1,023 erhalten wir den Werth 0,158 für den besonderen Einfluss in diesem Falle, was etwas mehr, als der bei den Isoverbindungen gefundene, ist. (Siehe Fig. 5).

Ohlor- und Brom-Substitutions-Derivate der Dicarbonverbindungen.

Die folgenden Körper sind untersucht worden:

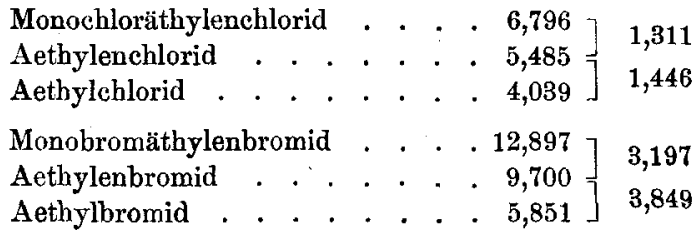

Wir finden hier, dass durch den successiven Eintritt der Halogene die Differenzen abnehmen. Die Abnahme ist viel grösser bei den Brom-als bei den Chlor-Verbindungen. (Siehe Fig, 12 und 13).

Methyl-Derivate des Aethylenbromids.

Die folgenden Körper sind untersucht worden:

Trimethyläthylenbromid - Isoamylenbromid 12,947 ] 1,057

Dimethyläthylenbromid - Isobutylenbromid 11,890

Monomethyläthylenbromid-Propylenbromid 10,820

Aethylenbromid

1,070

Nach Abzug des Werthes 1,023 erhielten wir die besondere, durch jedes Methyl hervorgerufene Zunahme:

$$
\begin{aligned}
& 1,057-1,023=0,034 \\
& 1,070-1,023=0,047 \\
& 1,120-1,023=0,097
\end{aligned}
$$

Wir haben hier wieder ein Beispiel dafür, dass durch den successiven Ersatz der Einfluss des eingeführten Radicals vermindert wird. (Siehe die graphische Darstellung Fig. 4). 
610 Perkin: Ueber magnetische Circular-Polarisation

Chlor- und Brom-Derivate der Tricarbonverbindungen.

Folgende Verbindungen sind untersucht und verglichen worden:

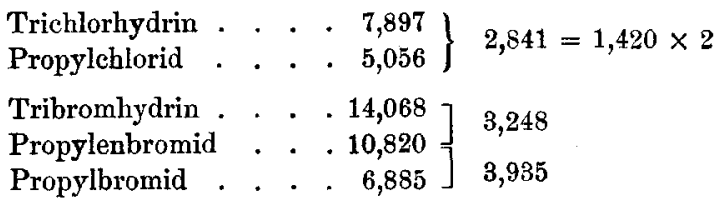

Trimethylenbromid giebt eine um 0,479 niedrigere $R_{0}-$ tation als Propylenbromid: nämlich 10,341. Diese Differenz, welche wahrscheinlich partiell von dem Vorhandensein eines Methyls im Propylenbromid herrührt, ist auffallend gross und noch nicht zu erklären. (Siehe Fig. 12 und 13).

Einfluss der Vertheilung der Halogene in der Verbindung.

Der folgende Vergleich der Trichlor- und TribromVerbindungen wurde angestellt, weil die Vertheilung der Halogenatome sich mit jeder Zunahme des Kohlenstoffs ändert. (Siehe Fig. 5).

Chloroform . . . . 5,559 $\mathrm{CH}_{2}$.

$\left.\begin{array}{lll}\text { Chlorathylenchlorid } & . & 6,796 \\ \text { Trichlorhydrin . . . . } & \mathbf{7 , 8 9 7}\end{array}\right] \begin{aligned} & 1,237-1,023=0,214 \\ & 1,101-1,023=0,078\end{aligned}$

Bromoform . . . . 11,626] $1,271-1,023=0,248$

Bromäthylenbromid . . 12,897 $] 1,171,068$ 1,171-1,023 $=0,148$

Man lernt daraus, dass durch Aenderung der Vertheilung der Halogene ein grösserer Einfluss auf die Rotation ausgeübt wird, als durch Aenderung der Zusammensetzung allein, und dass die Rotation sich vergrössert, je mehr die Halogene vertheilt werden.

Einfluss der Vereinigung des Vinylbromids mit Chlor.

Vinylbromid und sein Methylderivat, Brompropylen, haben für ungesättigte Körper sehr niedrige Rotationen. Das erste aber wird, wenn mit Chlor vereinigt, eine gesättigte Verbindung, und die Zunahme der Rotation ist grösser als die durch die Addition des Chlors gewöhnlich verursachte. 
d. Verbind. im Verhältn. zu deren chem. Constitut. etc. 611

\section{Ungesättigte Halogen-Derivate.}

Die Vinyl- und die Allylreihe, welche untersucht worden sind, zeigen merkwürdige Differenzen in ihren molekularen Rotationen.

I. Vinyl-Reihe.

\begin{tabular}{|c|c|c|}
\hline $\begin{array}{l}\text { Vinylbromid, } \mathrm{CH}_{2}: \mathrm{CHBr} . . \\
\text { Aethylbromid . . . . . . }\end{array}$ & $\left.\begin{array}{l}6,220 \\
5,851\end{array}\right\}$ & 0,369 \\
\hline $\begin{array}{l}\text { Bromopropylen oder Methylvinyl } \\
\text { bromid, } \mathrm{CH}_{3} . \mathrm{CH}: \mathrm{CHBr}\end{array}$ & 7,295 & \\
\hline Propylbromid . . . . . . & 6,885 & 0,410 \\
\hline
\end{tabular}

II. Allyl-Reihe.

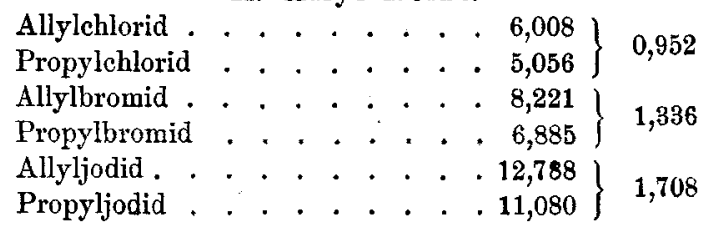

Hier erhalten wir das höchst eigenthümliche Resultat, dass die Bromide des Vinyls und des Methylvinyls Rotationen geben, die von denen der normalen Reihen nur um 0,390 abweichen, während das Allylbromid eine fast $3^{1} / 2$ mal so grosse Abweichung zeigt, nämlick 1,336.

Man bemerkt, dass die zwischen den Halogenverbindungen der normalen und der ungesättigten Körper bestehe. den Differenzen nicht wie in den anderen Reihen die nämlichen für alle Halogene sind, vielmehr wachsen sie mit dem Atomgewicht der Halogene. (Siehe Fig. 6, untere Hälfte).

Bemerkungen über Aethyl-Malonat und seine

Derivate sowie über Aethyl-Acetoacetat.

Einige dieser Derivate wurden schon erwähnt, folgende sind noch nicht besprochen worden:

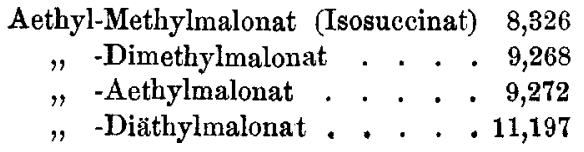

Unter diesen Körpern geben das Aethyl-Aethylmalonat und das Aethyl-Dimethylmalonat fast die nämliche Rotation. 
Dies ist analog dem, was wir schon bei den Fettsäuren gefunden haben, insofern Dimethylessigsäure (Isobuttersäure) und Aethylessigsäure (Buttersäure) gleiche Rotationen ergeben. Man erwartete, dass Aethylmalonsäureäther das erste, und Propylmalonsäureäther das zweite Glied einer homologen Reibe bilden werden. Der letztere zeigt aber eine Rotation, welche im Verhältniss 0,072 höher ist als die des Propylderivats. Die Rotation des Diäthylmalonsäureäthers ist bedeutend niedriger, als die des Monäthylmalonsäureäthers (natürlich mit Berücksichtigung des Unterschieds der Zusammensetzung). Ob dies der reducirenden Wirkung der zwei Carboxyle zuzuschreiben ist, lässt sich vorläufig nicht sagen. Rotationen, die denen der homologen Reihen entsprechen, sind bis jetzt für Derivate des Malonsäureäthers nicht gefunden worden.

Vergleichende Betrachtungen des Acetessigäthers und seiner Derivate werden von Interesse sein, da man erwarten darf, dass seine Derivate sich ähnlich wie die des Malonsäureäthers verhalten werden. Die Rotation des Allylacetessigäthers z. B. weicht von der des Acetessigäthers in fast gleichem Maasse ab, wie die des Allylmalonsäureäthers von der des Malonsäureäthers:

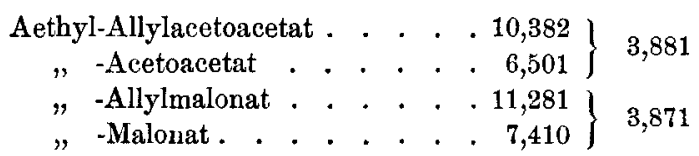

Nach Abzug von $1,023 \times 3$ von diesen Zahlen (um die Aenderung der Zusammensetzung zu berücksichtigen) erhält man 0,812 und 0,802 , eine kleinere Differenz als die gewöhnliche zwischen gesättigten und ungesättigten Verbindungen oder zwischen Propyl- und Allyl-Malonsäureäther. Diese Aehnlichkeit zwischen diesen Allyl-Derivaten macht es wahrscheinlich, dass Propylacetessigäther in derselben Weise von Acetessigäther abweichen werde, wie Propylmalonsäureäther von Malonsäureäther, und dass der Acetessigäther in der That Derivate gaben wird, die sich, in Bezug auf ihre Rotation, in derselben Weise verhalten wie die Derivate des Malonsäureäthers. 
Bemerkungen über die Succinsäurereihe.

Nach der Untersuchung der Aether dieser Reihe scheint die Succinsäure das erste Glied der homologen Reihe zu sein, obwohl die Glutarsäure, wie schon bemerkt, das erste Glied sein sollte, da sie ein mit Carboxyl nicht verbundenes Methylen $\mathrm{CH}_{3}$ enthält. Leider habe ich diese Säure nicht untersuchen können. Ich glaube, dass sie diese Stelle doch einnimmt, dass aber die Reihen-Constanten derselben und der Succinsäure sehr nahe zusammen liegen. In der That ist die Reihen-Constante des Succinsäureäthers ein wenig grösser als die des Korksäure- und des Sebacinsäureäthers. In der Figur habe ich sie gleich angenommen, da die Differenz nur sehr klein ist. (Siehe Fig. 7).

\section{Derivate des Aethylen- und Aethyliden-Glycols.}

Folgende Verbindungen sind untersucht worden:

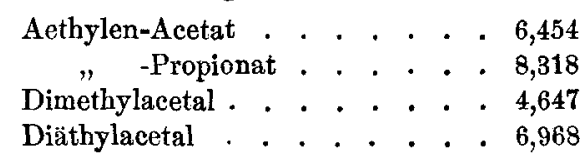

Leider sind bis jetzt keine anderen Verbindungen untersucht worden, mit denen obige Resultate verglichen werden können. Die erhaltenen Zahlen scheinen ontereinander zu harmoniren. Mindestens ist dies so wenn man aus den folgenden ungefähren Vergleichen schliessen darf.

$$
\left.\begin{array}{llllll}
\text { Aethylen-Acetat . . . . . . . . . } & 6,454 \\
\text { Glycol . . . . . . . . . } & 2,943
\end{array}\right\} 3,511
$$

Diese Differenz zeigt den Einfluss an, der durch den Ersatz zweier Hydroxyl-Wasserstoffatome durch Acetyl bervorgerufen wird. Der Einfluss einer einmaligen Substitution beträgt demnach 1,755 .

$\left.\begin{array}{l}\text { Propyl-Acetat . . . . . . . . . . } 5, \mathbf{5 8 7} \\ \text { Propylalkohol . . . . . . . . } 3,768\end{array}\right\}$

Die Differenz weicht von der obigen nicht sehr ab.

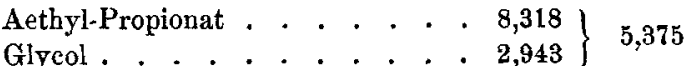

Die Differenz veranschaulicht den Einfluss, der durch den Ersatz zweier Hydroxyl-Wasserstoffatome durch Propionyl verursacht wird, also 2,687 für eine Substitntion. 
614 Perkin: Ueber magnetische Circular-Polarisation

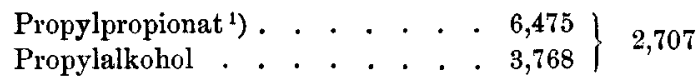

Diese Differenz stimmt mit der obigen sehr nahe überein. Mit den Acetalen oder Aethern (Oxyden) des AethylidenGlycols können ebenfalls ungefähre Vergleiche angestellt werden. Es ist schon bemerkt worden, dass, wenn eine Säure in ihren Methyläther, resp. Aethyläther übergeführt wird, die Reihen-Constante um 0,108, resp. 0,056 herabsinkt. Die relative Differenz zwischen Aethylalkohol und Aethyläther beträgt 0,049 ; es ist offenbar passend, diese Zahl beim Vergleich zwischen einem Alkohol und einem Oxyd zu verwenden: bei der Methylverbindung aber kann man nur von der obigen Zahl Gebrauch machen. Um dann den Werth des Aethylidenglycols zu finden, muss man von der Rotation seines Aethers die der Differenz der Zusammensetzung entsprechende Zahl abziehen, und dann $z u$ dem Resultat eine der obigen Zablen zweimal hinzu addiren, um die Rotation eines Aethers in die eines Alkohols überzuführen:

$$
\begin{aligned}
& \text { Methylacetal , . } \mathbf{4 , 6 4 7} \\
& \mathrm{CH}_{2} \times 2=1,023 \times 2 \frac{2,046}{2,601} \\
& 0,108 \times 2 \cdot \cdot \cdot \frac{0,216}{2,817} \text { Aethylidenglycol? } \\
& \text { Aethylacetal . . . 6,968 } \\
& \mathrm{CH}_{2} \times 4=1,023 \times 4 \frac{4,092}{2,876} \\
& 0,049 \times 2 . \cdot \cdot \frac{0,098}{2,974} \text { Aethylidenglycol? }
\end{aligned}
$$

Die letzte Zahl kommt der des Glycols sehr nahe: wenn aber ein Unterschied zwischen dem Aethylen- und dem A ethylidenglycol besteht ähnlich dem zwischen dem Aethylenund den Aethylidenchlorid gefundenen, so ist doch die erste Zahl beinahe richtig.

$$
\text { Paraldehyd. }
$$

Diese Verbindung darf als ein Oxyd des Aethylidens angesehen werden:

1) Mit den kürzlich gemachten neuen Bestimmungen des PropylPropionats gestaltet sich dieser Vergleich wie folgt:

$\left.\begin{array}{l}\text { Propyl-Propionat . . . . . . . . } 6,429 \\ \text { Propylalkohol . . . . . . . . } 3,768\end{array}\right\} \mathbf{2 , 6 6 1}$ 
d. Verbind. im Verhältn. zu deren chem. Constitut. etc. 615<smiles>C[C@H]1O[C@@H](C)O[C@@H](C)O1</smiles>

Seine molekulare Rotation beträgt 6,662. Bis jetzt sind keine Substanzen untersucht worden, mit denen dieser Körper sich vergleichen lässt.

Magnetisches Drehungsvermögen gebundener Elemente.

Wenn man den Werth 1,023, welcher der magnetischen Rotation der mit anderen Radicalen in Verbindung stehenden $\mathrm{CH}_{2}$-Gruppe entspricht, so oft von der Rotation eines Paraffins abzieht, als dieses Kohlenstoffatome enthält, so erhält man einen Rest, welcher den Werth für $2 \mathrm{H}$ vorstellt:

$$
\begin{aligned}
& \text { Heptan . . . . . . . . . . } 7,669 \\
& \mathrm{CH}_{2} \times 7=1,023 \times 7 \cdot \cdot \cdot \frac{7,161}{0,508}=2 \mathrm{H} \text { oder } \\
& 0.254=\mathrm{H}
\end{aligned}
$$

Halbirt man ferner den Werth eines, eine gerade Zahl Kohlenstoffatome enthaltenden Paraffins, so sollte das Produkt dem Werth eines Alkyls entsprechen: z. B. Hexan $=6,646 \div 2=3,323$, welche Zahl den Werth des Propyls dargestellt. Wenn diese Zahl von der Rotation des entsprechenden Paraffins abgezogen wird, so erhält man wiederum $\mathrm{H}=0,254$.

Ziehen wir endlich von dem Werthe für $\mathrm{CH}_{2}$ den für 2 H $\mathrm{ab}$, so resultirt 0,515 als Werth für $1 \mathrm{At}$. C.

Mittelst dieser Werthe erhalten wir folgende Werthe für die Halogene:

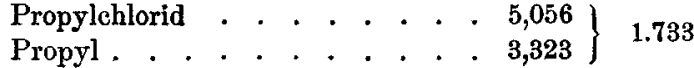

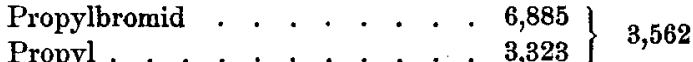

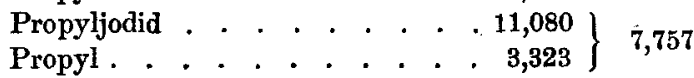

Der Einfluss des Ersatzes von Wasserstoff durch $\mathrm{Hy}$ droxyl in den Paratfinen ist schon besprochen worden; wie schon erwähnt, ist in diesem Falle der Werth für Sauerstoff gleich 0,194 , bei dem Hydroxyl der Säuren beträgt er 0,137 . 
616 Perkin: Ueber magnetische Oircular-Polarisation

Wenn aber der Sauerstoff zwei Atome Wasserstoff in einer Kohlenstoffverbindung ersetzt und dabei Carbonyl bildet, so wird die Rotation der Verbindung um 0,247 vermindert; daraus folgt, dass der Werth dieses Sauerstoffs viel geringer ist als der von $2 \mathrm{H}$, nämlich 0,261 unter diesen Bedingungen beträgt. Dies Resultat stimmt mit den Beobachtungen über das Brechungsvermögen der Körper überein, da der in dieser Weise verbundene Sauerstoff, sowie auch der in ungesättigten Verbindungen enthaltene Kohlenstoff hier besondere Werthe besitzen.

Diese Werthe lassen sich gut verwerthen, so lange sie für die Reihe, aus der man sie abgeleitet hat, benutzt werden; werden sie aber bei anderen homologen Reihen angewendet, so geben sie nur annähernd stimmende Resultate.

Hydroxyl-Sauerstoff ergiebt den Werth von 0,194 für Alkohole, und 0,137 für Säuren. Bei den Halogenverbindungen ändert sich die Rotation, wie schon erwähnt, einmal mit der successiven Substitution (wie im Kohlenstofftetrachlorid), sodann mit der verschiedenen Zahl der im Molekül enthaltenen Kohlenstoffatomen, mit der Art der Vertheilung der Halogene u. s. w.; und dieser Wechsel des Werthes nimmt zu, je grösser das Atomgewicht des Elementes wird.

Das Variiren der magnetischen Rotation der Verbindungen ist offenbar sowohl den Unterschieden der molekularen Anordnung der Elemente wie der ZusammensetzungsDifferenz zuzuschreiben. Dies ist ein besonders wichtiges Ergebniss dieser Arbeit; da keine andere, bis jetzt untersuchte physikalische Eigenschaft der Körper eine derartige Abhängigkeit in so deutlicher Weise- aufweist. Man darf annehmen, dass die Bestimmung der magnetischen Rotation der Verbindungen dem Chemiker von grossem Werthe sein werde, indem sie zu Schlüssen über die Constitution und Zusammensetzung der $\mathrm{zu}$ untersuchenden Körper führen wird.

In der folgenden Tabelle sind die Formeln angegeben, mittelst deren die magnetische Rotation der 26 Reihen angehörenden Körper berechnet werden können, und zwar in den meisten Fällen mit grosser Genauigkeit. Der Fehler, welcher in einer, nur aus einem Beispiel abgeleiteten Reihen-Constante 
d. Verbind. im Verhältn. zu deren chem. Constitut. etc. 617 vorhanden sein mag, wird wahrscheinlich $0,01-0,03$ nicht übersteigen.

Formeln für die Berechnung der magnetischen Rotation der den verschiedenen Reihen angehörenden Körper.

\begin{tabular}{|c|c|c|c|}
\hline & $\begin{array}{l}\text { Zusammen- } \\
\text { setzung }\end{array}$ & $\begin{array}{l}\text { Reihen } \\
\text { Const }\end{array}$ & $\begin{array}{l}\text { Werth } \\
\text { fürn } \mathrm{CH}_{2}\end{array}$ \\
\hline Paraffine . . . . . . . . . . . & $\mathrm{C}_{\mathrm{n}} \mathrm{H}_{2 \mathrm{n}+2}$ & \multicolumn{2}{|c|}{$0,508+\mathbf{n}(1,023)$} \\
\hline Isoparaffine . . . . . . . . . . . & & 0,621 & $n$ \\
\hline Alkohole . . . . . . . . . . . & $\mathrm{C}_{\mathrm{n}} \mathrm{H}_{2 \mathrm{n}+2} \mathrm{O}$ & 0,699 & $"$ \\
\hline Iso- und secund. Alkohole,$\cdot \cdot$. & " & 0,844 & $"$ \\
\hline Oxyde . . . . . . . . . . . . & 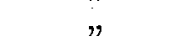 & 0,642 & $"$ \\
\hline Iso-Oxyde & $"$ & 0,932 & $\eta$ \\
\hline Aldehyde . . . . . . . . . . . & $\mathrm{C}_{\mathrm{n}} \mathrm{H}_{2 \mathrm{n}} \mathrm{O}$ & 0,261 & $"$ \\
\hline Iso-Aldehyde und Ketone. . . . . & & 0,375 & " \\
\hline Fettsäuren . . . . . . . . . . & $\mathrm{C}_{\mathrm{n}} \mathrm{H}_{2 \mathrm{n}} \mathrm{O}_{2}$ & 0,393 & $"$ \\
\hline Iso-Fettsäuren . . . . . . . . . & $"$ & 0,509 & $"$ \\
\hline Aether d.Ameisens. (Aethyl- u. höhere) & $"$ & 0,495 & 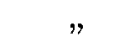 \\
\hline$"$ "Essigsäure ( $", \quad ")$ & $"$ & 0,370 & $"$ \\
\hline$" \quad, \quad, \quad$ (mit Iso-Alkylen) & $"$ & 0,485 & $\eta$ \\
\hline Methyläther aer Fettsäuren . . . & $"$ & 0,273 & , \\
\hline Aether d.Fettsäuren (Aethyl- u. höhere) & 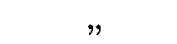 & 0,337 & $"$ \\
\hline Isoätherd.Fettsäuren (Aethyl-u.höhere) & & 0,449 & $"$ \\
\hline Methyläther der Succinsäure-Reihe . & $\mathrm{U}_{\mathrm{n}} \mathrm{H}_{2 \mathrm{n}-2} \mathrm{O}_{4}$ & 0,093 & " \\
\hline Aethyläther $" \quad, \quad "$ & " & 0,196 & $"$ \\
\hline Isoäther der Succinsäure-Reihe . & & 0,422 & $"$ \\
\hline Chloride . . . . . . . . . & $\mathrm{C}_{\mathbf{n}} \mathrm{H}_{2 n+1} \mathrm{Cl}$ & 1,988 & $"$ \\
\hline Iso- und secund. Chloride. & & 2,068 & $"$ \\
\hline Bromide . . . . . . . & $\mathrm{C}_{n} \mathrm{H}_{2 n+1} \mathrm{Br}$ & 3,816 & $"$ \\
\hline Iso- und secund. Bromide. & & 3,924 & $"$ \\
\hline Jodide . . . . . . . . & $\mathrm{C}_{\mathrm{n}} \mathrm{H}_{2 \mathrm{n}+1} \mathrm{~J}$ & 8,011 & $"$ \\
\hline Iso- und secund. Jodide . . . . & $"$ & 8,099 & $n$ \\
\hline Aethyläther $d$. unges. einbasisch. Säuren & $\mathrm{C}_{\mathrm{n}} \mathrm{H}_{2 \mathrm{n}-2} \mathrm{O}_{2}$ & 1,451 & $\eta$ \\
\hline
\end{tabular}

Manche andere Punkte giebt es noch, welche hier besprochen werden könnten, - z. B. die Differenz der Rotation zwischen gesättigten und ungesättigten Verbindungen etc. Bei dem jetzigen Stand der Untersuchung ist es jedoch zweckmässig, die bezüglichen Resultate so, wie sie in dieser $\mathrm{Ab}$ handlung mitgetheilt sind, zu lassen. Mehrere Reihen von Verbindungen, welche auch andere als die in dieser Mittheilung besprochenen Elemente enthalten, müssen noch unter- 
618 Perkin: Ueber magnetische Circular-Polarisation sucht werden. Für die Untersuchung mancher Reihen wie z. B. der Nitrate, der Nitrite, der Nitroverbindungen, so wie dar aromatischen Körper - habe ich schon die nöthigen Einrichtungen getroffen. Die Prüfung der physikalischen Isomeren habe ich ebenfalls begonnen.

Eine Tabelle der bisher untersuchten Körper nebst ihrer molekularen Rotation ist beigegeben.

Ich kann diese Abhandlung nicht schliessen, ohne meinem Assistenten, Dr. L. T. Thorne, für das Interesse, welches er dieser Arbeit gewidmet, für die Vorschläge, die er gemacht, sowie die Ausdauer und Sorgfalt, mit denen er mir bei deren Ausführung beigestanden hat, meinen besten Dank auszusprechen.

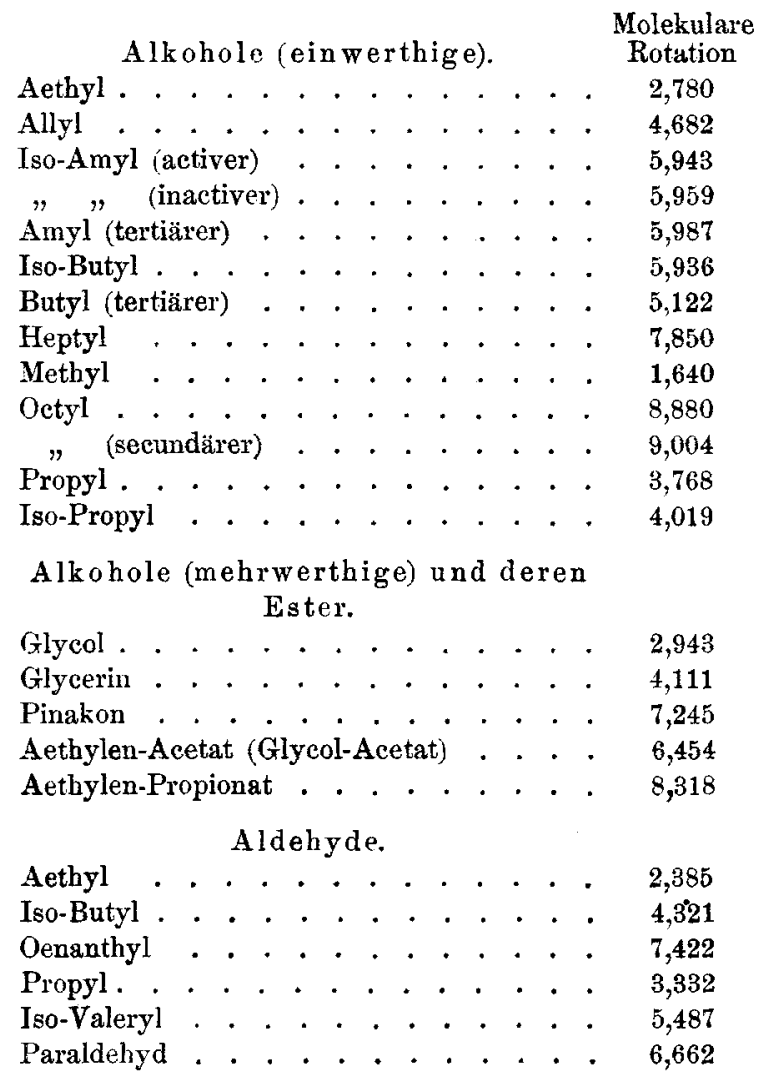


d. Verbind. im Verhältn. zu deren chem. Constitut. etc. 619

Molekulare

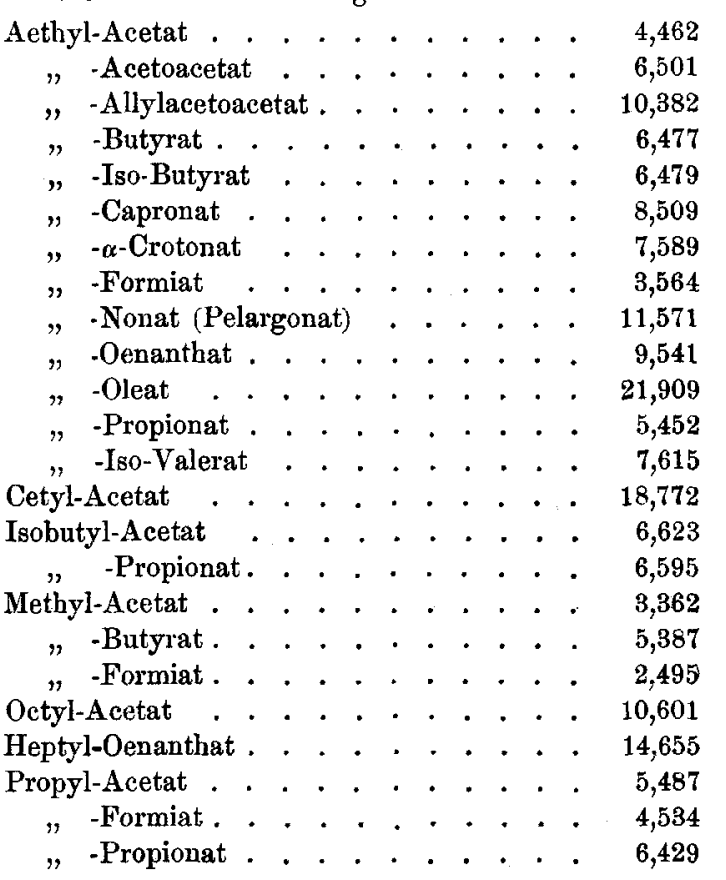

Aether der zweibasischen Säuren.

Aethyl-Acetosuccinat . . . . . . . 10,343

-Aethylmalonat . . . . . . . . 9,272

-Allylmalonat . . . . . . . . . 11,281

-Diäthylmalonat . . . . . . . . 11,197

-Diallylmalonat . . . . . . . . 14,998

-Dimethylmalonat . . . . . . . 9,268

-Isopropylmalonat . . . . . . . 10,482

-Malonat . . . . . . . . . . . 7,410

-Methylmalonat (Isosuccinat) . . . 8,326

-Methylsuccinat (Pyrotartrat) . . . 9,347

-Oxalat . . . . . . . . . 6,654

-Propylmalonat . . . . . . . . 10,367

-Sebat . . . . . . . . . 14,496

-Suberat . . . . . . . . . . . 12,461

-Succinat . . . . . . . . . . 8,380

Isobutyl-Succinat . . . . . . . . . . 12,707

Methyl-Malonat . . . . . . . . . . 5,280

$"$-Succinat . . . . . . . . . . 6,232 
620 Perkin: Ueber magnetische Circular-Polarisation

Aceton . . . . . . . . . . 3,514

Methyl-Propylketon . . . . . . . . . 5,499

Olefin.

Amylen . . . . . . . . . . . . . 6,121

Oxyde (Aether).

Aethyläther . . . . . . . . . . . . 4,777

Iso-Amyläther . . . . . . . . . . . 11,168

Diäthylacetal . . . . . . . . . . . $\quad 6,968$

Dimethylacetal . . . . . . . . . . . 4,647

Paraffine.

Diisopropyl . . . . . . . . . 6,784?

Heptan . . . . . . . . . . . . . 7,669

Hexan . . . . . . . . . . . . . . 6,670

Iso-Hexan . . . . . . . . . . . . $\quad 6,769$

Pentan . . . . . . . . . . . . . 5,638

Iso-Pentan . . . . . . . . . . . . 5,750

Säuren.

Ameisensäure . . . . . . . . . . . 1,671

Buttersäure . . . . . . . . . . . . 4,472

Iso-Buttersäure . . . . . . . . . . $\quad 4,479$

Caprylsäure . . . . . . . . . . . . 8,565

Essigsäure . . . . . . . . . . . . 2,525

Nonylsäure (Pelargonsäure) . . . . . . 9,590

Oenanthylsäure . . . . . . . . . . 7,552

Propionsäure. . . . . . . . . . . . 3,462

Valeriansäure . . . . . . . . . . . . $5,5,513$

Iso-Valeriansäure . . . . . . . . . . 5,685

Halogen-Verbindungen.

Aethyl . . . . . . . . . . . . . . 5,851

Allyl . . . . . . . . . . . . . . 8,221

Iso-Amyl . . . . . . . . . . . . . 9,042

Iso-Butyl . . . . . . . . . . . . . 8,003

Tertiäres Butyl . . . . . . . . . . 8,238

Methyl . . . . . . . . . . . . . 4,644

Octyl . . . . . . . . . . . . . . 12,025

Propyl . . . . . . . . . . . . . . 6,885

Iso-Propyl . . . . . . . . . . . . 7,003

Brompropylen $\mathrm{CH}_{3} . \mathrm{CH}: \mathrm{CHBr}$. . . . 7,295

Vinyl . . . . . . . . . . . . . . $6,2 £ 0$

Dibromide.

Aethylen . . . . . . . . . . . . . 9,700

Aethyliden . . . . . . . . . . . . 9,100

Iso-Amylen . . . . . . . . . . . . 12,947 
d. Verbind im Verhältn. zu deren chem. Constitut. etc. 621

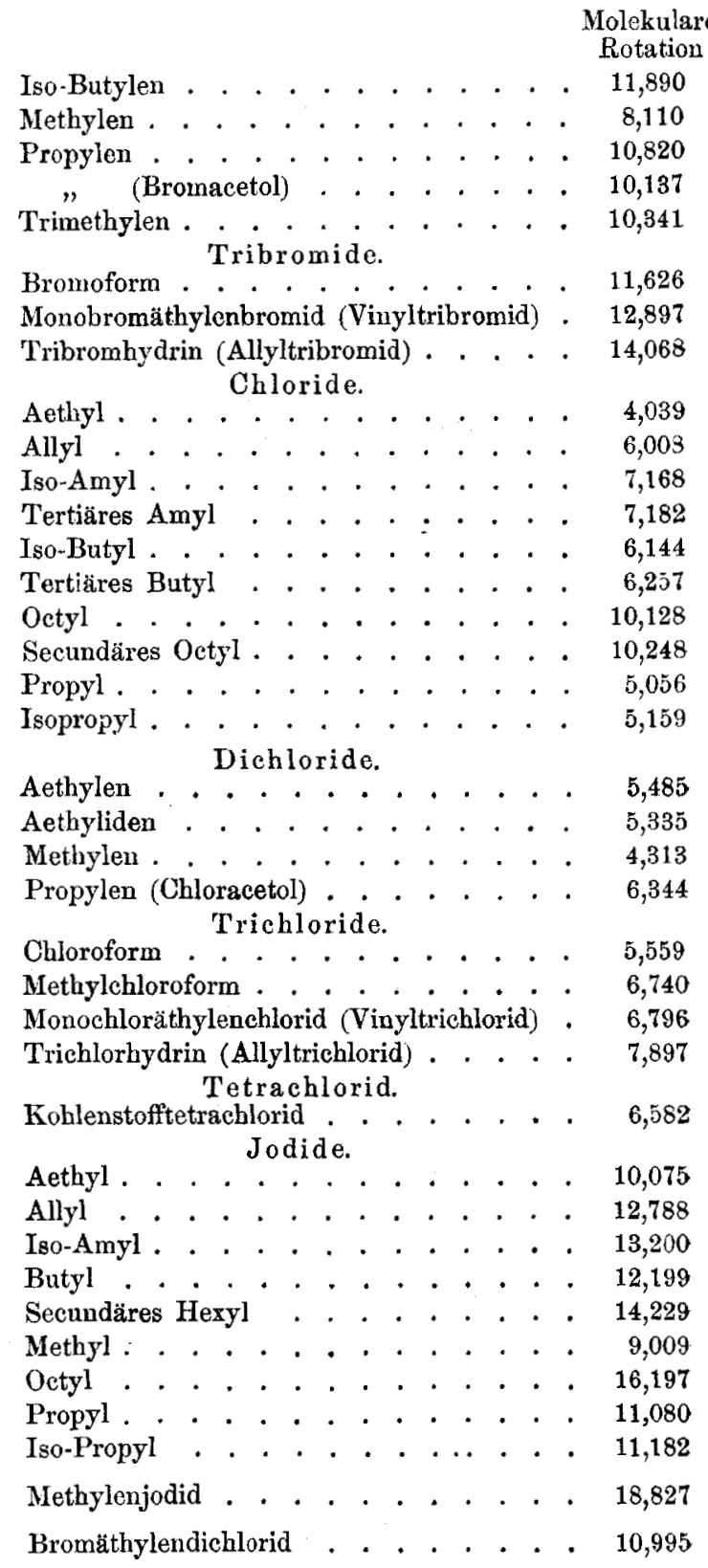


622 Elbs u. Tölle: Zur Kenntniss d. Triphenylessigsäure.

Cetyl-Acetat. - Krafft hat kürzlich nachgewiesen ${ }^{1}$ ), dass der gewöhnliche Cetylalkohol Octadecylalkohol enthält. Auch meine Beobachtungen zeigen, dass er kein einheitlicher Körper ist. Das zuerst untersuchte Präparat war durch Einwirkung von Essigsäureanhydrid auf den gewöhnlichen, von Kahlbaum bezogenen Cetylalkohol dargestellt, und wurde nicht fractionirt. Dasselbe besass eine höhere Dichte und eine kleinere magnetische Rotation, als die Substanz, mit der die S. 543 angegebenen Zahlen erhalten wurden. Bei dem, unter vermindertem Drucke vorgenommenen Fractioniren, siedete nur circa ein Drittel des Produkts zwischen den angegebenen Grenzen, und die Siedetemperatur stieg nach, und nach aber sehr langsam. Da die Fractionirung sehr sorgfältig ausgefürt wurde, so darf man wohl annehmen, dass das zuletzt untersuchte Präparat nahezu rein gewesen ist.

Sudbury bei Harrow (England).

\section{Zur Kenntniss der Triphenylessigsäure: \\ von}

\section{K. Elbs und E. Tölle.}

Die Triphenylessigsäure wurde im Jahre 1878 von E. und $\mathrm{O}$. Fischer dargestellt. ${ }^{2}$ ) Als Ausgangsmaterial diente das aus Triphenylmethan durch Oxydation gewonnene Carbinol, welches mit Phosphorpentachlorid in Triphenylmethylchlorid verwandelt und durch Erbitzen mit Quecksilbercyanid in Triphenylacetonitril übergeführt wurde. Die Verseifung desselben mit rauchender Salzsäure unter Druck lieferte die Säure. Die Umständlichkeit der Gewinnung und die geringe Ausbeute waren wohl der Grund, weshalb eine eingehende Untersuchung des interessanten Körpers bisher unterblieb. Als der eine von uns $^{3}$ ) eine bequemere Darstellung des Triphenylacetonitrils aus Triphenylmethylbromid und Cyankalium fand, war damit eine kleine Verbesserung, aber kein grosser Vortheil erreicht; denn einmal geht die Verseifung unter allen Umständen nụ schwierig und unvollständig vor

1) Ber. Berl. chem. Ges. 17, 1627.

2) Ann. Chem. Pharm. 194, 260.

3) Ber. Berl, chem. Ges. 17, 700. 